NUREG/CR-5935

EGG-2686

\title{
Summary of Work Completed Under the Environmental and Dynamic Equipment Qualification Research Program (EDQP)
}

WOFIVED

FEB 281994

USTI

Prepared by

R. Steele, Jr., D. L. Bramwell, J. C. Watkins, K. G. DeWall

Idaho National Engineering Laboratory

EG\&G Idaho, Inc.

Prepared for

U.S. Nuclear Regulatory Commission 


\section{AVAILABILITY NOTICE}

Availability of Reference Materials Cited in NRC Publications

Most documents cited in NRC publications will be avallable from one of the following sources:

1. The NRC Public Document Room. 2120 L Street. NW., Lower Level, Washington, DC 20555-0001

2. The Superintendent of Documents. U.S. Government Printing Office. Mail Stop SSOP. Washington. DC 20402-9328

3. The National Technical Information Service, Springfield. VA 22161

Although the listing that follows represents the majority of documents cited in NRC publlcations, it is not intended to be exhaustive.

Referenced documents available for inspection and copying for a fee from the NRC Public Document Room include NRC correspondence and internal NRC memoranda: NRC bulletins, circulars, information notices. Inspection and investigation notices: llcensee event reports; vendor reports and correspondence: Commission papers: and applicant and licensee documents and correspondence.

The following documents in the NUREG series are available for purchase from the GPO Sales Program: formal NRC staff and contractor reports. NRC-sponsored conference proceedings, international agreement reports, grant publications, and NRC booklets and brochures. Also available are regulatory guides, NRC regulations in the Code of Federal Regulations, and Nuclear Regulatory Commission Issuances.

Documents available from the National Technical Information Service include NUREG-series reports and technical reports prepared by other Federal agencies and reports prepared by the Atomic Energy Commission. forerunner agency to the Nuclear Regulatory Commission.

Documents avallable from public and special technical libraries include all open literature items. such as books. journal articles. and transactions. Federal Register notices. Federal and State legislation, and congressional reports can usually be obtained from these libraries.

Documents such as theses, dissertations, foreign reports and translations. and non-NRC conference proceedings are available for purchase from the organization sponsoring the publication cited.

Single copies of NRC draft reports are available free. to the extent of supply. upon written request to the Offlce of Administration. Distribution and Mall Services Section. U.S. Nuclear Regulatory Commission. Washington. DC 20555-0001.

Coples of industry codes and standards used in a substantive manner in the NRC regulatory process are maintained at the NRC Library, 7920 Norfolk Avenue. Bethesda. Maryland, for use by the public. Codes and standards are usually copyrighted and may be purchased from the originating organization or, If they are American National Standards, from the American National Standards Institute, 1430 Broadway. New York. NY 10018.

\section{DISCLAIMER NOTICE}

This report was prepared as an account of work sponsored by an agency of the United States Government. Neither the United States Government nor any agency thereof, or any of their employees, makes any warranty, expressed or implied, or assumes any legal liability of responsibility for any third party's use, or the results of such use, of any information, apparatus, product or process disclosed in this report, or represents that its use by such third party would not infringe privately owned rights. 
NUREG/CR-5935

EGG-2686

\section{Summary of Work Completed \\ Under the Environmental and \\ Dynamic Equipment Qualification \\ Research Program (EDQP)}

Manuscript Completed: December 1993

Date Published: February 1994

Prepared by

R. Steele, Jr., D. L. Bramwell, J. C. Watkins, K. G. DeWall

Idaho National Laboratory

Managed by the U.S. Department of Energy

EG\&G Idaho, Inc.

Idaho Falls, ID 83415

\section{DISCLAIMER}

Prepared for

Division of Engineering

Office of Nuclear Regulatory Research

U.S. Nuclear Regulatory Commission

Washington, DC 20555-0001

NRC FIN A6322
This report was prepared as an account of work sponsored by an agency of the United States Geither the United States Government nor any agency thereof, nor any of their Government. Neither the Unity express or implied, or assumes any legal liability or responsiemployees, makes any warranty, express or implied, of assuinformation, apparatus, product, or bility for the accuracy, completeness, or usefulness of any information, apparats, product, process disclosed, or represents that its use would not infringe privately owned rights. Reference herein to any specific commercial product, process, or service by trade name, its endorsement, recommanufacturer, or otherwise does not necessarily constitute or imply its endorsem. The views mendation, or favoring by the United States Government or any agency thereof. The and opinions of authors expressed herein do not
United States Government or any agency thereof. 


\begin{abstract}
This report documents the results of the main projects undertaken under the Environmental and Dynamic Equipment Qualification Research Program (EDQP) sponsored by the U.S. Nuclear Regulatory Commission (NRC) under FIN A6322. Lasting from fiscal year 1983 to 1987, the program dealt with environmental and dynamic (including seismic) equipment qualification issues for mechanical and electromechanical components and systems used in nuclear power plants. The research results have since been used by both the NRC and industry.

The program included seven major research projects that addressed the following issues: (a) containment purge and vent valves performing under design basis loss of coolant accident loads, (b) containment piping penetrations and isolation valves performing under seismic loadings and design basis and severe accident containment wall displacements, (c) shaft seals for primary coolant pumps performing under station blackout conditions, (d) electrical cabinet internals responding to in-structure generated motion (rattling), and (e) in situ piping and valves responding to seismic loadings. Another project investigating whether certain containment isolation valves will close under design basis conditions was also started under this program. This report includes eight main sections, each of which provides a brief description of one of the projects, a summary of the findings, and an overview of the application of the results. A bibliography lists the journal articles, papers, and reports that docurnent the research.
\end{abstract}

FIN A6322-Environmental and Dynamic Equipment Qualification Research Program 


\section{CONTENTS}

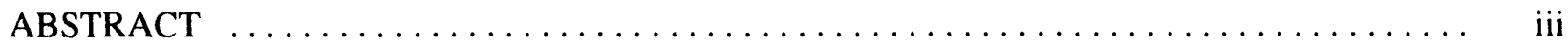

EXECUTIVE SUMMARY $\ldots \ldots \ldots \ldots \ldots \ldots \ldots \ldots \ldots \ldots \ldots \ldots \ldots \ldots \ldots \ldots \ldots \ldots \ldots$

ACKNOWLEDGMENTS $\quad \ldots \ldots \ldots \ldots \ldots \ldots \ldots \ldots \ldots \ldots \ldots \ldots \ldots \ldots \ldots \ldots \ldots \ldots \ldots \ldots \ldots \ldots \ldots$

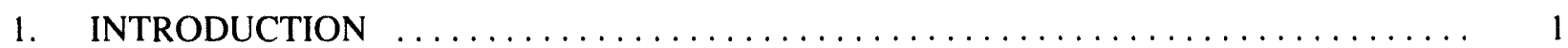

2. NUCLEAR CONTAINMENT PURGE AND VENT VALVE DESIGN BASIS

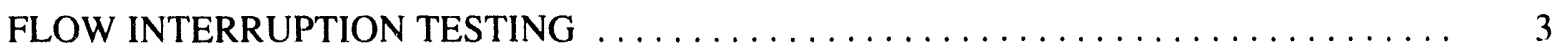

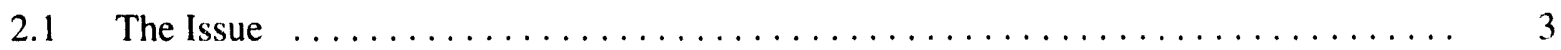

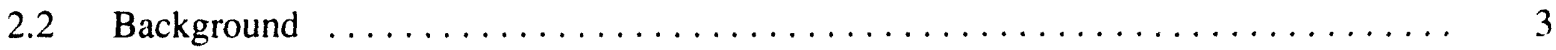

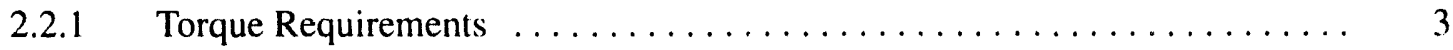

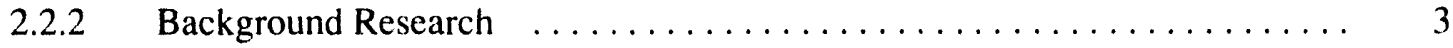

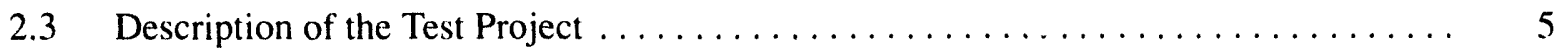

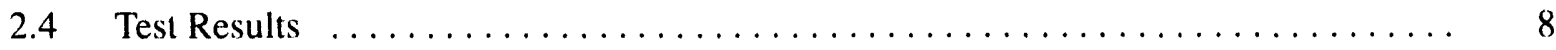

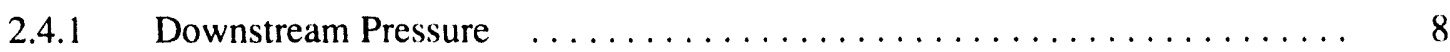

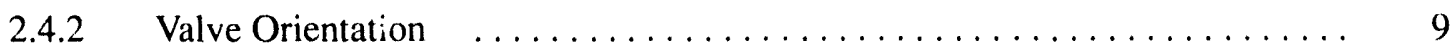

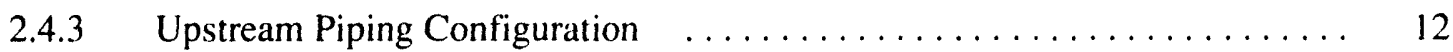

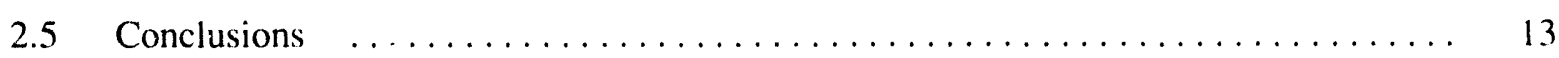

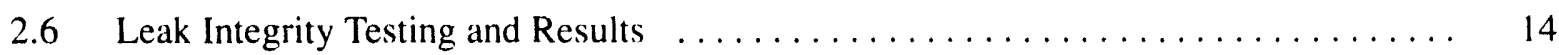

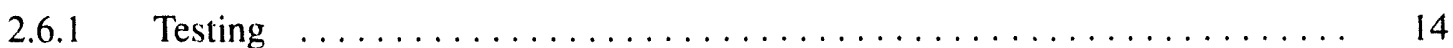

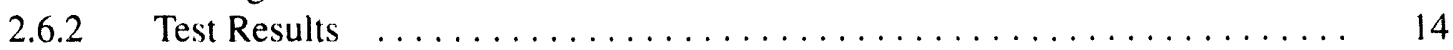

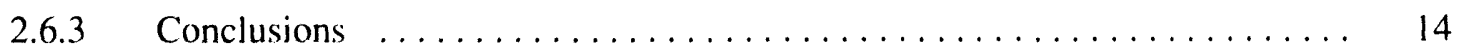

2.7 Application of the Research $\ldots \ldots \ldots \ldots \ldots \ldots \ldots \ldots \ldots \ldots \ldots \ldots \ldots \ldots \ldots \ldots$

3. SEISMIC TESTING OF TYPICAL CONTAINMENT PIPING

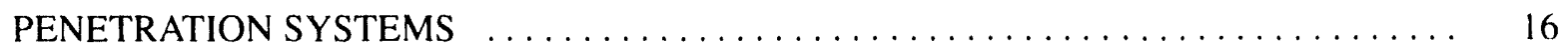

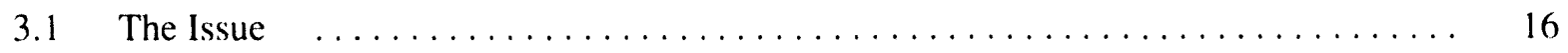

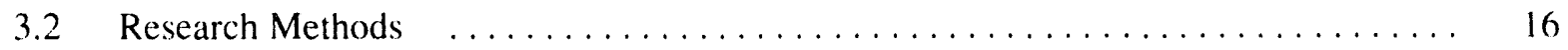

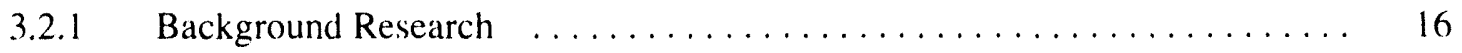

3.2.2 Description of the Test Project $\ldots \ldots \ldots \ldots \ldots \ldots \ldots \ldots \ldots \ldots \ldots \ldots$

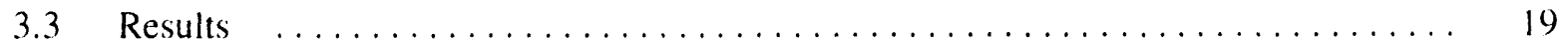

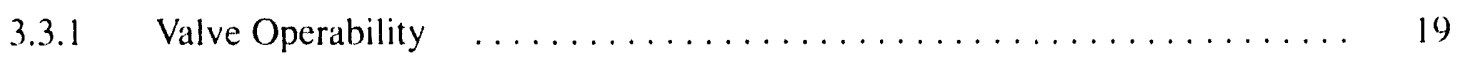

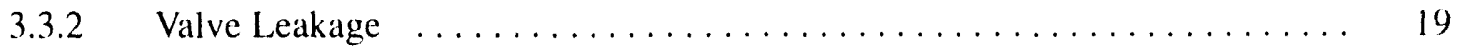




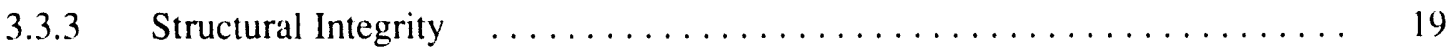

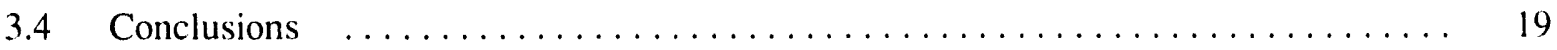

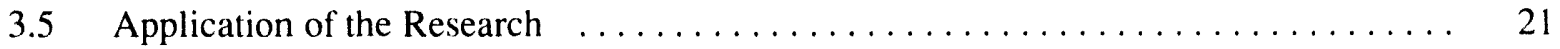

4. TESTING OF CONTAINMENT PENETRATION SYSTEMS AT

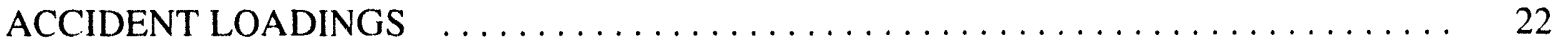

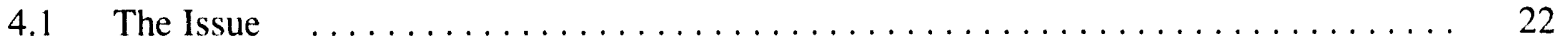

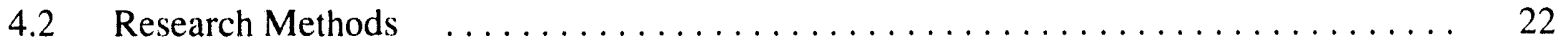

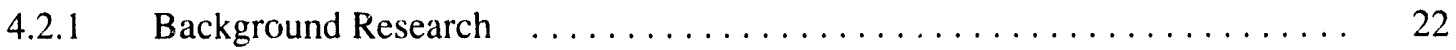

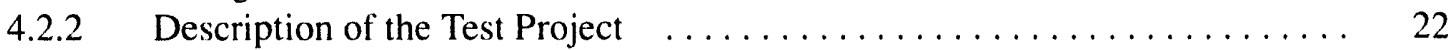

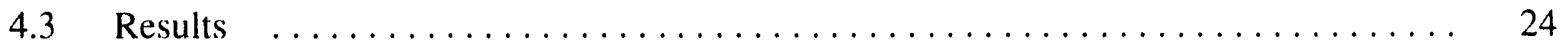

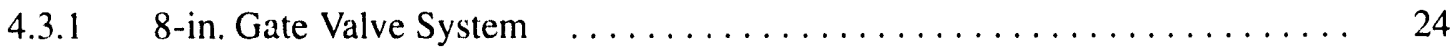

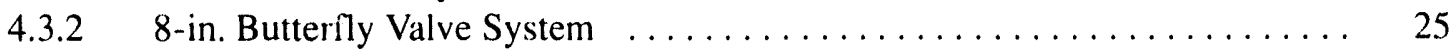

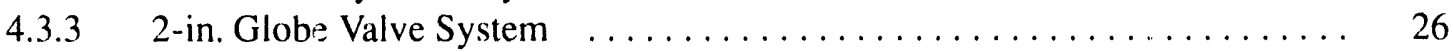

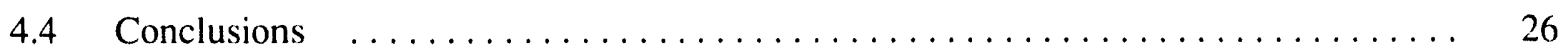

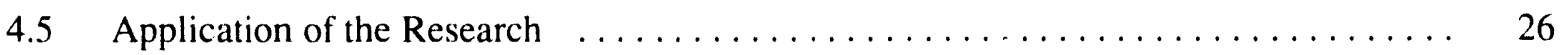

5. REACTOR COOLANT PUMP SHAFT SEAL PERFORMANCE DURING

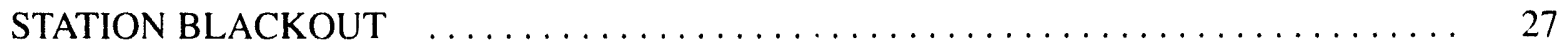

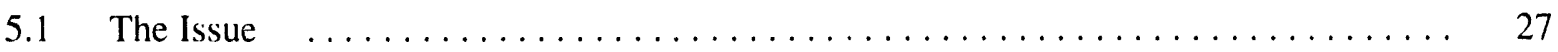

5.2 Assessment of Polymer Seal Performance $\ldots \ldots \ldots \ldots \ldots \ldots \ldots \ldots \ldots \ldots$

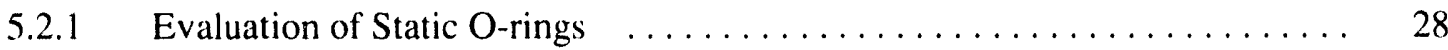

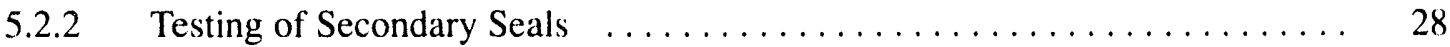

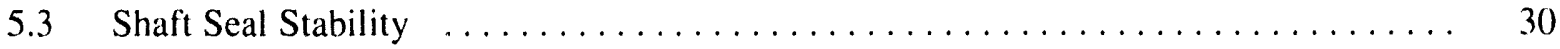

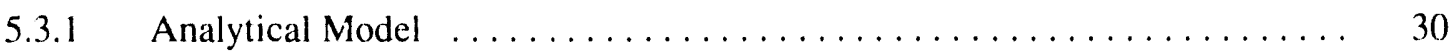

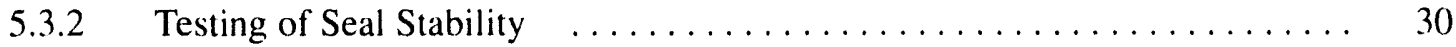

$5.4 \quad$ Review of Full-Scale Testing by Others $\quad \ldots \ldots \ldots \ldots \ldots \ldots \ldots \ldots \ldots \ldots \ldots \ldots \ldots \ldots \ldots$

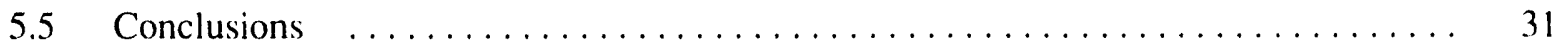

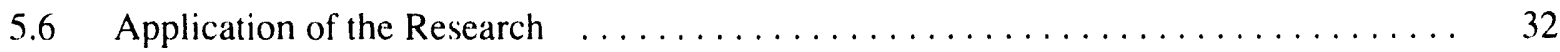

6. SIGNIFICANCE OF RATTLING IN ELECTRICAL CABINETS DURING

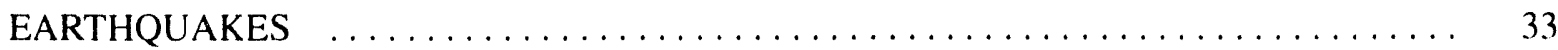

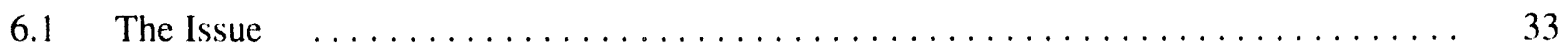




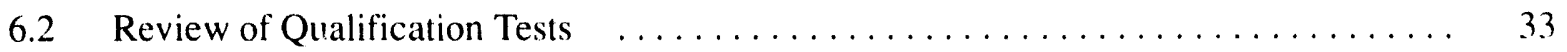

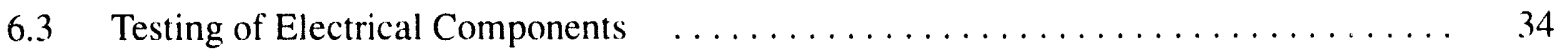

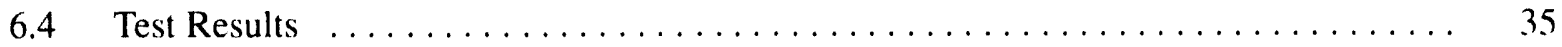

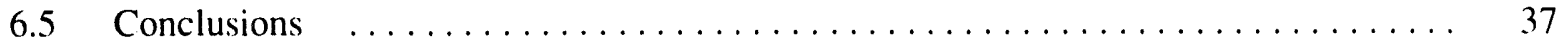

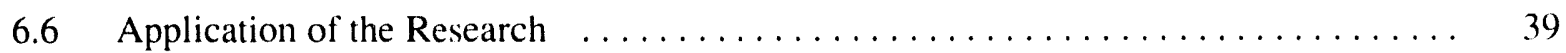

7. SHAG TEST SERIES: IN SITU SEISMIC TESTING OF A VALVE AND

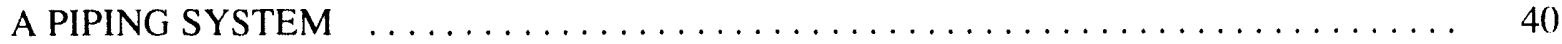

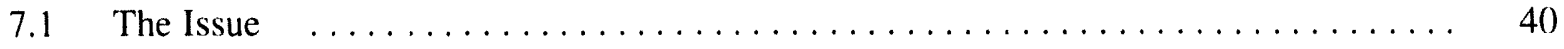

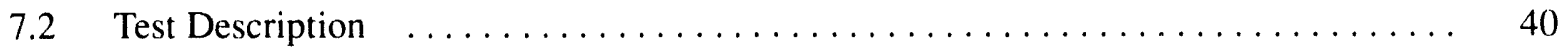

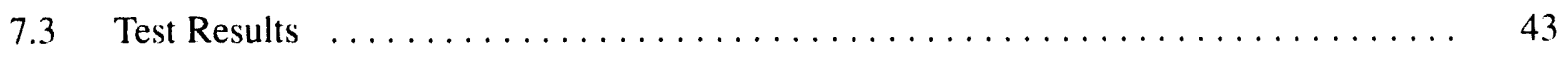

7.3.1 Comparison of Piping Support Systems $\ldots \ldots \ldots \ldots \ldots \ldots \ldots \ldots \ldots \ldots$

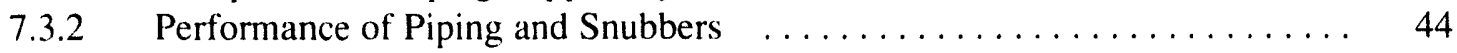

7.3.3 Operability of the Motor-operated Valve $\ldots \ldots \ldots \ldots \ldots \ldots \ldots \ldots \ldots . \ldots \ldots$

7.3.4 High-Frequency Amplification in the Valve Assembly $\ldots \ldots \ldots \ldots \ldots .44$

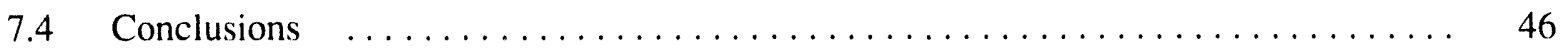

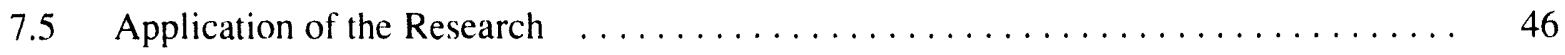

8. SHAM TEST SERIES: HIGH-LEVEL SIMULATED SEISMIC

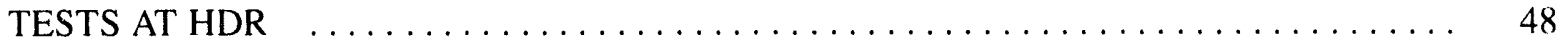

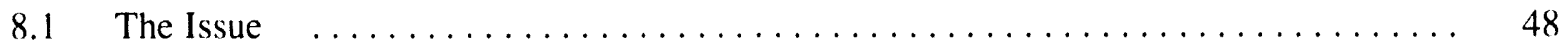

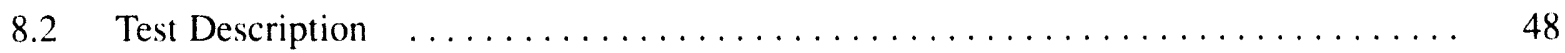

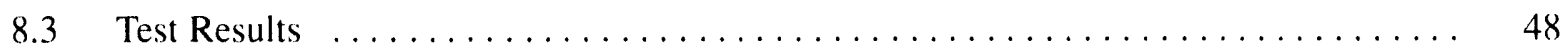

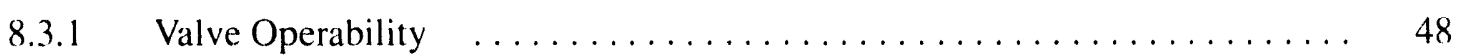

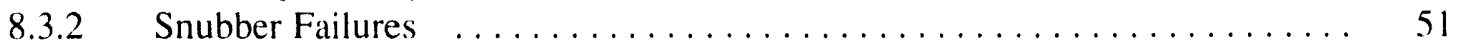

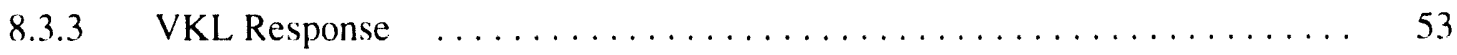

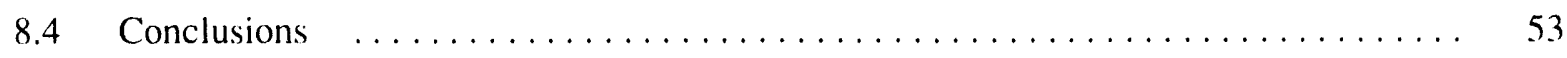

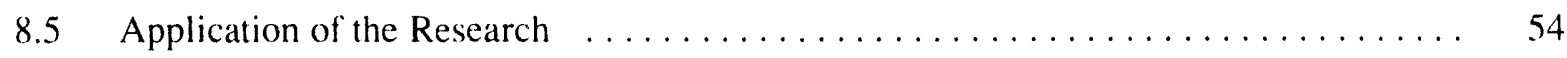

9. EARLY RESEARCH FOR THE GENERIC SAFETY ISSUE 87 TEST PROJECTS $\ldots \ldots .55$

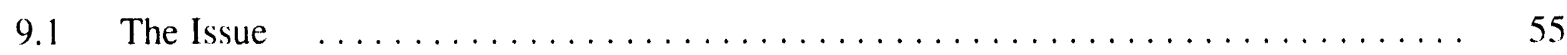

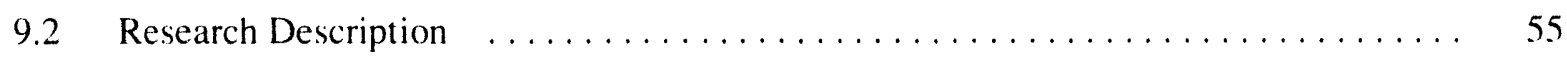

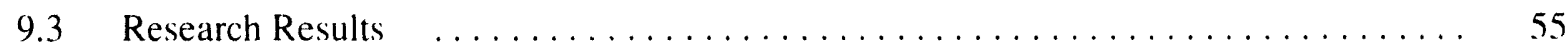




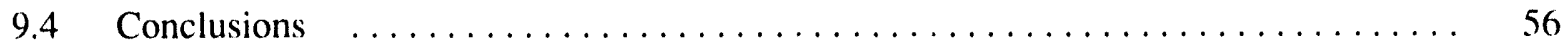

9.5 Application of the Research $\ldots \ldots \ldots \ldots \ldots \ldots \ldots \ldots \ldots \ldots \ldots \ldots \ldots \ldots \ldots \ldots \ldots \ldots \ldots$

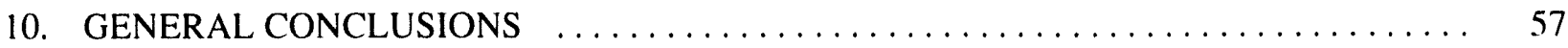

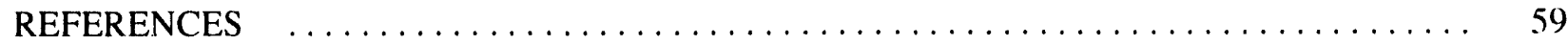

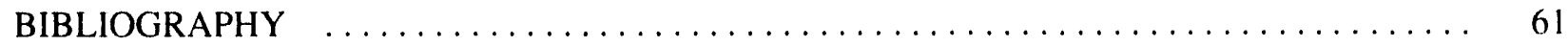




\section{LIST OF FIGURES}

2-1. Cross section of a typical butterfly valve used in containment purge and

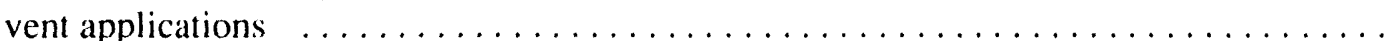

2-2. Diagram of the test section with uniform inlet flow (straight section of pipe),

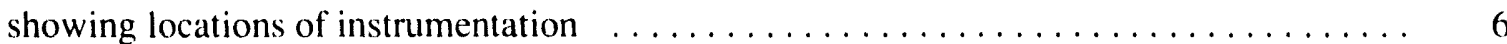

2-3. Valve orientations installed in the test section with uniform inlet flow $\ldots \ldots \ldots \ldots$

2-4. Diagram of the test section with nonuniform inlet flow (upstream elbow). showing locations of instrumentation $\ldots \ldots \ldots \ldots \ldots \ldots \ldots \ldots \ldots \ldots \ldots$

2-5. Valve orientations installed in the test section with nonuniform inlet flow.

The CW and CCW notations identify orientations with the disc rotating clockwise or counterclockwise relative to the figure $\ldots \ldots \ldots \ldots \ldots \ldots \ldots \ldots \ldots$

2-6. Static pressure 15 diameters downstream of valve versus valve position. Valves 1 and 2 are the 8 -in. valves; Valve 3 is the 24 -in. valve $\ldots \ldots \ldots \ldots \ldots \ldots \ldots$

2-7. Peak torque versus upstream static pressure, first 8 -in. valve $\ldots \ldots \ldots \ldots \ldots \ldots \ldots$

2-8. Torque versus upstream pressure and angle for the second 8-in. valve, curved-side-upstream orientation, with uniform flow $\ldots \ldots \ldots \ldots \ldots \ldots \ldots \ldots \ldots$

2-9. Torque versus upstream pressure and angle for the 24 -in. valve, curved-side-upstream orientation, with uniform flow $\ldots \ldots \ldots \ldots \ldots \ldots \ldots \ldots$

2-10. Torque versus upstream pressure and angle for the second 8-in. valve, flat-side-upstream orientation, with uniform flow $\ldots \ldots \ldots \ldots \ldots \ldots \ldots \ldots \ldots$

2-11. Torque versus upstream pressure and angle for the 24-in. "alve, flat-side-upstream orientation, with uniform flow $\ldots \ldots \ldots \ldots \ldots \ldots \ldots \ldots$

3-1. Comparison of the measured SSE test response spectrum with the SSE required response spectrum and with the analytically predicted SSE response spectra for selected plants; horizontal response spectra for the upper half of the building

3-2. Sketch of the test fixture with the 8 -in. gate valve assembly installed

3-3. Leak rates across the seat of the 2 -in. globe valve $\ldots \ldots \ldots \ldots \ldots \ldots \ldots \ldots \ldots \ldots \ldots \ldots$

4-1. Sketch of the test fixture with an 8 -in. gate valve system installed $\ldots \ldots \ldots \ldots \ldots \ldots$

4-2. Overhead view of the test fixture with the 8 -in. gate valve assembly installed $\ldots \ldots \ldots \quad 24$

5-1. Simplified diagram of a cross-section of an RCP shaft seal; this represents one of the three or four seals that constitute the entire seal assembly $\ldots \ldots \ldots \ldots \ldots \ldots$

5-2. Test cell for extrusion and friction testing of secondary seals $\ldots \ldots \ldots \ldots \ldots \ldots \ldots$ 
5-3. Cross-sections of the typical secondary seals subjected to testing $\ldots \ldots \ldots \ldots \ldots \ldots$

5-4. Sketch of the device used for the seal stability tests $\ldots \ldots \ldots \ldots \ldots \ldots \ldots \ldots \ldots$

6-1. Sketch of the test fixture showing where the accelerometers were mounted $\ldots \ldots \ldots .34$

6-2. Velocity and displacement of the GE relay during recorded chatter events.

Chatter events are indicated by the voltage pulses labeled $W$ and GE $\ldots \ldots \ldots \ldots \ldots$

7-1. A simplified cross section of the HDR facility, showing the locations of the shaker, the VKL, and the reactor pressure vessel $\ldots \ldots \ldots \ldots \ldots \ldots \ldots \ldots \ldots \ldots \ldots$

7-2. A schematic of the VKL showing the 8-in. gate valve and the U.S. stiff piping support system as configured for the SHAG tests $\ldots \ldots \ldots \ldots \ldots \ldots \ldots \ldots \ldots$

7-3. Power spectral density (PSD) plots calculated from measurements taken in the $\mathrm{Z}$ axis (horizontal direction paraliel to flow through the valve) at three locations during two tests with a starting frequency of $8 \mathrm{~Hz}$

8-1. A schematic of the VKL showing the 8-in. gate valve and the U.S. stiff piping support system as configured for the SHAM tests

\section{LIST OF TABLES}

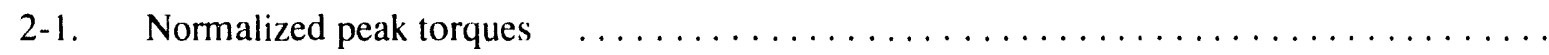

3-1. Overview of measurements during seismic testing of the three containment

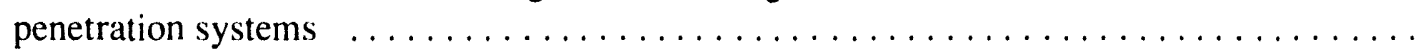

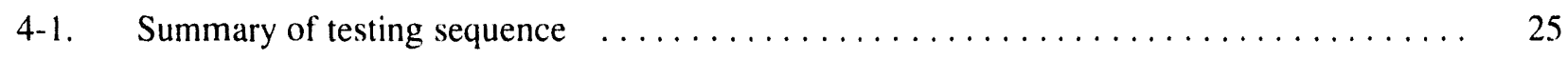

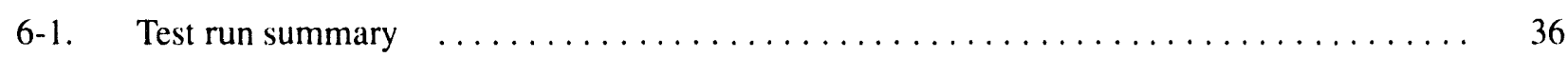

6-2. Waveform characterization at time of chatter $\ldots \ldots \ldots \ldots \ldots \ldots \ldots \ldots \ldots \ldots$

7-1. Type of supports used in the SHAG test series $\ldots \ldots \ldots \ldots \ldots \ldots \ldots \ldots \ldots \ldots$

8-1. Participants' support configurations for the SHAM test series $\ldots \ldots \ldots \ldots \ldots \ldots \ldots$

8-2. U.S. stiff support system test matrix $\ldots \ldots \ldots \ldots \ldots \ldots \ldots \ldots \ldots \ldots \ldots \ldots \ldots \ldots \ldots \ldots \ldots$

8-3. Snubber installation matrix for U.S. stiff support system $\ldots \ldots \ldots \ldots \ldots \ldots \ldots \ldots \ldots$

8-4. Maximum loads for struts and snubbers installed in the U.S. stiff support system $\ldots \ldots \quad 52$ 


\section{EXECUTIVE SUMMARY}

The Environmental and Dynamic Equipment Qualification Research Program (EDQP) was sponsored by the U.S. Nuclear Regulatory Commission under FIN A6322. The program was initiated in late 1982. Activities began in FY 1983 and continued until nearly all the main issues of the program were completed. Activities then continued in FY 1988 with the Equipment Operability Program (FIN A6857). The objectives of the program were to improve the technical basis for developing qualification requirements for mechanical and electromechanical equipment in nuclear power plants. The requirements were $e: a-$ luated against acceptance criteria, which included dynamic (seismic) and environmental conditions for qualification of mechanical equipment and dynamic (including seismic) conditions for quali. fication of electrical equipment.

The sets of equipment prioritized for research under this program were selected from a number of sources, including components and systems identified in several Nuclear Regulatory Commission (NRC) plans and research priority lists. Among these plans and priority lists are the Nuclear Power Plant Severe Accident Research Plan (NUREG-0900), the NRC Action Plan as a Result of the TMI-2 Accident (NUREG-0660), Clarification of TMI Action Plan Requirements (NUREG-0737), and A Prioritization of Generic Safety Issues (NUREG-0933).

This report formally documents the work of a major research program. The program has produced technical insights to support the NRC effort regarding Generic Safety Issue 23, "Reactor Coolant Pump Seal Failures at Station Blackout Conditions," Unresolved Safety Issue A-46, Seismic Qualification of Equipment in Operating Nuclear Pon'er Plants (NUREG-1030, 1987), and the containment integrity portion of the NRC's severe accident research (NUREG-1264). The program also included preliminary work to address Generic Safety Issue 87, "Failure of the HPCI Steam Line Without Isolation." The research program included the following major research projects described in the following discussion.

1. Nuclear containment purge and vent valves were subjected to flow interruption and leak integrity tests. These were the first such tests performed with full-scale valves and piping at design basis conditions. The results of these tests contributed signifi. cantly to the nuclear industry's understanding of the torque requirements of the butterfly valves typically installed in these applications.

2. Containment penetration systems, including the penetration itself, the two isolation valves, the associated piping, and the piping supports, were subjected to seismic tests. The results confirmed that these cumponents are resistant to earthquake loadings, in terms of the structural integrity of all the components and the leak integrity and functionality of the valves.

3. Containment penetration systems were also subjected to design basis accident and severe accident containment responses, including significant displacement of the penetration relative to the anchored piping. The results raised some minor concerns, but in general, testing showed that containment penetration systems are extremely strong.

4. Reactor coolant pump shaft seals were evaluated and some of their components tested for their resistance to station blackout conditions. This project identified some temperature concerns with the polymer materials used in the secondary seals in the seal assemblies in some designs. The project also investigated the tendency of the primary seals to pop open during station blackout conditions.

5. The significance of rattling in electrical cabinets subjected to earthquake motion was evaluated, along with the effect of the rattling on relays, switches, and other electrical 
devices mounted in the cabinets. The evaluation included seismic testing of relitys at conditions simulating the high-frequency effects of cabinet rattling. The results of the study showed that cabinets respond at higher frequencies during a seismic event than the frequencies for which many of these cabinet-mounted devices are qualified. Relays were also found to be sensitive to low frequencies.

6. A full-scale piping system was subjected to seismic loadings to determine the piping system's in situ response. The seismic loads were simulated by a large shaker mounted high in the containment building, a decommissioned test facility in Germany. The piping system included a naturally aged, motor-operated gate valve. The aged valve was not affected by the seismic loadings, but other anomalies in valve performance became the source of two NRC information notices, one on aging in motor operator torque springs and the other on undersized dc power cables.

7. In a follow-on test project, the piping system described in item 6 above was subjected to seismic loads simulated by two large ser- vohydraulic shakers. In the most severe test, the magnitude of the loading; imposed by the shakers on the piping system, the valve, and the snubbers, struts, and other piping supports was approximately eight times that of a typical safe shutdown earthcuake. The results provided insights on the fatilure loads and failure modes of snubbers subjected to high loadings. Both of these in situ test projects (items 6 and 7) provided insight on the ability of piping and valves to maintain their structural integrity when subjected 10 earthquake-like loadings.

8. The program also supported early research on the ability of isolation valves in the highpressure coolant injection steam line and other high-pressure lines to close against design basis line break flows. Two full-scale test projects followed, funded as part of a subsequent research program. The results of those test projects challenged some of the equations the industry uses to size operators on motor-operated gate valves and set the operators' control devices. The results have also contributed to the industry's understanding of the behavior of motor-operated gate valves. 


\section{ACKNOWLEDGMENTS}

This summary report describes eight separate research projects. Many of the researchers who did the original work in those eight projects are not listed as authors of this report. We acknowledge their effort here, and we refer the reader to the bibliography, where the reports and papers published by those researchers are listed. Specifically, we acknowledge the work of Robert C. Hill, James A. Close, Herbert S. Crapo, David B. Rhodes, Ron G. Wensel, Gary L. Thinnes, Vladimir Glozman, James G. Arendts, and Michael E. Nitzel.

We also acknowledge the following Idaho National Engineering Laboratory staff for their help in the production of this document: J. S. Isom, K. L. Lynes, C. A. Priest, D. K. Iverson, and J. L. Stoecker for text processing, G. S. Reilly and C. W. White for graphics, and D. R. Pack and J. M. Steffes for technical editing. 


\section{Summary of Work Completed Under the Environmental and Dynamic Equipment Qualification Research Program (EDQP)}

\section{INTRODUCTION}

The Environmental and Dynamic Equipment Qualification Research Program (EDQP), conducted by the Idaho National Engineering Laboratory (INEL) and sponsored by the U.S. Nuclear Regulatory Commission (NRC) was performed because much of the safety equipment in nuclear power plants experiences very limited operation at design basis conditions. Similarly, some of the components were not tested during initial qualification phase because of the complexity and expense of performing tests at maximum design conditions. Such equipment generally was qualified through analysis and limited testing. As a result of this limited operating experience. it was difficult to answer some questions that arose concerning equipment performance. These questions, typically brought about by observed anomalous behavior in operating plants or identified by related research, challenged earlier assumptions or judgments applied in the qualification process. New research was needed to answer these questions. The program plan for the EDQP is presented in NUREG-1209.

Although the EDQP performed research on diverse equipment, there were some common threads. All research included component or system testing at design basis conditions. Thus, the research provided empirical data for comparison with the results of the analytical methods used in the earlier qualification processes. The accident load simulations were realistic, and in most cases the tested hardware was typical of that installed in nuclear plants. The research requirements, methods, and results were reviewed by representatives of the NRC and, in most cases, by the nuclear power industry, other national laboratories, and international organizations.
Research was designed by the INEL and performed at a number of sites, including the INEL, the Santa Suzanna Field Laboratory in California, Chalk River National Laboratories in Ontario, Canada, and the decommissioned Heissdampfreaktor iacility located near Frankfurt, Germany.

In most cases, research on a subject was reported in more than one document. The bibliography section contains a complete list of the journal articles, meeting papers, and reports published for each major topic of the EDQP. This report summarizes the research results in a single document.

Each of the major research projects is described in a section of the report. The material is summarized but presented in sufficient detail that the reader can become reasonably familiar with the research subject.

The report covers the following major research projects:

1. Testing to determine the requirements for typical nuclear containment purge and vent valves to close against design basis flows and to maintain leak-tightness against design basis accident and severe accident pressures and temperatures

2. Testing the response of containment piping penetrations and associated piping and isolation valves to simulated earthquake loadings

3. Testing the response of containment piping penetrations and associated piping and isolation valves to the containment temperatures and pressures and the containment 
wall displacements that would occur in the event of a design basis loss-of-coolant accident and a severe accident inside the containment

4. Evaluating the performance of primary coolant pump shaft seals during station blackout conditions

5. Testing the response of relays to seismic excitation typical of earthquake-induced rattling in electrical cabinets
6. Testing the response of a full-scale in situ piping system and a motor-operated gate valve to simulated earthquake loadings produced by a building shaker

7. Testing the response of the same piping system (described in item 6 above) to normal and high-level simulated earthquake loadings produced by servohydraulic shakers

8. Preliminary work preparing for full-scale testing of motor-operated gate valves at very high design basis pressures, temperatures, and flows. 


\section{NUCLEAR CONTAINMENT PURGE AND VENT VALVE DESIGN BASIS FLOW INTERRUPTION TESTING}

\subsection{The Issue}

The containment purge and vent systems consist mostly of air conditioning ducting and filters. These are open loop systems where the containment atmosphere communicates directly with the atmosphere outside the containment. The only ASME code class piping in the system is the containment penetration, a short length of piping, and two isolation valves, typically butterfly valves (see Figure 2-1). The penetration and the valves are a part of the containment barrier. If a design basis loss of coolant accident (LOCA) were to occur inside the containment, failure of the isolation valves to close and seal might allow the environment inside the containment to escape to the outside.

Following the Three Mile Island (TMI) accident in 1979, NUREG-0660, NRC Action Plan as a Result of TMI-2 Accident, was published. Item II.E.4.2 of that document, "Containment Isolation Dependability," formalized the concern about the ability of the containment purge and vent valves to close against design basis pressure loads. NUREG-0737, Clarification of TMI Action Plan Requirements, was published in 1980 , adding leak integrity to the purge and vent valve concerns.

The research summarized here provided information to address those concerns. Specifically, the purpose of the research was (a) to provide empirical data to determine the requirements for typical nuclear containment purge and vent valves to close during a design basis LOCA inside the containment, (b) to evaluate the methods used in the nuclear industry to estimate those requirements, (c) to determine whether the results of testing of small valves can be extrapolated to reliably predict the torque requirements of larger valves, and (d) to determine whether typical purge and vent valves will maintain their leak-tightness when subjected to design basis accident and severe accident temperatures and pressures.

\subsection{Background}

2.2.1 Torque Requirements. Dynamic torque requirements for a butterfly valve are typically determined by the following equation:

$$
T_{d}=C_{T} D^{3} \Delta P
$$

where

$$
\begin{aligned}
& \mathrm{T}_{\mathrm{d}}=\begin{array}{l}
\text { dynamic torque (torque required } \\
\text { to overcome loads imposed by } \\
\text { flow through the valve) }
\end{array} \\
& \mathrm{C}_{\mathrm{T}}=\text { torque coefficient } \\
& \mathrm{D}^{3}=\text { valve diameter cubed } \\
& \Delta \mathrm{P}=\text { pressure drop across the valve. }
\end{aligned}
$$

The total torque requirement is the sum of the dynamic torque and the torque required to overcome bearing and packing resistance. Bearing and packing torques are easily measured and were not subject to controversy. The variable $\mathrm{C}_{\mathrm{T}}$ (the torque coefficient) is usually developed from test results with scale model valves using the following equation:

$$
C_{T}=\frac{T_{d}}{D^{3} \Delta P}
$$

Industry methodologies for extrapolating torque requirements are based on the assumption that in geometrically scaled systems, when all other conditions are the same, the flow characteristics and pressure drop across the valves that have been scaled to each other will be the same. This assumption was originally based on testing using incompressible fluids.

2.2.2 Background Research. To obtain background information to support the test project, we surveyed the available literature to determine the manufacturers, types and sizes of valves used, 

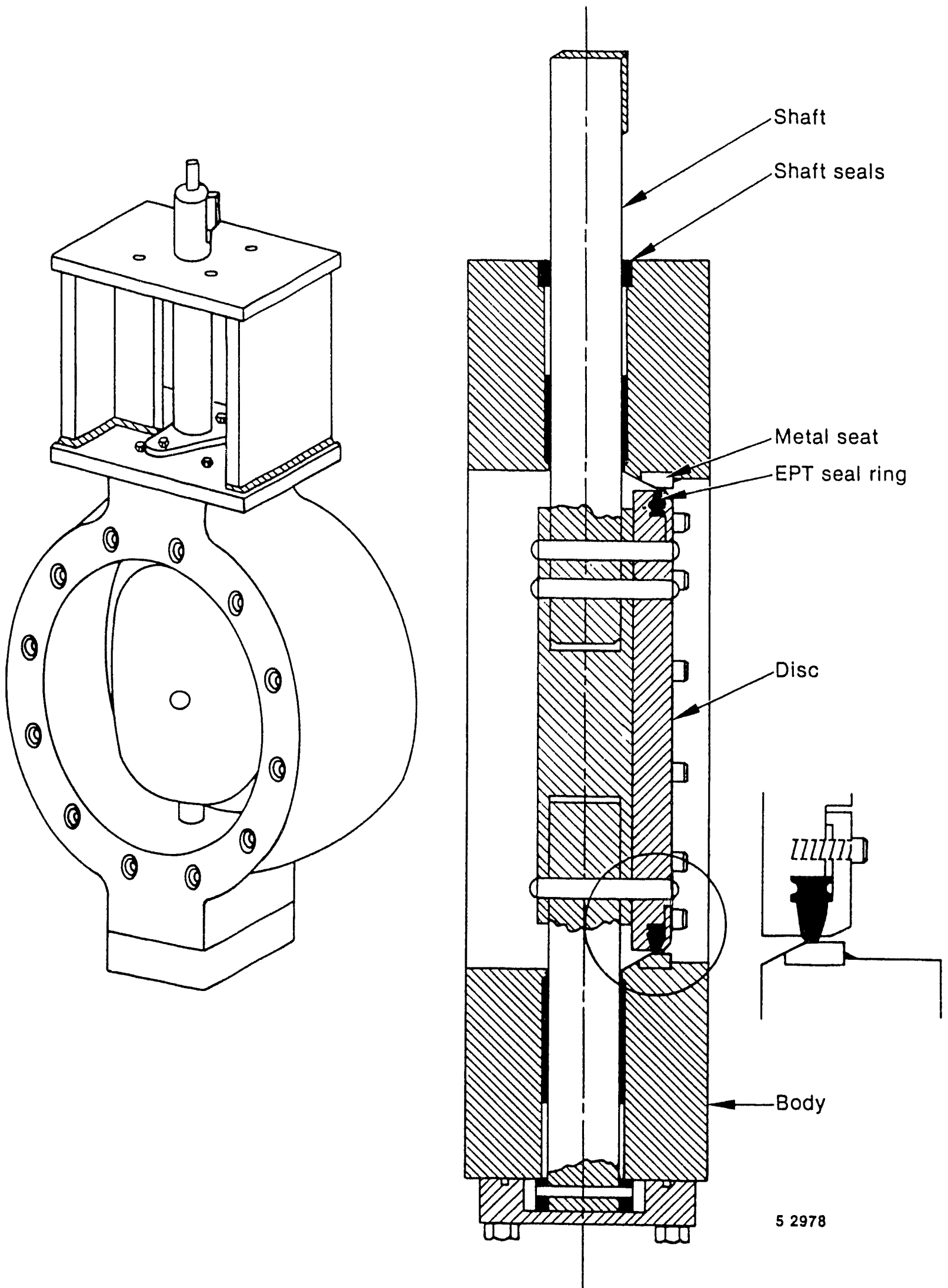

Figure 2-1. Cross section of a typical butterfly valve used in containment purge and vent applications. 
and operational status of valves installed in nuclear containment purge and vent applications. In addition, we conducted a literature search to investigate related research done previously by others.

We found butterfly valves in sizes 2 to $66 \mathrm{in}$. (diameter) to be the predominant design. The valve manufacturers had done very little testing to qualify the valves for nuclear purge and vent applications, and most of that testing had used incompressible fluids. Testing performed with incompressible fluids does not necessarily validate industry equations being used for extrapolation; butterfly valves installed in purge and vent applications are expected to operate with flow of compressible fluids. Previous testing performed using compressible fluids was done at pressures too low and usually with valves too small to fully characterize valve performance at design basis LOCA conditions. The INEL butterfly valve test project described in the following discussion was the first full-scale test project performed with a gaseous flow medium at full design basis conditions and incorporating more than one valve size.

\subsection{Description of the Test Project}

Three butterfly valves typical of valves used in containment purge and vent applications were tested, two 8-in. (nominal pipe diameter) valves and one 24 -in. valve. The valves were American National Standards Institute (ANSI) 150-lb class, elastomer sealed, offset disc, high-aspect-ratio valves. (The aspect ratio is the ratio of disc thickness to disc diameter.) High-aspect-ratio offset disc designs were chosen for testing because they are typical of most installed valves, and because their response to flow is known to be one of the most demanding of the valve designs installed in purge and vent systems. In the offset disc design, the seat or sealing surface is off set from the centerline of the valve shaft. This configuration maintains leak tightness better than the in-line seal configuration.

The two 8 -in. valves, made by different manufacturers, are representative of a large popu- lation of installed valves. Their different internal designs are typical of most of the designs and sealing features of other manufacturers' offset disc designs installed in commercial power plants.

The 24-in. valve was the same design as one of the 8-in. valves; thus, testing of this valve provided insight for extrapolation methodologies. The 24-in. valve also represents the largest butterfly valve installed in purge and vent applications in operating nuclear power plants that is allowed to open to the full open position. (Larger valves installed in purge and vent applications are typically blocked, preventing them from opening more than $70 \%$, and in many cases, $40 \%$ open.)

Testing was conducted at the Energy Technology Engineering Center (ETEC), a Department of Energy laboratory operated by Rockwell International at their Santa Suzanna Field Laboratory in California. Facility preparation and checkout started in late 1983, and testing started in early 1984.

The valves were subjected to two separate test series. Testing of valve operation with the valves closing against flow is described in the following discussion, with results and conclusions presented in Sections 2.4 and 2.5. Testing of the valves for leak integrity when subjected to accident loadings is discussed separately in Section 2.6.

In all, the three valves were subjected to 64 flow tests, with valve inlet pressures ranging from 5 to $60 \mathrm{psig}$. (The design basis pressure for most containments is between about 40 and 60 psig.) The flow medium was nitrogen at ambient temperature. The valves were tested in various orientations relative to the flow. Figure 2-2 shows the uniform flow test section (straight pipe) and Figure 2-3 shows the two valve orientations tested in that section. Figure 2-4 shows the nonuniform flow section where the valves were installed immediately downstream of an elbow, and Figure 2-5 shows the four valve orientations tested in that section. 


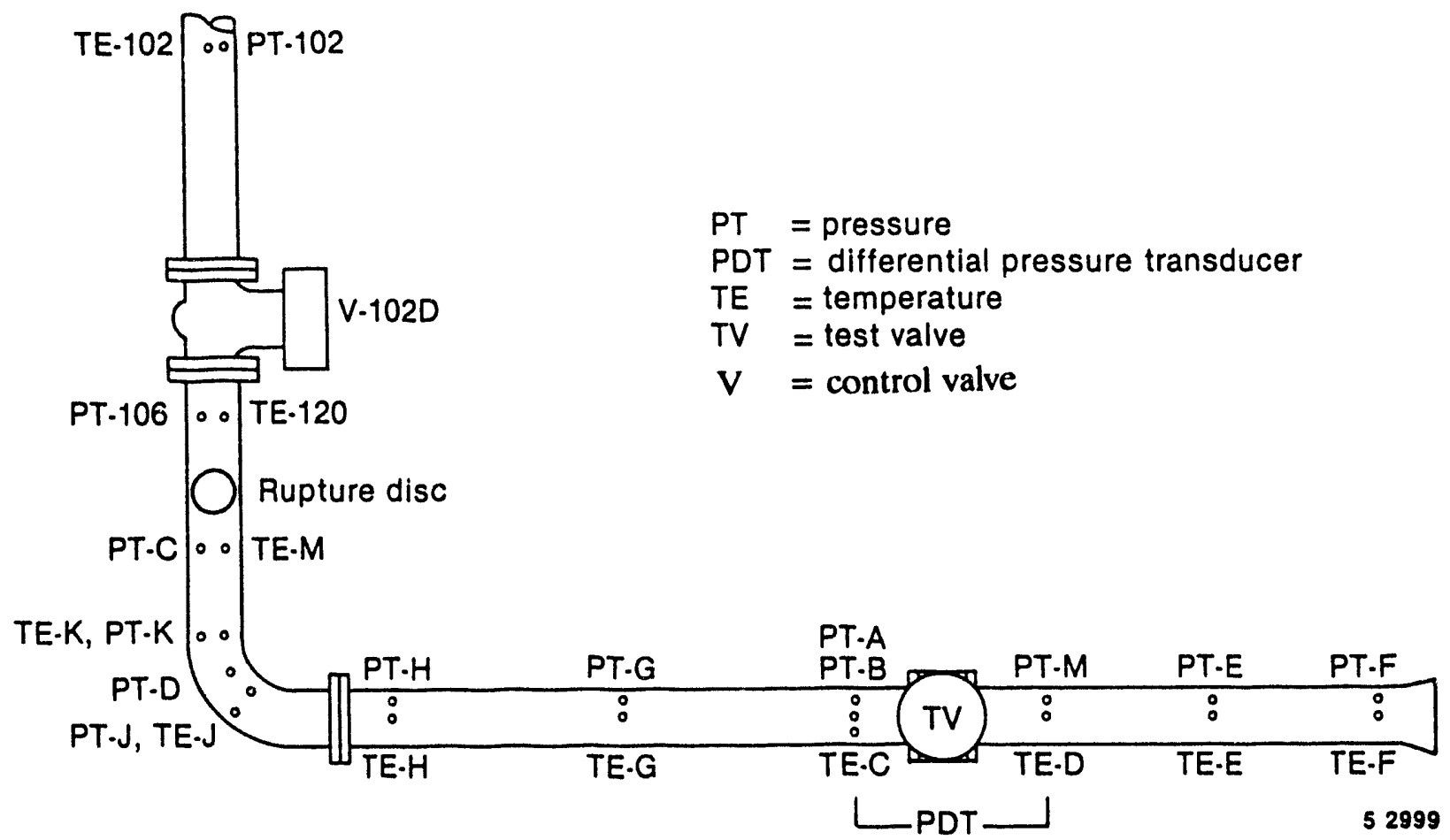

Figure 2-2. Diagram of the test section with uniform inlet flow (straight section of pipe), showing locations of instrumentation.

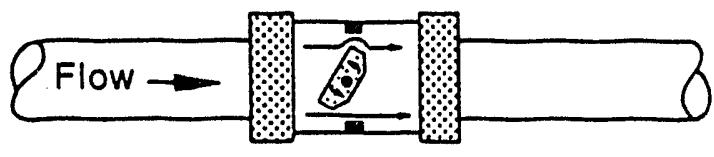

Flat face forward

(FFF)

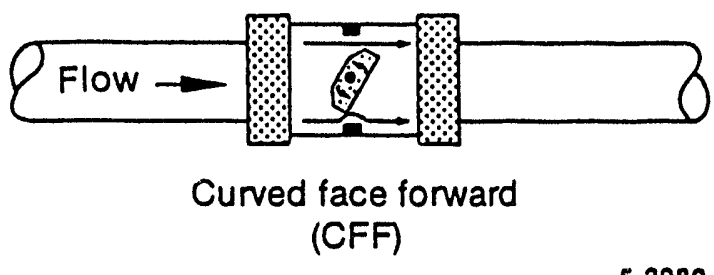

52980

Figure 2-3. Valve orientations installed in the test section with uniform inlet flow.

It was necessary to flow test these numerous installation orientations and upstream piping configurations because of the wide variety of purge and vent valve installations in the plants. There was some evidence that valve orientation and upstream piping configuration have an influence on the torque loads imposed on the valve during closure against flow. When a valve is partially open, the shape of the high-aspect-ratio disc causes it to behave somewhat like an airplane wing as the fluid flows around it, with high and low pressure areas applying forces on the disc to either assist or resist closure. If the valve closes with the flat side of the disc facing upstream
(FSU), these forces resist closure. If the valve closes with the curved side of the disc facing upstream (CSU), these forces assist closure.

For each test, the control valve was opened to establish the inlet pressure at the test valve at the specified value with the test valve fully open, and then the inlet pressure was maintained as constant as possible as the valve closed.

The test loop was instrumented to take up to 48 separate measurements of temperature, pressure, differential pressure, valve torque, and valve position. Figures 2-2 and 2-4 show the pressure 


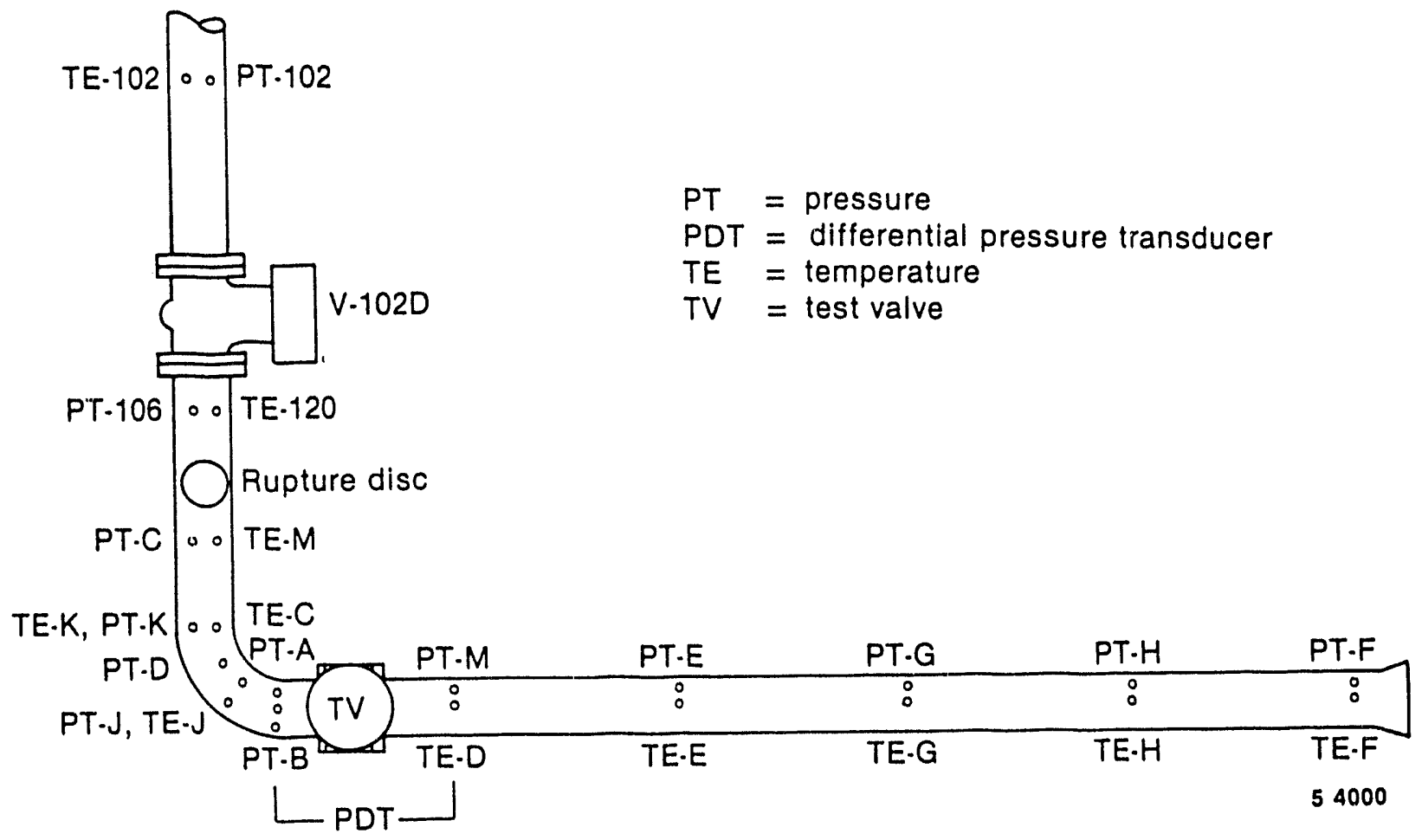

Figure 2-4. Diagram of the test section with nonuniform inlet flow (upstream elbow), showing locations of instrumentation.
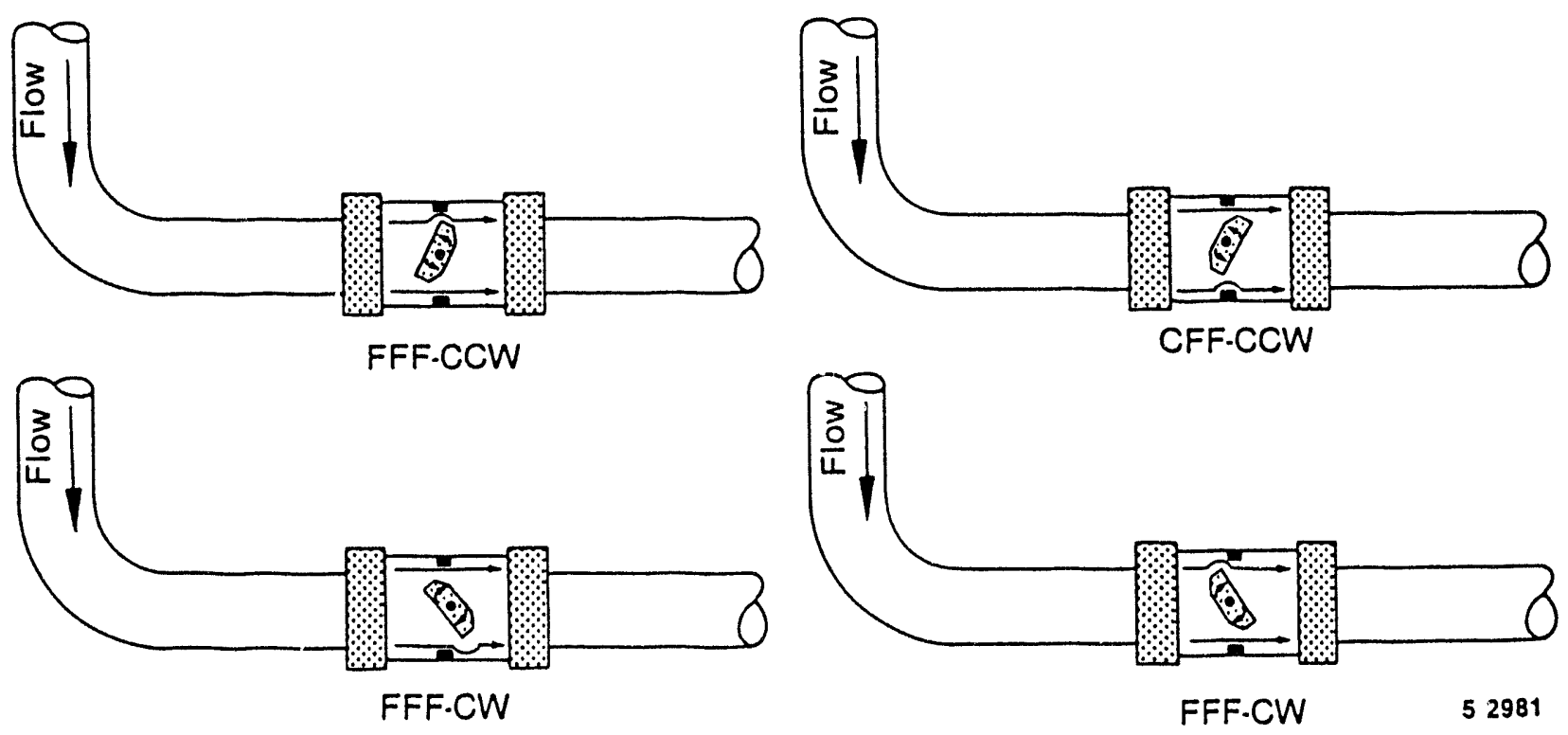

Figure 2-5. Valve orientations installed in the test section with nonuniform inlet flow. The CW and CCW notations identify orientations with the disc rotating clockwise or counterclockwise relative to the figure. 
and temperature measurements made on the test sections. The direct, in-line torque cell mounted to the test valve shaft, and the rotary transformer used to monitor valve disc position, are not shown. All 48 measurements were input to a Hewlett-Packard-based data acquisition system at 155 data points per second.

\subsection{Test Results}

The results of the tests provided evidence that the methods typically used in the industry for determining closing torque requirements and for extrapolating small valve torques to predict large valve torques were not consistently conservative. We found that because of irregularities in the downstream pressure, the differential pressure measurement was not very helpful in characterizing valve performance at high flows. More important, we found that valve installation orientation and upstream piping geometry significantly affected the magnitude of the torque load imposed on the valve during closure.
2.4.1 Downstream Pressure. Choked and supersonic flow downstream of the disc influenced the downstream pressure measurement, thus affecting the differential pressure measurement or calculation. Figure 2-6 is a plot showing typical measurements of the static pressure 15 diameters downstream of the test valve. The downstream pressure profiles are different for each valve and are different from what one would get from measurements involving incompressible flow. We found that by using the upstream static pressure instead of the differential pressure (in Equation 1), we could more consistently characterize valve performance in these tests with compressible flow. In essence, we assumed that the downstream pressure was 0 psig.

We found the peak torque for a given valve in a given installation to be linear with upstream static pressure, regardless of valve design, size, or orientation or upstream piping configuration. Figure 2-7 is a typical plot of upstream static pressure versus peak torque. Note, however, that the slope

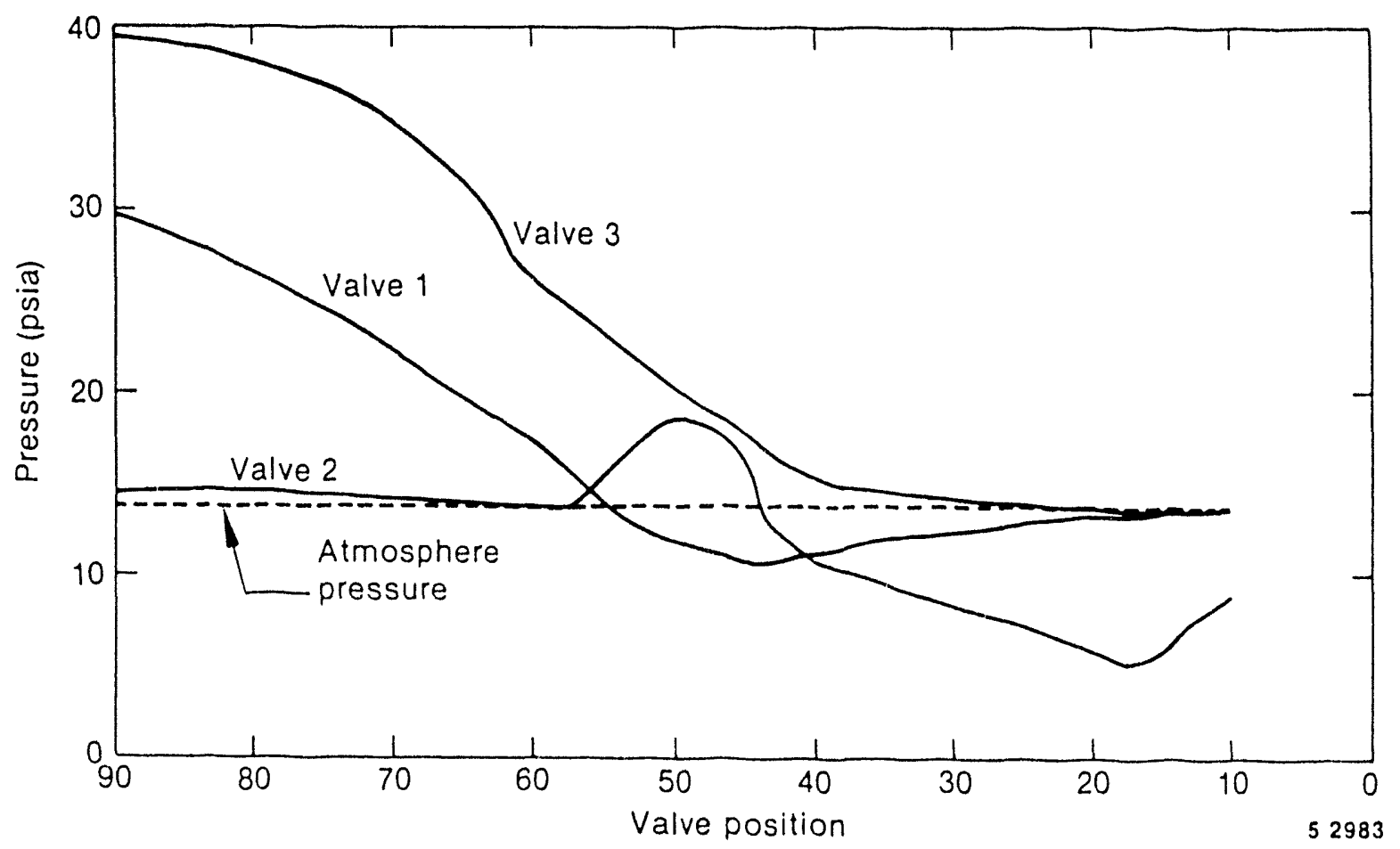

Figure 2-6. Static pressure 15 diameters downstream of valve versus valve position. Valves 1 and 2 are the 8 -in. valves; Valve 3 is the 24 -in. valve. 


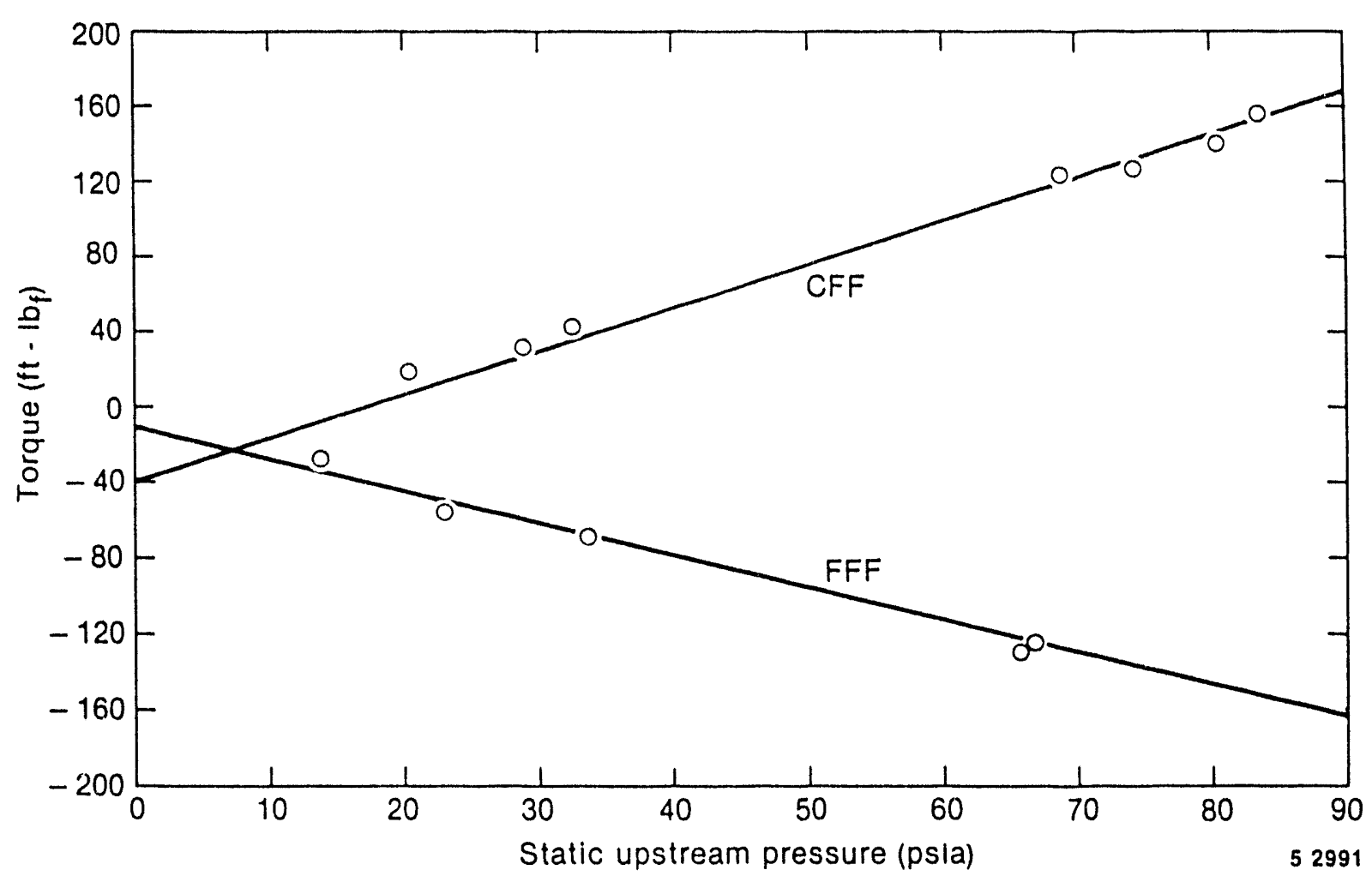

Figure 2-7. Peak torque versus upstream static pressure, fïst 8 -in. valve.

of the linear response was not the same for different valves or for different installations. This fact prevents any universal extrapolation of valve response based on upstream pressure, but such an extrapolation of the response of a butterfly valve is possible, provided that pressure response curves are developed for each valve size and design, each orientation, and each upstream piping configuration. Note also that though the peak torque for a given valve in a given installation was linear with pressure, the disc angle at which peak torque occurred was different for different valves, different installations, and different upstream test pressures.

After our tests were performed, we used the measured results and Equation 1 to develop $\mathrm{C}_{T}$ curves for each valve, except that we used the upstream static pressure instead of the differential pressure. We also calculated large valve torque requirements from small valve $C_{T}$ curves, and we evaluated the typical industry equations and assumptions by comparing the calculations to the test results.
2.4.2 Valve Orientation. Early review efforts revealed that the accepted industry method (Equation 1) for estimating butterfly valve performance was based on the symmetrical disc design used in a few nuclear plants built in the early 1960s. The symmetrical dise design is not as sensitive to the orientation of the disc relative to the flow as the offset disc design. The industry guidance did not account for the fact that valves with offset, high-aspect-ratio discs exhibit different torque performance, depending on which way the valve is installed. In addition, the industry guidance in the use of scale model test data did not account for this difference. The following discussion addresses these two issues.

We found that not only is the direction of the torque response different for the different valve orientations, but the magnitude of the peak torque and the predictability of the response are different. Generally (within reasonable tolerances allowing for data scatter). the magnitude of the peak torque measured with the valve oriented with the curved side of the disc facing upstream 
was greater than that measured with the flat side upstream. 'This result indicates that the torque response of the valve in the curved-side-upstream orientation can be used to bound the response of the same valve in the flat-side-upstream orientation, but not vice versa.

We gained confidence in this method for bounding valve response by comparing the various valve responses as indicated by carpet plots. (Similarity among carpet plots is an indication of predictability of response from one design and one valve size to the next.) All carpet plots from tests with the curved-side-upstream orientation and were geometrically similar, even those from tests with an elbow immediately upstream of the valve. However, the plots from tests with the flatside-upstream orientation were not geometrically similar. Figures 2-8 and 2-9 are carpet plots from an 8 -in. valve and from the 24 -in. valve oriented with the curved side upstream. Figures 2-10 and 2-11 are carpet plots from the same valves oriented with the flat side upstream. The geometric similarity of Figures 2-8 and 2-9 is evident.
To evaluate the relationship between scale model test data and valve orientation, we predicted the response of the 24 -in. valve from the measured response of the 8 -in. valve of the same design, then compared the predictions with the measured response of the 24 -in. valve. We found that extrapolations based on the response of the small valve with the flat side of the disc facing upstream consistently failed to bound the response of the larger valve in either orientation. However, when the small valve was oriented with the curved side of the disc facing upstream, the resultant torques could always be extrapolated to conservatively bound the response of the large valve in either orientation, provided that the upstream pressure was not greater than 60 psig (see discussion below). (Note that we are speaking here of valve response in terms of the magnitude of the peak torque, regardless of the direction of the torque. As explained earlier, valves oriented with the flat side of the disc facing upstream respond with forces that resist closure, while valves oriented with the curved side facing upstream respond with forces that assist closure.)

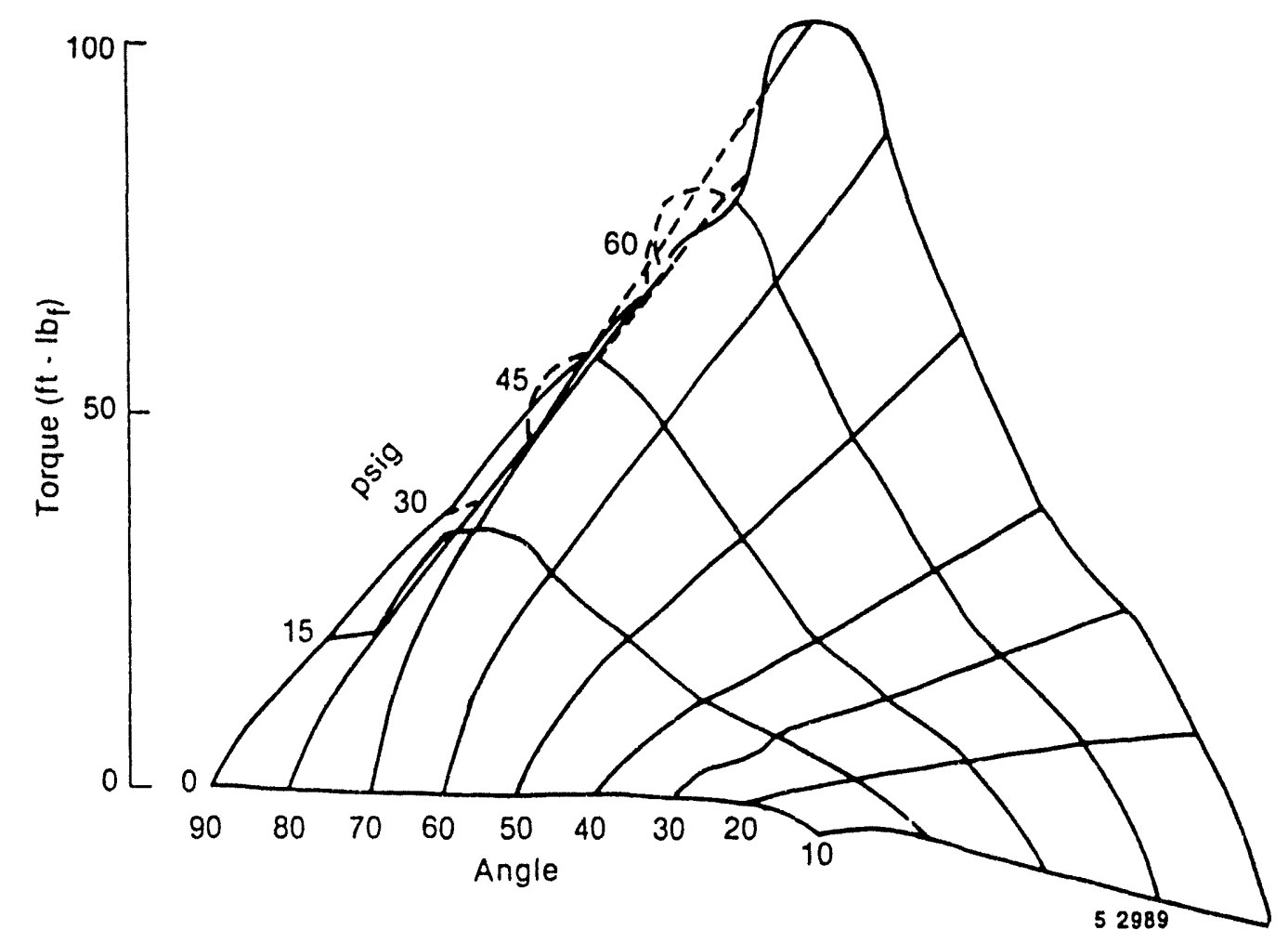

Figure 2-8. Torque versus upstream pressure and angle for the second 8-in. valve, curved-side-upstream orientation, with uniform flow. 


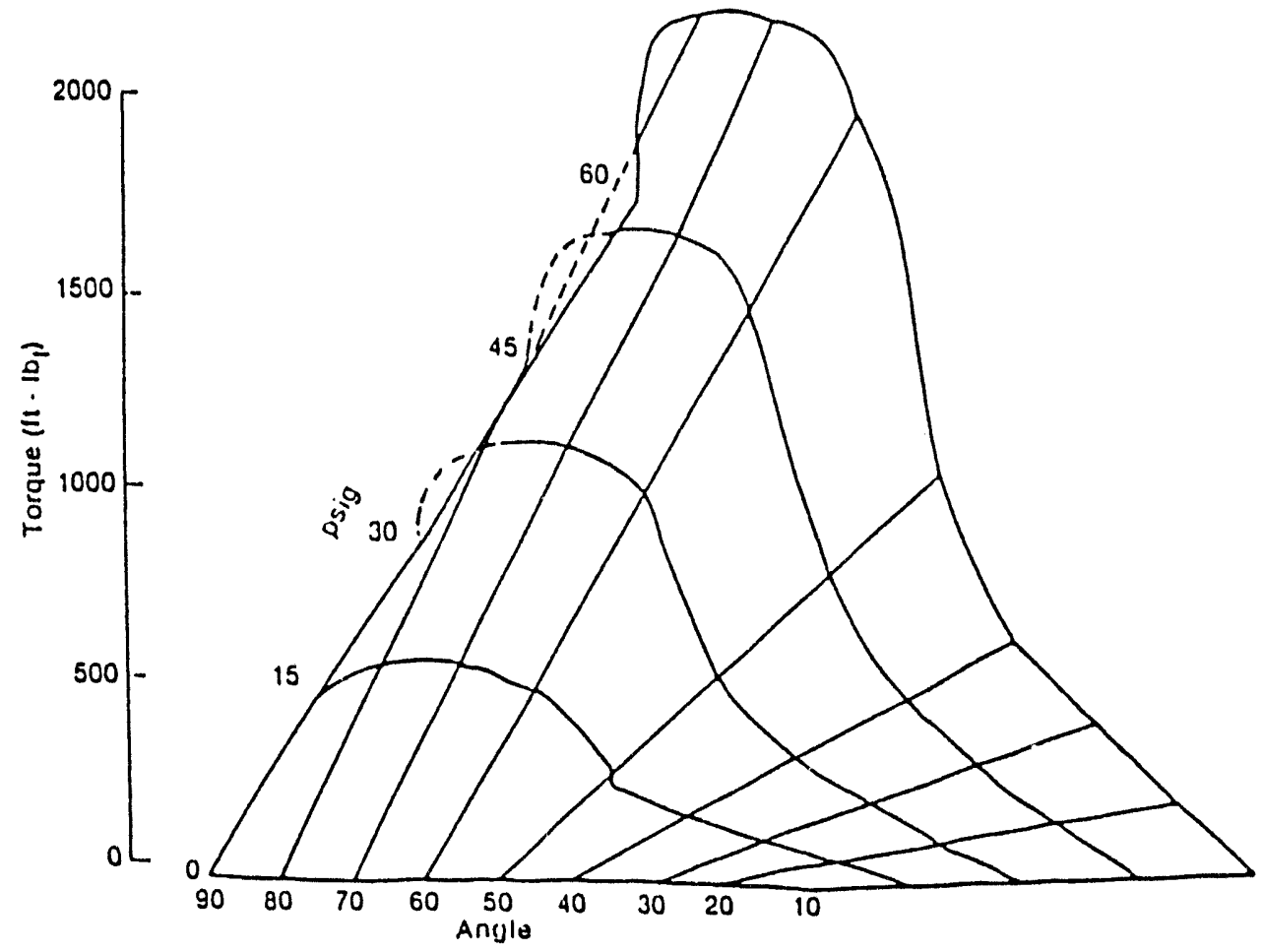

Figure 2-9. Torque versus upstream pressure and angle for the 24-in. valve, curved-side-upstream orientation, with uniform flow.

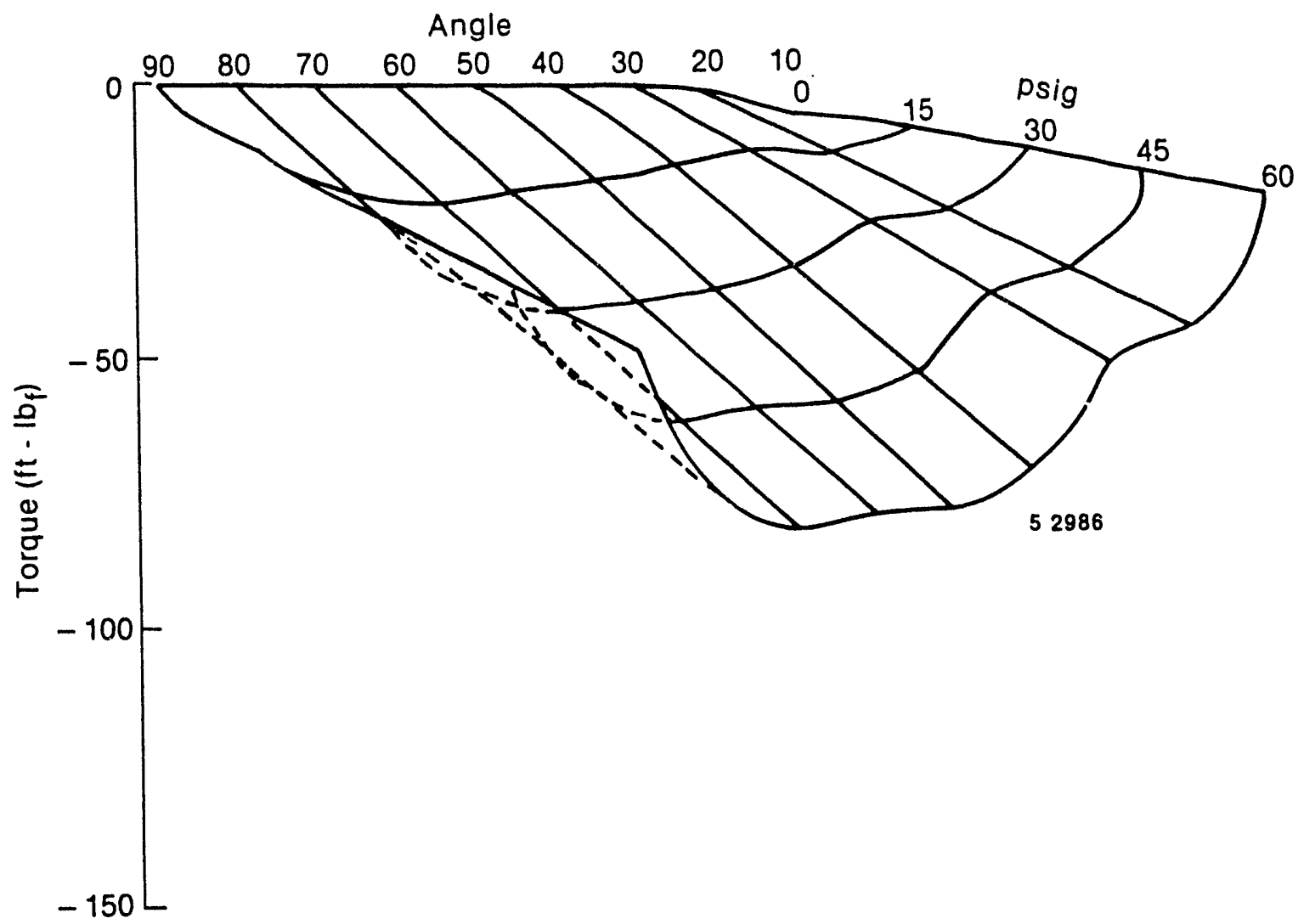

Figure 2-10. Torque versus upstream pressure and angle for the second 8-in. valve, flat-side-upstream orientation, with uniform flow. 


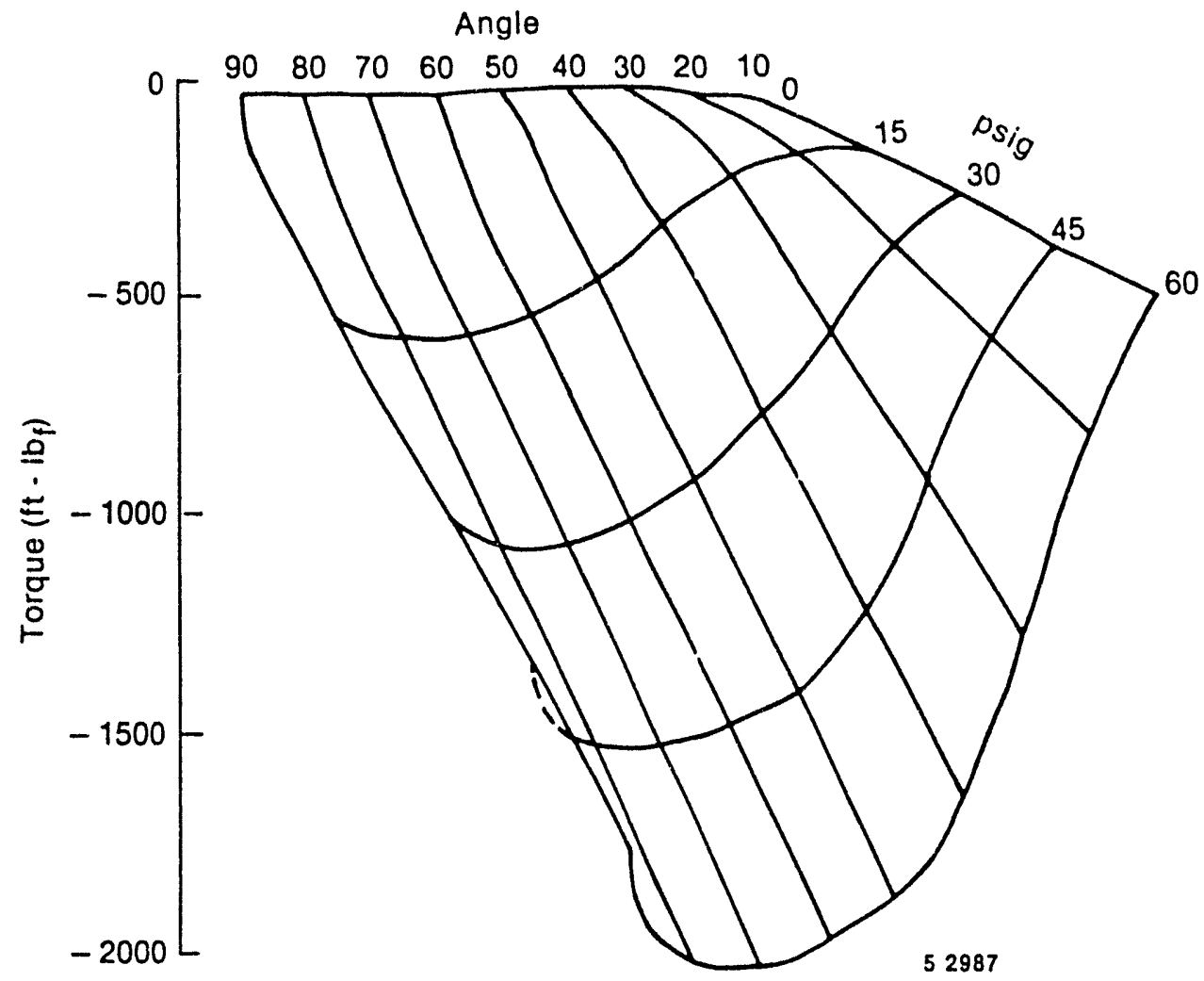

Figure 2-11. Torque versus upstream pressure and angle for the 24 -in. valve, flat-side-upstream orientation, with uniform flow.

We also evaluated the validity of the diameter cubed term in Equation I as it is typically used to predict the response of larger valves from the response of smaller valves. (This is simply another way of looking at the issue discussed in the previous paragraph.) We found the exponent of 3 adequate for extrapolation purposes with the curved side upstream at inlet pressures up to $60 \mathrm{psig}$. At higher inlet pressures, the prediction tended to become unconservative. With the flat side upstream, the prediction tended to be unconservative regardless of the upstream pressure.

\subsubsection{Upstream Piping Configuration.}

Table 2-1 lists results from tests with the test valve installed in the straight section of piping for comparison with results from tests with the test valve installed downstream of an elbow. The values listed in the table are normalized peak torques measured in tests with a nominal inlet pressure of $60 \mathrm{psig}$. For each valve, the peak torque from the test with a straight section of pipe and with the valve oriented with the curved side of the disc facing upstream is assigned a value of 1.00. All other responses are compared to this value.

As stated previously, the response with the curved-side-upstream orientation with uniform flow (straight piping) generally bounds the response with the flat-side-upstream orientation with uniform flow. The exception shown in Table 2-1, where the flat-side-upstream response of the first 8 -in. valve is $106 \%$ of the curvedside-upstream response, can be attributed to data scatter.

Table 2-1 shows that in some instances the presence of an elbow upstream of the test valve had a significant effect on the peak torque response of the valve. One of the curved-side-upstream orientations with an elbow had a peak torque that was $129 \%$ of the curved-side-upstream response of the same valve in a straight section of pipe, and one of the flat-side-upstream orientations with an elbow had a peak torque 
Table 2-1. Normalized peak torques.

\begin{tabular}{llccc}
\hline $\begin{array}{c}\text { Valve } \\
\text { orientation }\end{array}$ & $\begin{array}{c}\text { Upstream piping } \\
\text { configuration }\end{array}$ & $\begin{array}{c}\text { First } 8 \text {-in. } \\
\text { valve }\end{array}$ & $\begin{array}{c}\text { Second 8-in. } \\
\text { valve }\end{array}$ & $\begin{array}{c}\text { 24-in. } \\
\text { valve }\end{array}$ \\
\hline CSU & Straight pipe & 1.00 & 1.00 & 1.00 \\
FSU & Straight pipe & 1.06 & 0.81 & 0.94 \\
CSU-CCW & Elbow & 1.29 & 1.00 & 1.04 \\
CSU-CW & Elbow & 1.14 & 0.95 & 0.92 \\
FSU-CCW & Elbow & 0.90 & 0.83 & 1.33 \\
FSU-CW & Elbow & 1.02 & 0.84 & 0.87
\end{tabular}

a. CSU indicates valve orientation with the curved side of the disc facing upstream. FSU with the flat side facing upstream. CW and $\mathrm{CCW}$ indicate direction of rotation relative to Figure 5 .

response that was $133 \%$ of the curved-side-upstream response of the same valve in a straight section of pipe. We did not attempt to analyze for extrapolation purposes the responses of valves with upstream elbows, because there is no apparent pattern to the responses. Our best recommendation for installations downstream of an elbow is to estimate the required torque using the best available test information available, taken with the curve side upstream, and then to multiply the result by 1.5 . This method should bound the worst-case response with an upstream elbow with either valve orientation.

\subsection{Conclusions}

In analyses involving offset-disc butterfly valves, torques for larger valves using compressible fluid can be determined using Equation (1) and torque coefficients ( $\mathrm{C}_{\mathrm{T}}$ curves) determined from realistically scaled smaller valves tested in compressible fluids, providing the following conditions are met: (a) upstream pressure is used instead of $\Delta \mathrm{P}$ in the development of the $\mathrm{C}_{T}$ curves and in their application, (b) the torque coefficients are determined from scale model valves oriented with the curved side of the disc facing upstream. and (c) upstream flow perturbations (nonuniform flow) such as those caused by an upstream elbow are accounted for. These three issues are not subtleties; they were not widely known before this work, and their effect on the analytical determination of torque requirements can be significant. These conclusions are based on the following findings.

In our testing of three butterfly valves, the upstream static pressure served better than the differential pressure as an indicator of the torque response of offset-disc, high-aspect-ratio butterfly valves closing in compressible high-flow applications.

The torque response of these valves oriented with the curved side of the disc facing upstream was predictable, but the response with the flatside-upstream orientation was not. However, the response with the curved-side-upstream orientation generally bounded the response with the flatside-upstream orientation, in terms of the magnitude of the peak torque.

Nonuniform flow caused by an elbow upstream of the valve can have a significant effect on the torque response of the valve. This effect varied depending on the orientation of the valve and the direction of rotation of the disc. A multiplier of 1.5 times the curved-side-upstrean response of the valve with uniform flow conservatively bounded 
the worst-case response of a valve downstream of an elbow.

\subsection{Leak Integrity Testing and Results}

2.6.1 Testing. The leak integrity part of the test project was performed to provide information on the generic potential for purge and vent valves to leak during or after a design basis LOCA or a severe accident. The loads resulting from design basis accidents and severe accidents are radiation, pressure, and temperature. Because the elastomers used in the seals of purge and vent valves have high radiation allowables, this load was not addressed in this test project. A pressure of $60 \mathrm{psig}$ was chosen to represent the design basis pressure. (The design basis pressure for most containments is between about 40 and 60 psig.) A design basis temperature was set at $280^{\circ} \mathrm{F}$, the saturation temperature for the pressure. Two times the design basis pressure ( 120 psig) was chosen for the severe accident pressure, and $350^{\circ} \mathrm{F}$ was chosen for the temperature, the saturation temperature for that pressure.

Investigating the elastomer sealing material [ethylene propylene terpolymer (EPT)] used in the valves, we found that the design basis conditions were well within the specified allowables for the material. On the other hand, the severe accident temperature typically exceeded the material temperature allowables.

All three of the valves we tested had relatively new seals. Each valve was pressure tested at both the design basis accident temperature and pressure and at the severe accident temperature and pressure. Each valve was pressure tested at ambient temperature before and after each high-temperature pressure test. In each instance, pressure testing consisted of pressurizing one side of the disc while monitoring for leakage on the other side, then releasing the pressure, pressurizing the other side. and monitoring for leakage.

2 8.2 Test Resuts. The two 8-in. valves performed well during exposure to the design basis accident and severe accident temperatures and pressures, with no significant leakage detected. The 24-in. valve did not leak during exposure to the design basis accident temperature and pressure, and it leaked only a very small amount during exposure to the severe accident temperature and pressure.

Two of the valves leaked on cooldown. The first 8-in. valve, which has the elastomer seal in the valve body, leaked after exposure to the design basis temperature and after exposure to the severe accident temperature. The 24 -in. valve, which has the elastomer seal on the disc, leaked after exposure to the severe accident temperature. Leakage through the 8-in. valve was as high as 470 scfh (standard cubic feet per hour), and leakage through the 24 -in. valve was as high as $320 \mathrm{scfh}$. This leakage occurred because the seals experienced compression set at the elevated temperatures. Compression set was obvious in the first 8 -in. valve after cooldown; one could see daylight between the disc and the seat. The second 8-in. valve, which has the seal on the disc (the design shown in Figure 2-1), did not leak on cooldown. The seal in this valve may have been less susceptible to compression set because of the seal's smaller cross section.

2.6.3 Conclusions. Containment purge and vent valves exposed to design basis conditions or severe accident conditions may leak after cooldown. These valves are installed in pairs, with one valve inside the containment and one valve outside. In most accident scenarios, the outside valve would be less likely to leak than the inside valve.

\subsection{Application of the Research}

The results of the research were provided to all leading manufacturers of butterfly valves. Two of them, Allis-Chalmers and Henry Pratt, actively reviewed the project from the planning through the testing and analysis.

The results provided criteria for evaluating utility submittals on containment purge and vent valves, and were used in checking utility responses to the TMI action plan (NUREG$066(0)$. 
The results are also being incorporated in the Electric Power Research Institute (EPRI) butterfly valve application guide. It is expected that this application guide will be widely used by the nuclear industry. EPRI is also expected to use the results in their MOV prediction methodology being developed to address the NRC's Generic Letter 89-10. 


\section{SEISMIC TESTING OF TYPICAL CONTAINMENT PIPING PENETRATION SYSTEMS}

\subsection{The Issue}

Among the important safety-related containment features used in nuclear power plants are the containment penetrations, installed wherever piping, electrical cabling, etc. penetrate the containment structure. A typical piping penetration system consists of the penetration itself along with piping, adjacent piping supports, and two isolation valves, usually one on each side of the penetration. These containment penetration systems (CPSs) are as important as the containment structure itself in serving as the last barrier to fission product release in the event of an accident inside the containment. Because of the large number of piping penetrations ( 100 to 200 in plants of U.S. design), CPS valves are among the prime potential sources of local leakage through the containment.

The research summarized in this section addressed the operability and leak integrity of CPS isolation valves during and after seismic events and the structural integrity of the valves, piping, and other CPS components when subjected to seismic loads. Thus, this research served to support the NRC effort regarding Unresolved Safety Issue A-46. Seismic Qualification of Equipment in Operating Nuclear Power Plants (NUREG-1030). We opted to perform full-scale tests of complete systems (valve, penetration. piping, and supports) to avoid the uncertainties inherent in extrapolating results from small-scale tests or from tests of individual components. These tests, conducted in 1986, were the first fullscale, triaxial seismic tests performed on piping and valves. The purpose of the testing was to provide empirical data on the behavior of valves subjected to seismic loads and to provide results that would serve to either support or challenge the analytic assumptions used in the design of CPS piping, valves, and supports.

\subsection{Research Methods}

3.2.1 Background Research. A review of CPS designs used in a considerable number of plants determined that most plants are unique. However, there are some similarities in the piping layouts for CPSs, especially inside the containment. (The piping in most CPS installations makes a 90-degree bend within $15 \mathrm{ft}$ of the penetration, with the inside valve either before or after the elbow.) We decided to set up three typical CPS configurations that would represent a large number of systems. We also chose to represent systems that are important to plant safety, that is, systems with a potential for leaking the containment environment directly to the outside atmosphere, and systems that would be needed to mitigate a design basis accident or an advanced severe accident.

Design basis loads vary a great deal among different plants and plant locations. Gravity, pressure, flow-induced vibration, and earthquake loads were considered.

We conducted a study of the analytically predicted acceleration response spectra for operational basis earthquakes (OBEs) and safe shutdown earthquakes (SSEs) for numerous types of containment vessel designs at varying building elevations, as reported in the appropriate NUREG reports and Final Safety Analysis Reports for 17 nuclear power plants. From that study we developed eight response spectra as specified spectri for the test project to address horizontal and vertical acceleration at two building elevations (the lower third and the upper half) for OBEs and SSEs. For an example, see Figure 3-1, which shows the specified horizontal response spectrum (labeled "test specification") for the upper half of the containment for an SSE. The analytically predicted spectra for several plants are also shown for comparison, as is the spectrum derived from the measured test input. Figure 3-1 is addressed in more detail later in this discussion. 


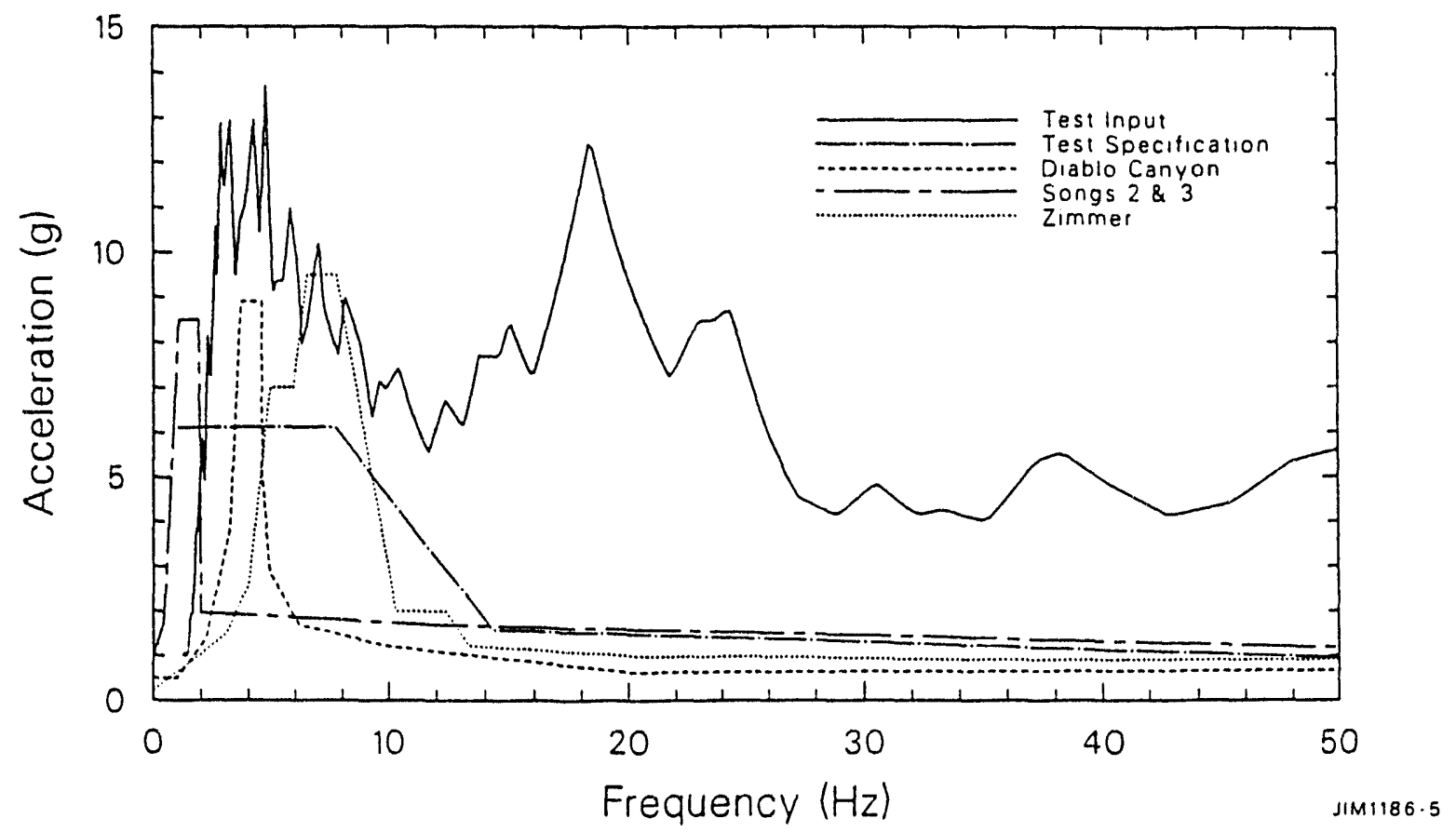

Figure 3-1. Comparison of the measured SSE test response spectrum with the SSE required response spectrum and with the analytically predicted SSE response spectra for selected plants; horizontal response spectra for the upper half of the building.

3.2.2 Description of the Test Project. One of the three configurations chosen for testing was an 8 -in. gate valve system (Schedule 40 piping) modeling a containment spray system. This system was chosen because it is important to containment integrity as the final heat removal system. A containment spray system is a closed loop. liquid-filled system that requires leak integrity and valve operability for plant safety. An 8 -in. butterfly valve system (Schedule 40 piping) modeling a purge and vent system was also chosen. This system is important to containment integrity because of the risk of leakage to the outside environment. The other configuration chosen for testing was a 2 -in. globe valve system (Schedule 160 piping) modeling the many small bore piping systems that make up a large fraction of a power plant's CPSs. One concern with these small diameter systems is the large ratio of valveplus-operator mass to pipe size.

We designed a test fixture that would accommodate either the 2-in. CPS or the 8-in. systems. The test fixture itself consisted of a large frame measuring $23 \times 13 \times 8 \mathrm{ft}(7.6 \times 4.3 \times 2.6 \mathrm{~m})$ constructed of 14-in. square steel tubing and mounted on pressurized air bags. Each piping system was individually installed in the test frame using nuclear grade supports, including rigid struts, spring hangers, and box beam supports. Support configurations were designed to approximate those in existing nuclear power plants. Independent triaxial motion was input into the frame by large, computer-controlled hydraulic actuators mounted to the frame. A sketch of the 8-in. gate valve system installed in the test fixture is shown in Figure 3-2.

The test fixture was designed to test only the inside half of a CPS. The connection of the piping to the containment at the penetration is stiff enough that no significant interaction between the inside piping and the outside piping would occur during an earthquake.

The piping systems were designed and fabricated in accordance with ASME Code requirements. The valves and penetrations were obtained from cancelled nuclear power plants. The piping 


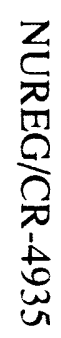

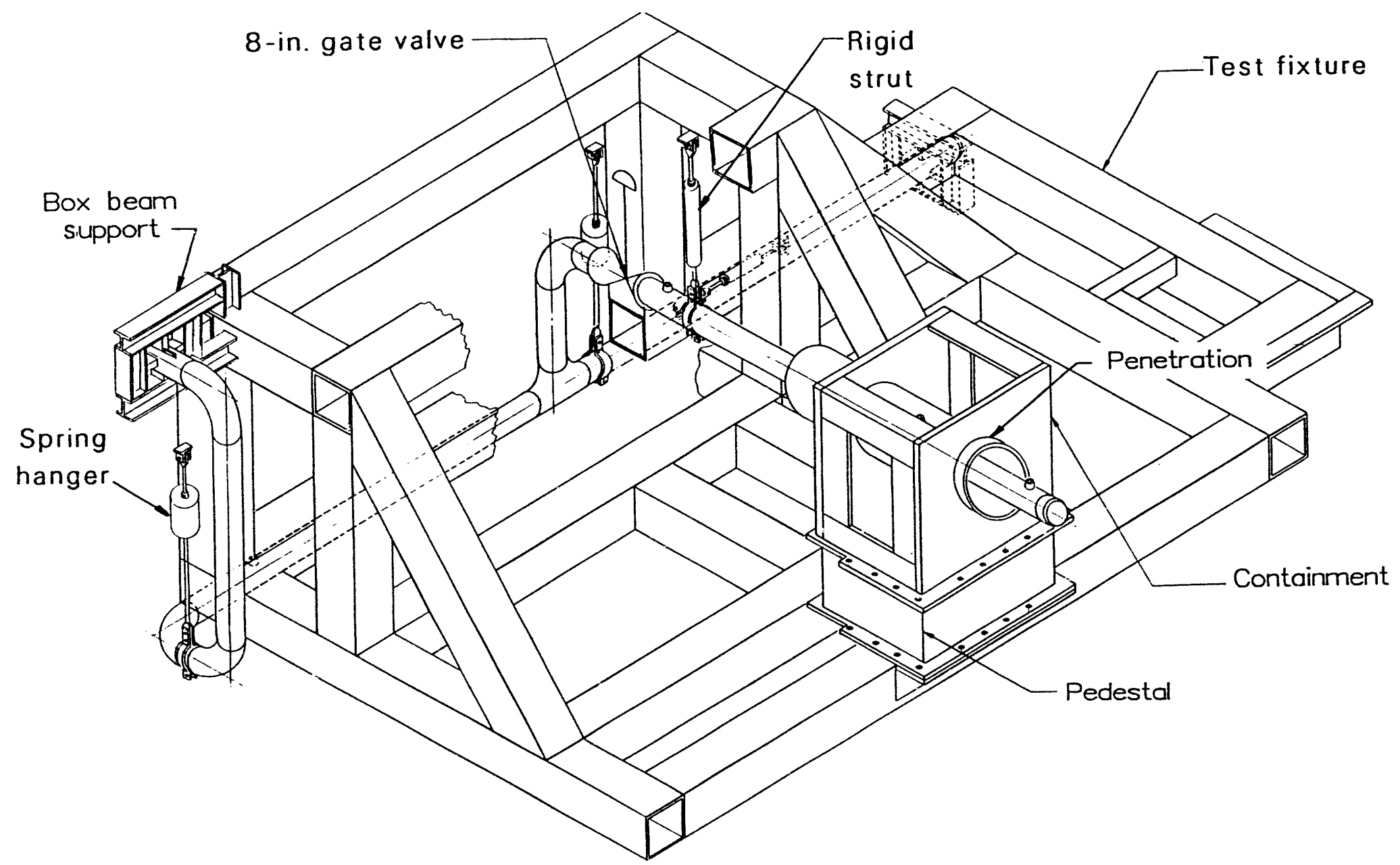

Figure 3-2. Sketch of the test fixture with the 8-in. gate valve assembly installed. 
and supports were purchased from nuclear power plant suppliers.

The systems were instrumented to measure leak rates, pressures, temperatures, valve motor operator current, and valve stroke times. In addition, strain gages and accelerometers were installed on supports, valve assemblies, and piping to provide test data for comparison with predictions derived from analytical methods widely used in the industry.

Each of the three CPSs was subjected to the same test sequence, shown in Table 3-1. The fluids and pressures shown in the first column are those typical of the systems being modeled. The two low-amplitude vibration tests, conducted for 5 min each at one tenth of OBE loads, served not only to test the operability and leak integrity of the valves at those loads, but also to impose an arbitrary but reasonable amount of vibratory aging on the piping before subjecting it to the OBE and SSE loads. In the OBE and SSE tests, the 8 -in. gate valve CPS and the 2 -in. globe valve CPS were tested using the input resporise spectra for the lower third of the building, while the 8-in. butterfly valve CPS was tested using the input response spectra for the upper half of the building. After each step of testing, the acceptability of the previous test step was checked to make sure that desired load levels were achieved and that system responses were adequately measured.

\subsection{Results}

In general, the acceleration measured at the base of the test stand during the simulated OBEs and SSEs was equal to or considerably greater than the required response spectra specified in the test plan. In a few cases, the input spectra derived from the acceleration measurements failed to completely envelope the predicted response spectra specified in the plant reports we researched, but only at very low frequencies $(2.0$ to $2.5 \mathrm{~Hz}$ ). For an example, see Figure 3-1. We judged these results to be acceptable because the lowest natural frequency for our piping systems was $3.9 \mathrm{~Hz}$, so no amplification would occur at the low frequencies in question. Note also that the plant spectra shown in this figure are those that have the greatest horizontal response spectra of the 17 plants whose data we reviewed.

3.3.1 Valve Operability. The seismic loads imposed during the test sequence had no adverse effects on the operability of any of the three valves we tested. Small variations occurred in the stroke times, but these were caused not by the seismic loads, but by such factors as wear-in of new valve packing. In some cases, the measurements of motor current were slightly lower during seismic loading than after the loading ceased. Apparently, the vibration associated with the seismic loads caused a slight reduction in friction during valve operation.

3.3.2 Valve Leakage. The seismic loads did not cause any significant leakage through the valves. The 8-in. butterfly valve did not leak at all during the test sequence. The 8 -in. gate valve leaked slightly during the simulated OBE (approximately $300 \mathrm{~cm}^{2} / \mathrm{h}$ ); leakage returned to zero with cycling after the simulated OBE, and remained at zero during and after the simulated SSE. Leakage through the 2-in. globe valve is shown in Figure $3-3$. The valve leaked more than expected during leakage tests conducted before the simulated seismic loads. The general trend during the test sequence was for leakage to decrease with successive operation and with cumulative exposure to seismic loads.

3.3.3 Structural Integrity. The seismic loads did not cause any observable structural damage in CPS piping, valves, penetrations, or supports. No leakage occurred at any of the welds, but some very minor leakage occurred at a flange. (The 8 -in. gate valve and the 2 -in. globe valve were welded in place, while the 8 -in. butterfly valve was welded on one side and flanged on the other.) No leakage occurred through any of the valve bonnets.

\subsection{Conclusions}

These tests were the first full-scale triaxial seismic tests ever performed on complete piping systems. Although the three CPSs discussed here 
Table 3-1. Overview of measurements during seismic testing of the three containment penetration systems.

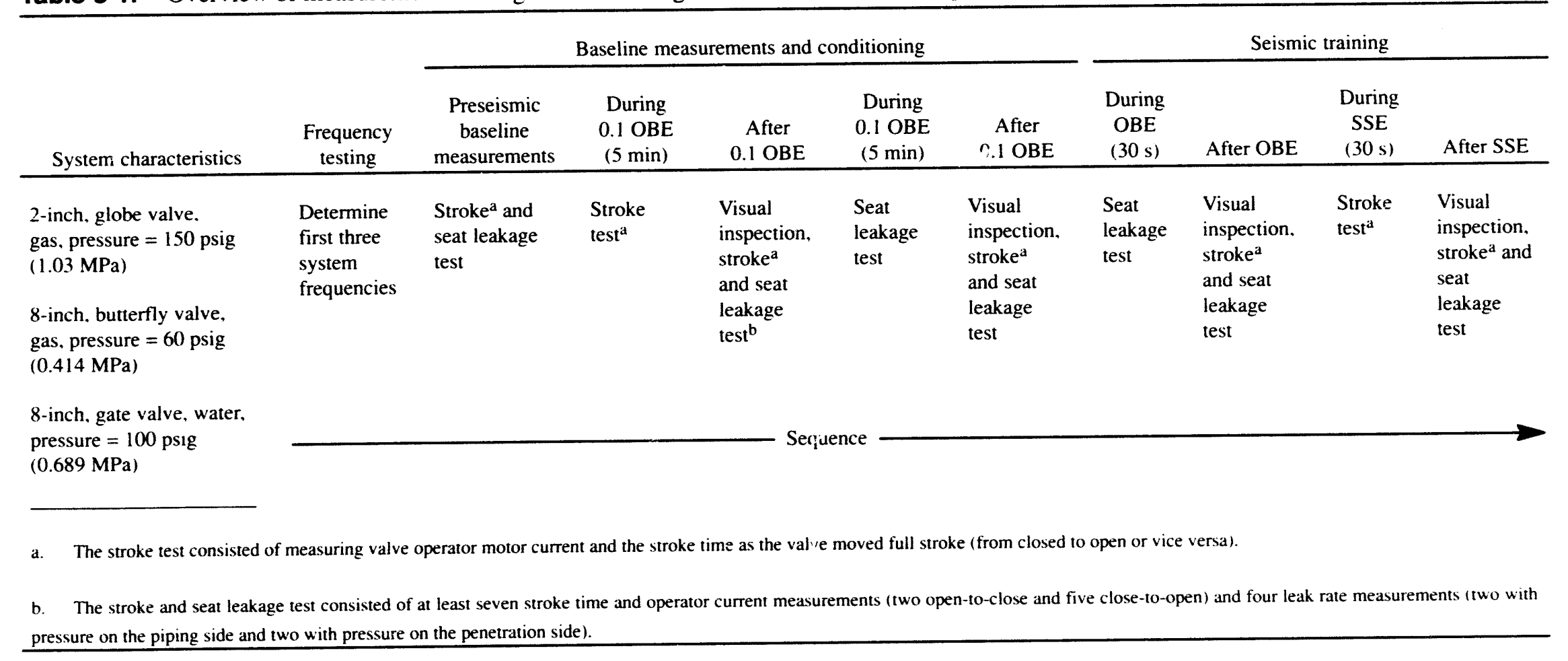




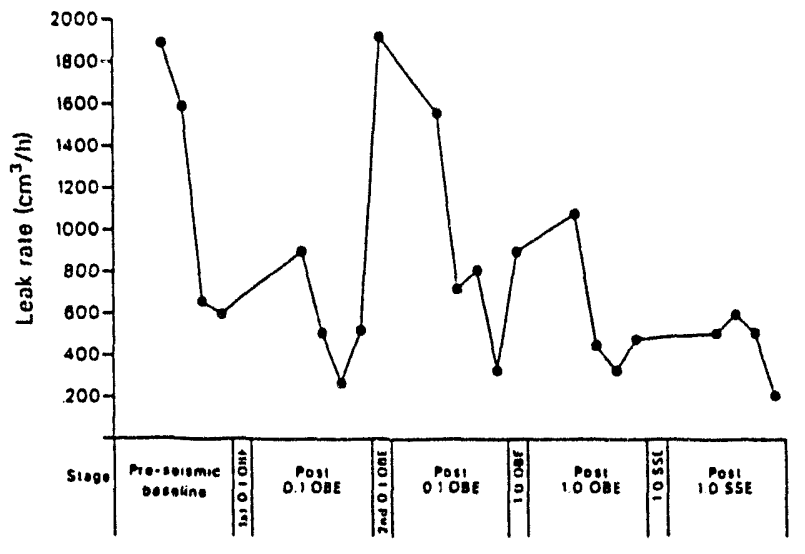

Figure 3-3. Leak rates across the seat of the 2-in. globe valve.

were not tested to failure, the applied loads were close to the most severe response spectra predicted for U.S. commercial plants. Of the changes in performance that occurred during the test sequence, any that could be attributed to the seismic loads tended to be improvements. No operational or structural failures occurred.

These results indicate that the worst case earthquakes anticipated in the design of nuclear power plants will not (a) increase the torque required for operation of CPS valves, (b) induce leaks in CPSs, or (c) cause structural failures in CPS piping, valves, penetrations, or supports.

The performance of these CPSs alleviated some concern that bench testing of individual CPS components might not be adequate. How- ever, the test results also raised one concern. Data from accelerometers mounted on the valve and operator showed a dynamic response at frequencies higher than those for which the operator components are qualified. The implications are that vibration at these higher frequencies might cause electrical components such as relays to chatter, thus affecting the switches they control. These results concur with the results of the SHAG seismic test project, where a similar phenomenon was observed. See Section 7.3.4 of this summary report.

\subsection{Application of the Research}

These tests provided useful insights into the loads that piping systems might see in an earthquake environment. The results of this work. along with the results of the work reported in Sections 7 and 8 of this report, contributed to the data base that supported the NRC effort regarding Unresolved Safety Issue A-46, Seismic Qualification of Equipment in Operating Nuclear Power Plants (NUREG-1030). The fact was established through our work and the work of others that nuclear valves and piping will not be damaged by any credible seismic loading. The implementation plan currently in effect for addressing USI A-46 incorporates this important finding by allowing that older plants built before the modern seismic requirements were imposed can be judged by criteria less strict than a full seismic requalification. 


\section{TESTING OF CONTAINMENT PENETRATION SYSTEMS AT ACCIDENT LOADINGS}

\subsection{The Issue}

A companion project to the testing described in Section 3 of this report was the testing of fullscale CPSs under design basis loadings and severe accident loadings. (For a brief description of CPSs and a discussion of their importance to plant safety, see Section 3.1.) The concern for the containment penetration, piping, and isolation valves was that the containment could grow both vertically and radially in response to a severe loss-of-coolant accident inside the containment. Because the piping is supported either from the basemat or from an internal structure that would not grow with the containment, the containment might literally pull the piping apart, causing a leak to the outside.

The tests described in this section consisted of subjecting the valves and piping to elevated temperatures and pressures and displacing the penetration relative to the piping to simulate th. thermal and pressure expansion of the containment wall during design basis accidents and severe accidents. The tests were conducted in late 1987 and early 1988. During the tests, we monitored the operability and leak integrity of the valve, and we monitored the effects of the wall displacement (as much as $18 \mathrm{in}$.) on the piping and supports. The effects of radiation, steam, chemical spray, and very high temperatures (temperatures above the saturation temperature for the simulated containment pressure) were not addressed. Those loads would be better addressed in special effects testing of individual components.

\subsection{Research Methods}

4.2.1 Background Research. A search of the available literature and a study we conducted on thermal effects indicated that combined thermal and pressure expansion of the containment wall during a severe accident could be as great as 12 in.
4.2.2 Description of the Test Project. The three CPSs modeled and tested in the seismic test project described in Section 3 were also used for testing in this test project: an 8 -in. gate valve system, an 8 -in. butterfly valve system, and a 2 -in. globe valve system. Some of the hardware used in the seismic testing was used again in this testing. and some new hardware was installed. The test fixture used for the seismic tests was modified and used in this test project. The 8-in. CPSs were installed in the test fixture with the penetration assembly mounted on rollers that traveled on rails to provide for a controlled displacement of the penetration relative to the piping, which was anchored to the frame of the test fixture with struts and other supports. A hydraulic ram was used to incrementally move the penetration. The rails on which the penetration rode sloped upward at 15 degrees, so that movement of the penetration would simulate both the radial and vertical displacement of the containment wall during an accident. Figure 4-1 is a diagram of the test fixture with one of the 8 -in. CPSs installed. Figure 4-2 is a photograph of the 8-in. gate valve assembly installed in the test fixture.

The 8-in. containment spray test system and the 8-in. purge and vent test system modeled piping inside and outside the containment; thus each of the 8-in. systems used two valves. The two 8 -in. systems were similar in design and used much of the same type of hardware.

The 2-in. system modeled only the inside piping, with the penetration end of the pipe capped to simulate the outside valve in the closed position. The configuration of the system was simpler, featuring one strut and one elbow. Containment wall displacement was modeled by anchoring the penetration and displacing the piping. At the request of $\mathrm{NRC}$, the 2 -in. system testing included enclosed-volume water expansion testing to determine whether overpressurization might occur in the piping between the two closed valves in a plant CPS when subjected to the high temperatures anticipated in accident conditions. 


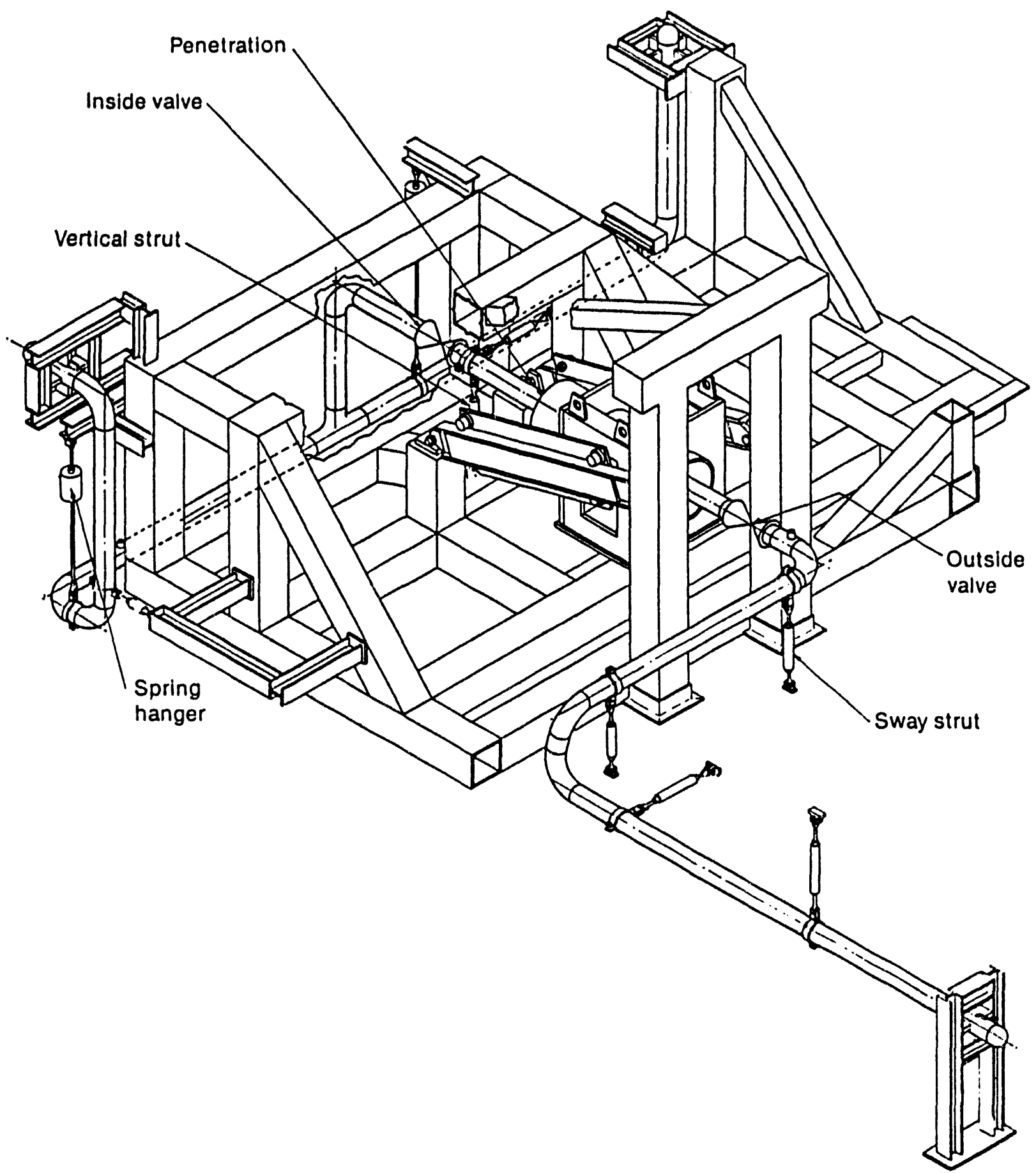

Figure 4-1. Sketch of the test fixture with an 8 -in. gate valve system installed.

The piping systems were designed and fabricated in accordance with ASME Code requirements. The valves and penetrations were obtained from cancelled nuclear power plants. The piping and supports were purchased from nuclear power plant suppliers. 


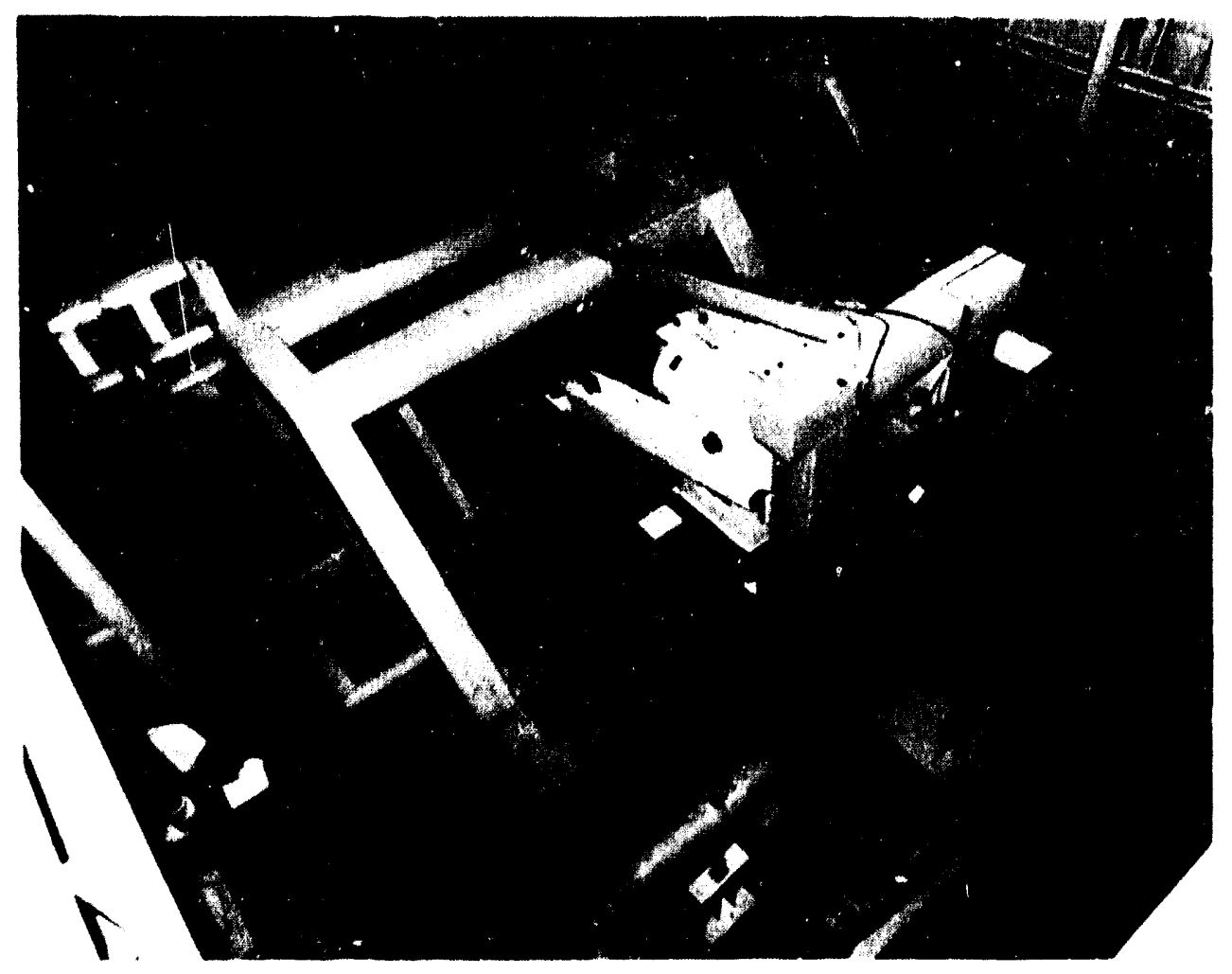

Figure 4-2. Overhead view of the test fixture with the $X$-in. gatte valve assembly installed.

The systems were instrumented to measure leak rates, pressures, temperatures, valve motor operator current, and valve stroke times, and strains on the valves and piping.

The basic testing sequence for each of the three CPS consisted of (a) performing operational baseline tests on the system and (b) heating the inside valve and displacing the penetration in a stepwise fashion until reaching the desired conditions, while monitoring valve function, valve seat leakage, and strains on the piping. Table 4.1 summarizes the temperatures, pressures, and displacements imposed during the test sequence.

\subsection{Results}

4.3.1 8-in. Gate Valve System. The 8-in. gate valve CPS was subjected to a horizontal displacement of 13.2 in. with a corresponding vertical displacement of $3.3 \mathrm{in}$. Two of the struts were subjected to loads more than seven times their rated capacity. Some of the supports showed evidence of damage (for example, a bent end pin, a bent pipe clamp, an elongated end connection. et(.), but none of the supports in the 8 -in. gate valve CPS failed.

The piping responded in a ductile manner with significant yielding but no local buckling. In addition, some minor, local deformations occurred where the piping slipped through the clamps that provide for connection to the piping supports. Ovalization occurred at one elhow, changing the external shape of the pipe from a circular cross-section with a diameter of 8.67 in. 10 an oval cross-section with major and minor axes of 9.16 and 8.36 in., respectively. None of the piping experienced a significant reduction in flow area.

Valve operation was not affected by the loads. However, leakage through the inside valve increased from an insignificant amount (less than $0.005 \mathrm{scfm}$ ) to about $0.103 \mathrm{scfm}$ (standard cubic feet per minute) when the horizontal displace. ment reached $12.6 \mathrm{in.}$ (more than twice the design basis accident specification). As the displacement increased, leakage decreased to about 0.02 to $0 .(14 \mathrm{scfm}$. The leakage immediately increased to 
Table 4-1. Summary of testing sequence.

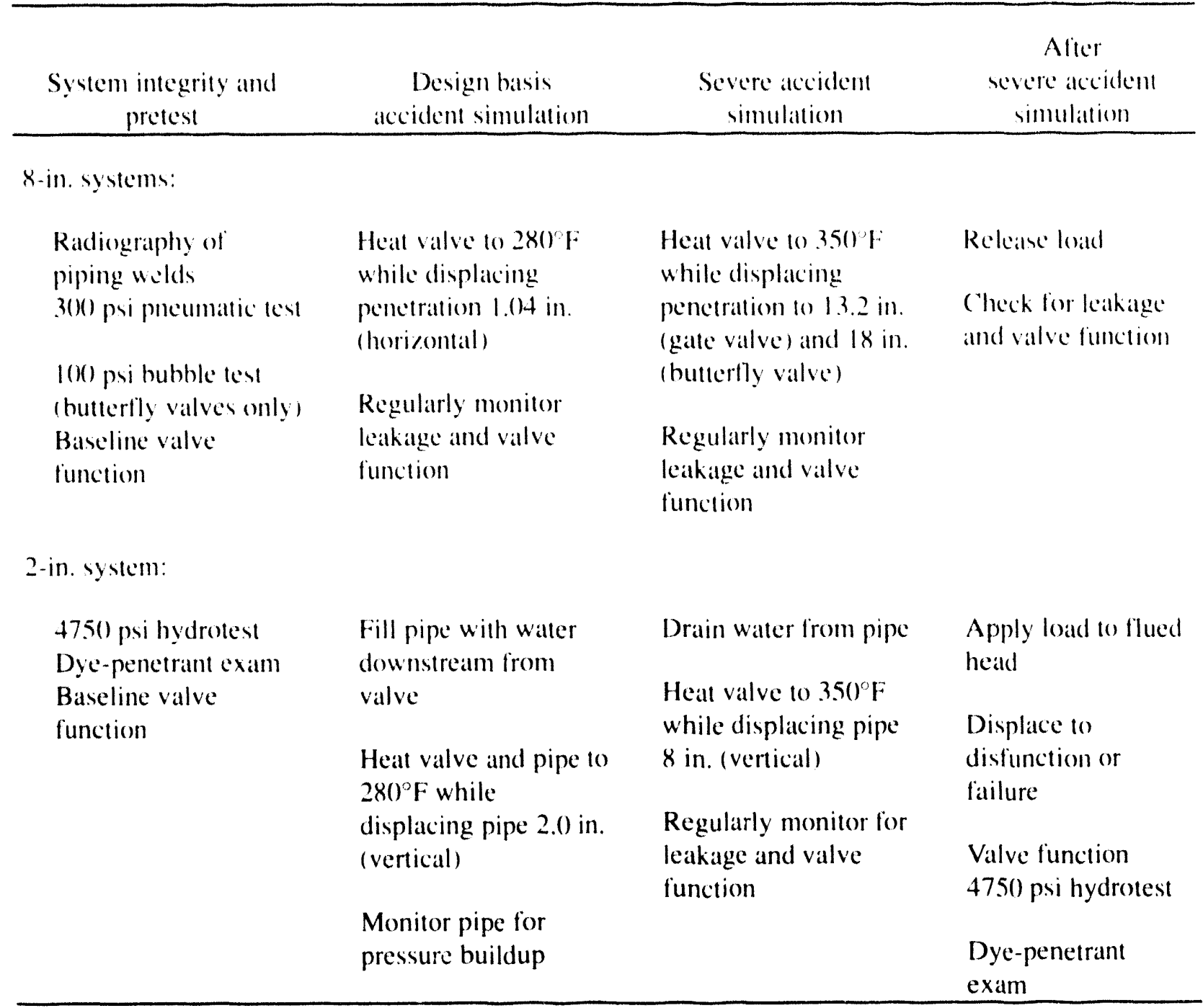

$0.89 \mathrm{scfm}$. when, at the end of the test sequence, the load was released from the penetration and the piping returned about 4.2 in. toward its original position. A posttest examination indicated that the valve body had yielded slightly. No significant leakage occurred through the outside valve.

4.3.2 8-in. Butterfly Valve System. The 8 -in. butterfly valve CPS was subjected to a horizontal displacement of $18.0 \mathrm{in}$. with a corresponding vertical displacement of 4.8 in. Two of the struts failed: a horizontal strut buckled under very high compression loads, and one rod end of a vertical strut yielded enough to allow the pin to pull through the end of the eye.
As in the gate valve testing, the piping responded in a ductile manner with significant yielding but no local buckling. Some minor, local deformations occurred at the clamps. Ovalization occurred at three elbows.

The displacement loads did not affect valve operation. Neither valve leaked during the heated portion of the test. However, the inside valve leaked at about $0.88 \mathrm{scfm}$ after cooldown after the test sequence. (This same result was produced in earlier testing of butterfly valves. See Section 2.6.2.) We attributed this leak to elevated temperatures imposed on the valve with the valve in the closed position. Under those conditions, the valve's elastomeric seal is especially susceptible 
to compression set, thus reducing the seal's effectiveness after cooldown. (New seals had been installed in the valves at the beginning of the testing.)

4.3.3 2-in. Globe Valve System. The enclosed-volume water expansion test of the 2-in. globe valve system (Schedule 160 piping) was performed as part of the design basis accident simulation. After the temperature reached $280^{\circ} \mathrm{F}$, the pressure rose to over $4000 \mathrm{psig}$ and would have continued to rise had we not shut off the heaters to prevent pipe rupture.

The globe valve CPS was tested beyond the severe accident displacement of 8 in. (vertical displacement of the end of the pipe section) to a maximum displacement of 48 in. There were no failures nor loss of function of any of the equipment. Stresses in the strut remained well within the elastic limit throughout the test. (The strut was disconnected after the displacement reached 8 in.) The piping behaved in a ductile manner with no cracking, buckling. or leakage in either the piping or the welds. Although the pipe experienced significant yielding. the cross section remained circular.

\subsection{Conclusions}

The pressure, temperature, and displacement loads imposed on the three CPSs we tested did not affect the operation of the valves: no noticeable changes occurred in operating current or stroke time.

No valve leakage occurred at or below design basis accident conditions. The plastic deformation of the valve body of the inside gate valve at higher displacement loadings was unexpected. but the resulting leak was small. The leak through the inside butterfly valve after cooldown raised concerns about the resistance of the eiastomeric seals to high temperatures.

The CPS valves inslalled outside of the containment were not subjected to the high temperature loadings imposed on the inside valves. Neither of the corresponding outside valves leaked during or after our CPS testing, indicating that in an in-plant installation, both of these valve leaks we observed would have been contained by the redundant valve on the outside of the containment.

Testing showed that CPSs are extremely tough and forgiving. Damage to the piping even at severe accident displacements was minor and showed no evidence of affecting the integrity of the piping. Instances of strut failure and clamp slippage served to reduce rather than increase the stress on the piping.

Water trapped in the piping between the two valves in a CPS can build up excessive pressure at design basis temperature if no pressure relief is provided. Rupture of the pipe and possibly the valve could result. Such an occurrence would not necessarily cause a breach of containment, but it would disable the system (or at least part of the system) in which the piping and valve are installed.

\subsection{Application of the Research}

Part of the NRC's severe accident research was to determine the existing margins for components, systems. structures, etc. if subjected to conditions more severe than the design basis conditions. Our work, along with the work of Sandia National Laboratory (SNL), addressed the containment integrity portion of that research (NUREG-1264). The results provided many insights on the available margins of the containment and the containment penetration piping systems in accidents that progress beyond design basis loads. The results of our testing showed that the components of the containment piping penetrations (the penetrations, associated piping. and isolation valves) would not be the weak link in any credible severe accident scenario that threatened the integrity of the containment. 


\section{REACTOR COOLANT PUMP SHAFT SEAL PERFORMANCE DURING STATION BLACKOUT}

\subsection{The Issue}

A typical reactor coolant pump ( $R C P$ ) shaft seal assembly consists of three (or four) seals in a series. The first and intermediate seals are designed to contain a portion of the pressure while allowing some leakage through a small path toward the next seal and out through a leakoff line, while the final seal contains the remaining pressure with little or no leakage. Cooler water $\left(100\right.$ to $160^{\circ} \mathrm{F}$ ) is injected into the flow path ahead of the first seal to keep the seals and the leakage path cool, because typical operating temperatures of approximately $550^{\circ} \mathrm{F}$ in PWRs can damage certain polymer components of the seal assembly. and because otherwise the pressure drop in the leakage path might cause hot water to flash into steam between the faces of the main seal rings. One of the concerns with these seal assemblies is that during a station blackout, the pumps that supply the cooler water to the seals will be without power, allowing the hotter water to reach the vulnerable polymer components. In addition, the occurrence of flashing between the seal faces could cause one or more of the seals to pop open (seal instability), ultimately leading to a smallbreak loss-of-coolant accident. The research reported here addressed these concerns and thus provided information to support the NRC effort regarding Generic Safety Issue 23. "Reactor Coolant Pump Seal Failures at Station Blackout Conditions."

Figure 5-1, a sketch of a typical pump shaft seal, shows the components of interest: a static O-ring, the secondary seal, and the main seal rings. The primary hydraulic seal occurs at the main seal rings and is provided by the proximity of the rotating seal ring and the nonrotating seal ring. One of the main seal rings (in this particular design it is the nonrotating seal ring) is mounted so that limited axial motion is permitted, thus maintaining a very small, virtually constant gap between the main seal rings as the shaft moves axially relative to the housing in response to thermal and pressure-induced expansions. The

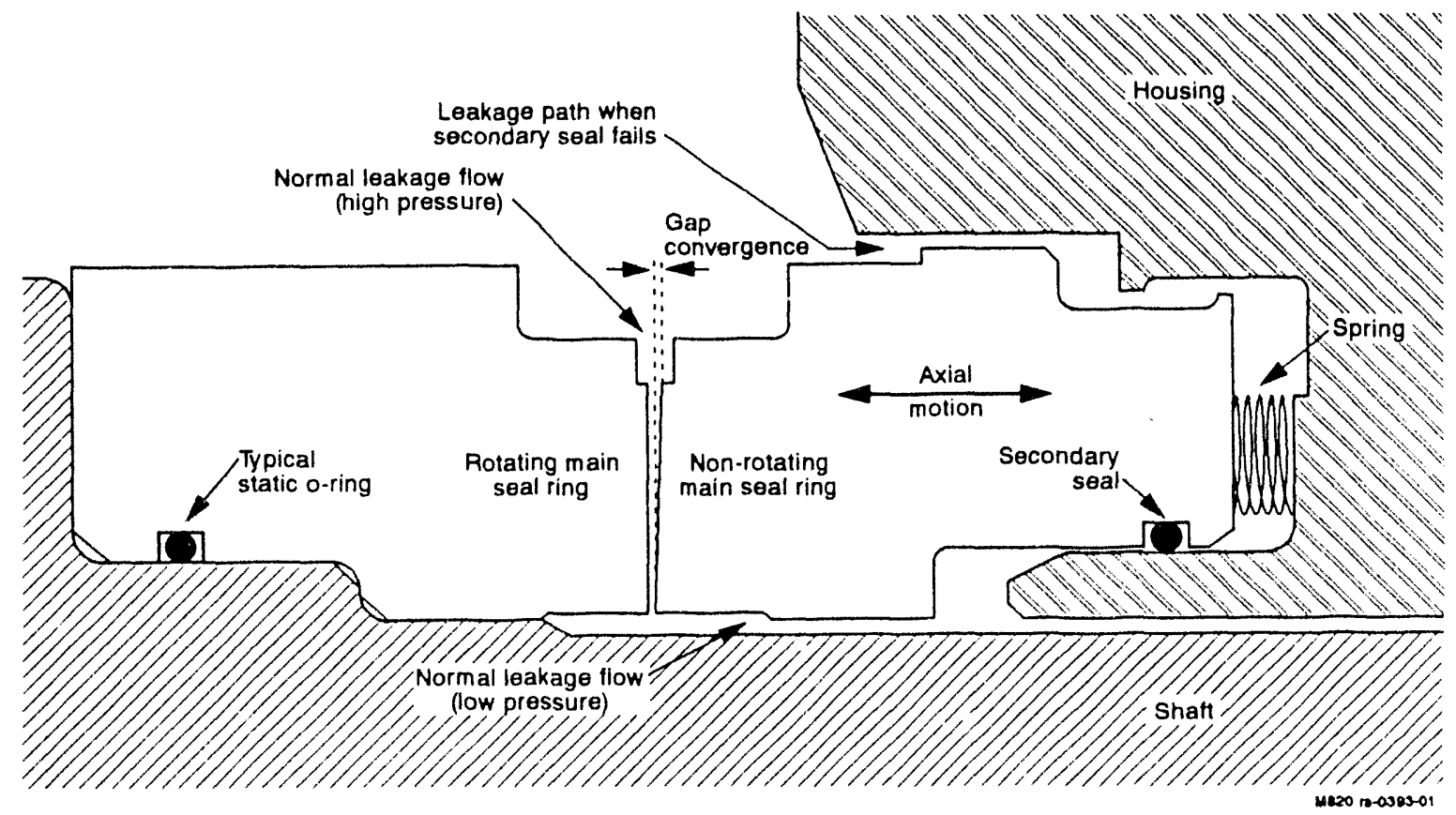

Figure 5-1. Simplified diagram of a cross-section of an RCP shaft seal: this represents one of the three or four seals that constitute the entire seal assembly. 
opening between the seal faces is controlled by a balance of opening and closing forees. As the seal faces close down. the flow is reduced, and the pressure drop across the seal changes. The resulting change in opening forces causes the seal faces to open until a balance of forces is achieved. The secondary seal accommodalcs axial motion of the non-rotating main seal ring relative to the housing withoul allowing leakage hetween the two. These secondary seals are among the poiymer components that can be damaged by high temperatures. The seal assembly includes several other polymer O-rings as static seals; one such (O-ring is shown in Figure 5-1 as an example. These static O-rings seal interfaces between components that remain stationary relative to each other. Some of these static ()-rings can also be damaged by station blackout temperatures and pressures.

The insestigation summarized here consisted of (a) conducting a limited evaluation of the potential for static ()-rings to blow out during station blackout. (b) lesting the polymer seal components of the secondary seals in three different designs, with displacement of the sealing surface relative to the seal under conditions simulating the high temperalures and pressures anticipated during a station blackout, (c) conducting a computer analysis of the effects of flow, pressure, fluid condition. and seal design on the stability of the main seals (their resistance to popping open), (d) conducting limited testing of RCP shaft seals to validate the computer analysis, and (e) reviewing the available results of full-scale pump shaft seal tests conducted by others. The tests were conducled in 1986.

\subsection{Assessment of Polymer Seal Performance}

5.2.1 Evaluation of Static O-rings. Earlier research (reference 3 ) investigating the behavior of typical polymer seals used in Westinghouse RCP shaft seal assemblies showed that at some station blackout conditions, some of the static $O$-rings would blow out. The investigation summarized here included a limited evaluation of the potential for failure of static ()-rings in Byron
Jackson and Bingham International pump seal assemblies. This evaluation was based on (a) the information available on the materials used and the pressures and gaps to be sealed in these assemblies and $(b)$ the results of the earlier testing of the Westinghouse seal assemblies. The evaluation included several assumptions on these designs that would require proprictary information to confirm, so the results are tentative. The evaluation found one static ()-ring in the Bingham International seal design, namely the ()-ring that seals the interface between the stationary main seal ring and its carrier, to be all risk during a station blackout.

5.2.2 Testing of Secondary Seals. The investigation summarized here included laboratory lesting of secondary seals. The purpose of this testing was (a) to determine the response of the seals (whether or not they would extrude or blow out), (b) to determine the effects of relative movement of the surfaces being sealed on the extrusion behavior of the seals, and (c) to determine the friction forces developed between degraded seals and the movable main seal rings they are intended to seal. The tests were conducted by the Atomic Energy of Canada Limited Research Company (AECL) al Chalk River Nuclear Laboratories in Ontario, Canada. Three types of secondary seals were tested: Westinghouse O-rings with channel seals, Byron Jackson U-cups, and Bingham International O-rings with backup rings. See Figures 5-2 and 5-3. The Westinghouse $\mathrm{O}$-rings were not the same as the O-rings typically installed in Westinghouse applications; the test project used O-rings of a different material, in anticipation of a material replacement by Westinghouse.

The test rig included a smooth cylindrical sleeve (simulating the nonrotating movable main seal ring in Figure 5-1) that was inserted into a concentric housing containing two secondary seals of the same design oriented back to back. Pressure was applied to the cavity between the two seals by distilled water supplied from a vessel pressurized by nitrogen cover gas. A linear actuafor attached to the sleeve provided for axial motion of the sleeve relative to the housing. The 


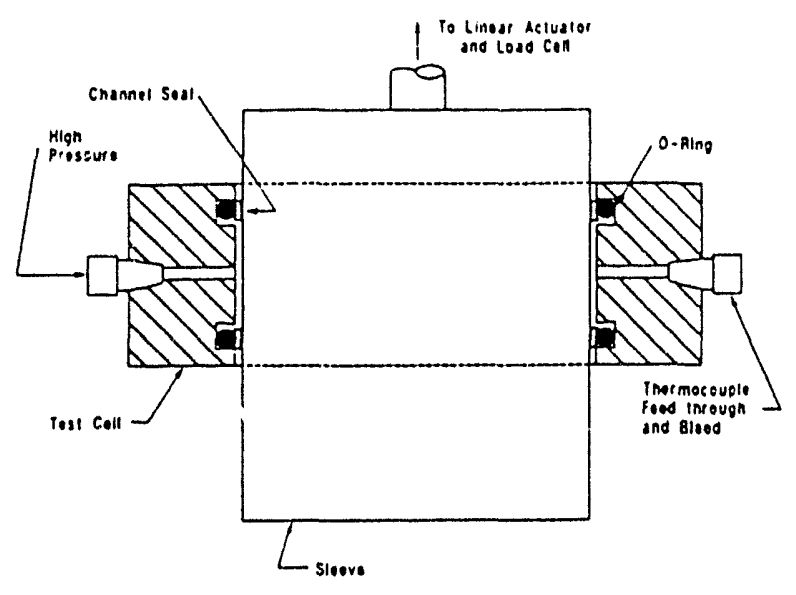

a. Westinghouse.

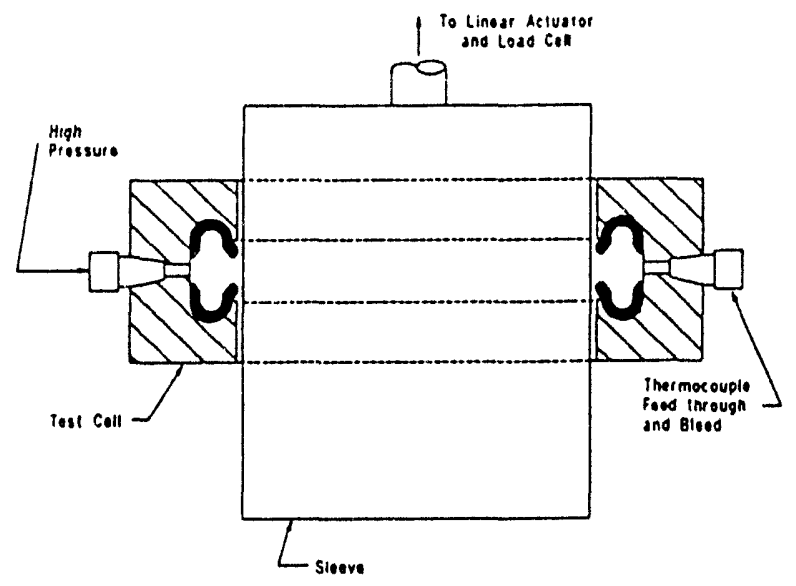

b. Byron Jackson.

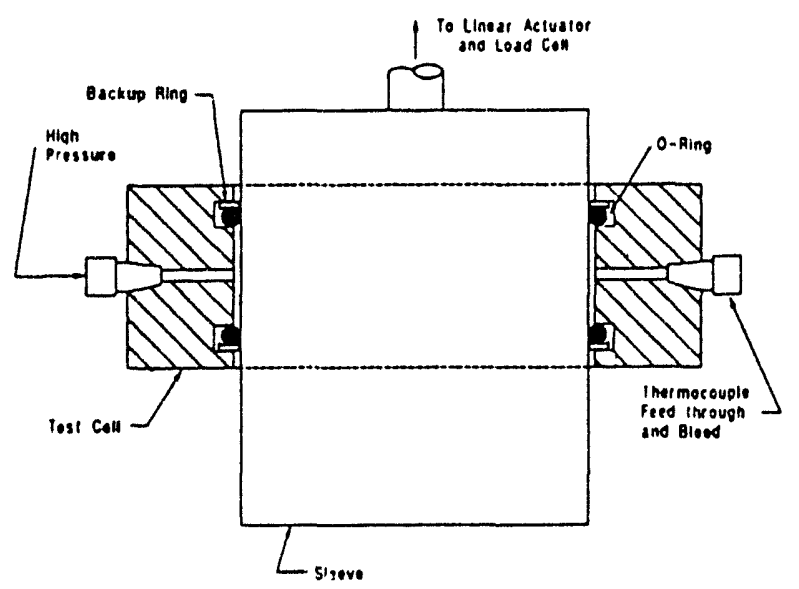

c. Bingham International.

Figure 5-2. Test cell for extrusion and friction testing of secondary seals.

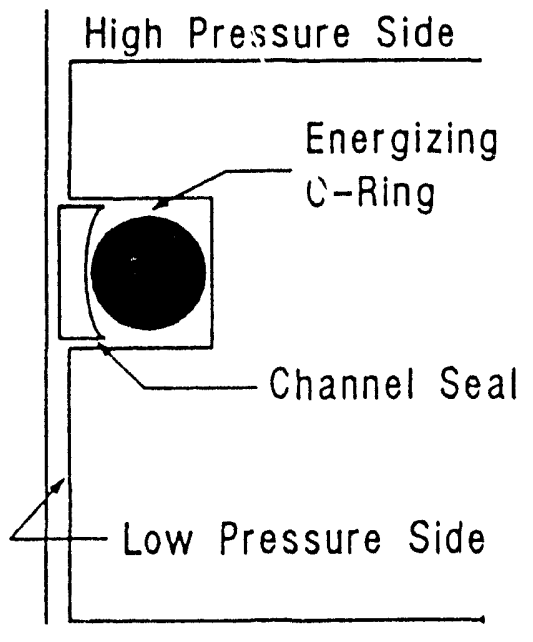

a. Westinghouse Channel Seal.

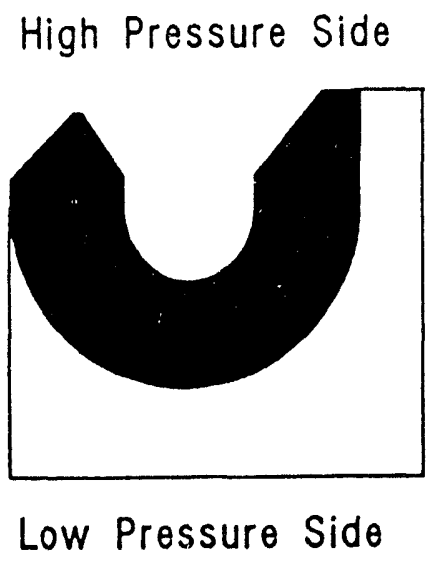

3. Byron Jackson round-back U-cup.

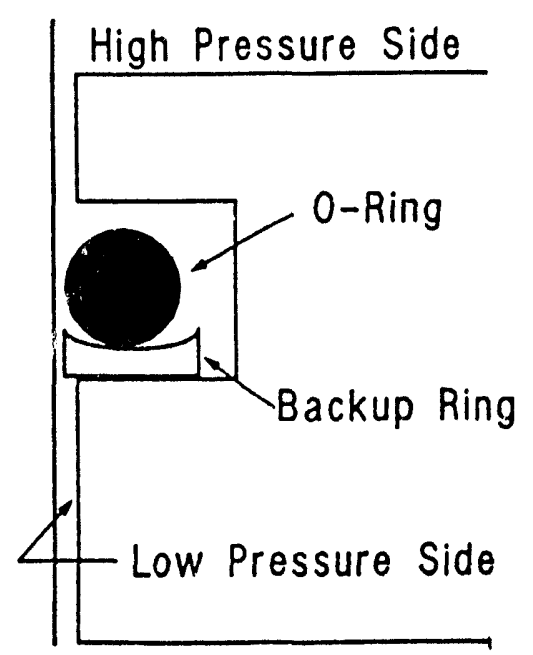

c. Bingham International O-ring with backup ring.

Figure 5-3. Cross-sections of the typical secondary seals subjected to testing. 
linear actuator was instrumented with a load cell to measure the force required to slide the sleeve past the polymer seals. During testing, the housing and sleeve were heated and maintained at uniform temperature in laboratory ovens. Tests were conducted at temperatures as high as $550^{\circ} \mathrm{F}$ and at pressures as high as 2200 psi, with sleeve-tohousing diametrical clearances varying from 0.009 to 0.035 in.

In five tests of Westinghouse O-rings with channel seals, all the channel seals extruded. Leakage occurred in only one case; in all other cases, the O-ring took over the sealing. The force required to initiate axial movement of the sleeve at high temperature was as high as $210 \mathrm{lb}$ (for two seals), almost twice that measured for the seals before exposure to high temperatures.

Seven tests using Byron Jackson U-cups were run. No significant extrusion occurred, but the U-cups did experience permanent set and severe embrittlement. Significant leakage attributable to the test conditions occurred only in the test with the most severe conditions, at $550^{\circ} \mathrm{F}$ and $2200 \mathrm{psi}$; the lip of the U-cup fractured. The force required to initiate axial movement of the sleeve in that test was $625 \mathrm{lb}$, the highest measured in the U-cup tests.

Nine tests using Bingham International O-rings with backup rings were run. No leakage occurred. Some extrusion of the back-up ring occurred in all the high-temperature tests $\left(500\right.$ to $550^{\circ} \mathrm{F}$ ). (Three tests were run at $70^{\circ} \mathrm{F}$ ). The highest force required to initiate axial movement of the sleeve was $660 \mathrm{lb}$.

\subsection{Shaft Seal Stability}

Our investigation of RCP shaft seal stability, that is, the seal's resistance to popping open when flashing occurs between the seal faces, consisted of (a) a computer analysis simulating two-phase flow through the seal assemblies, and (b) limited experimental testing to validate the computer analysis.
5.3.1 Analytical Model. The computer analysis used a computer code developed by Atomic Energy of Canada Limited Research Company (AECL) of Chalk River National Laboratories. Given (a) the seal face inner and outer diameters, (b) the gap convergence or divergence (see Figure 5-1), (c) the inlet state of the fluid, and (d) the back pressure, the code calculates the leakage, the state of the fluid through the gap. and the critical balance ratio (a dimensionless value relating to the balance of opening and closing forces at which the seal becomes unstable) for a wide range of seal face separations.

The results of the computer analysis are summarized in the following discussion.

Assuming zero back pressure and $100 \mu \mathrm{in}$. convergence in the seal gap, unstable operation of the seal was predicted if the subcooling of the inlet fluid is less than $20^{\circ} \mathrm{F}$ (the seal pops open to the limit of its travel). Bistable operation (the seal opens to a larger gap and remains stable in that position) was predicted with inlet subcooling between 20 and $50^{\circ} \mathrm{F}$, and stable operation was predicted with inlet subcooling above $50^{\circ} \mathrm{F}$.

Assuming a seal gap convergence of $100 \mu$ in., stable operation was predicted if the back pressure is greater than about $50 \%$ of the inlet pressure, even with the inlet fluid conditions at saturation.

The effect of gap convergence depends greatly on other conditions. The computer analysis predicted that with an inlet temperature of $530^{\circ} \mathrm{F}$ and with zero back pressure, seals with a convergence of $100 \mu \mathrm{in}$. are more likely to be stable than seals with a $10 \mu \mathrm{in}$. convergence as fluid conditions approach saturation.

5.3.2 Testing of Seal Stability. Testing to validate the computer analysis used the test device illustrated in Figure 5-4. Most of the tests used a main seal ring with 100 - $\mu$ in. convergence. Representative temperatures and pressures were established and a closing load was applied to the movable main seal ring. The closing load was then gradually decreased until the seal popped 


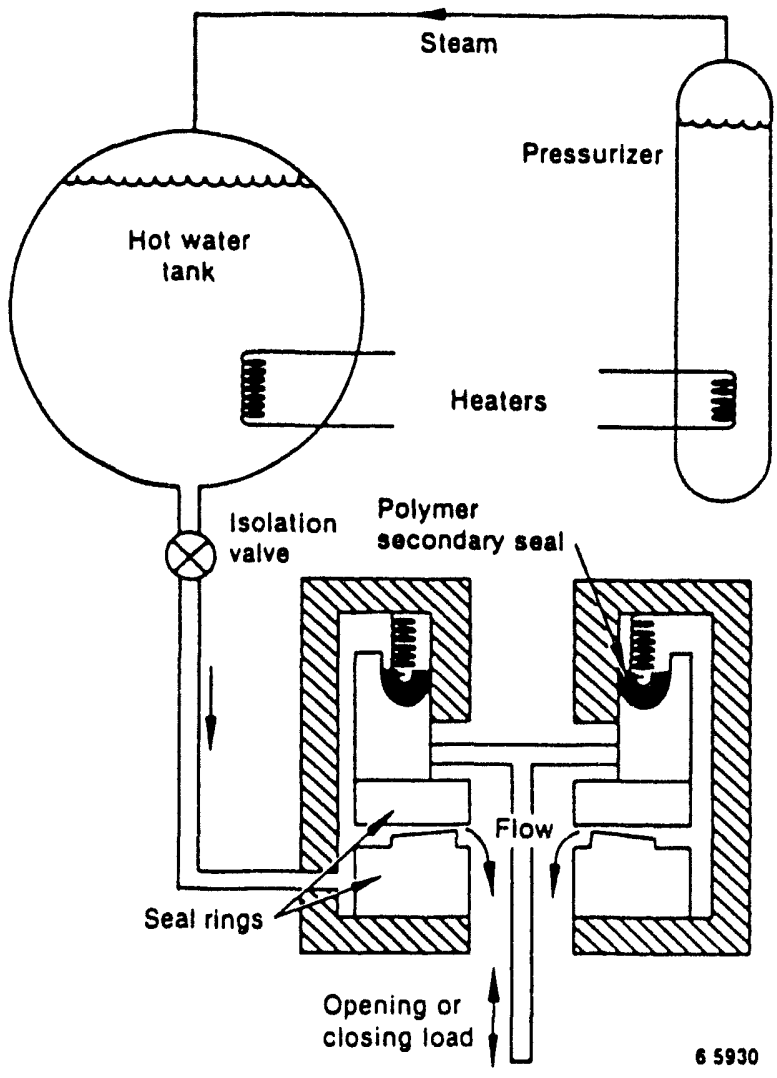

Figure 5-4. Sketch of the device used for the seal stability tests.

open. This testing allowed us to determine empirically the critical balance ratios for the conditions being tested (that is, the conditions at which seal instability occurs).

The results of the testing of convergent seal faces showed agreement within about $7 \%$ between the critical balance ratios measured during testing and the values calculated by the computer analysis. One test using a seal with the seal faces divergent by about $400 \mu \mathrm{in}$. (that is, the minimum gap was at the outside diameter of the seal instead of the inside) showed less agreement between calculated and measured values. The seal popped open at balance ratios at which the computer analysis predicted stability.

\subsection{Review of Full-Scale Testing by Others}

The results from two full-scale seal tests were made accessible to us, with restrictions on the amount of detail authorized for public disclosure, some of the information being proprietary. In a joint effort, Westinghouse Electric Corporation, the Westinghouse Owners Group, and Electricite de France (EdF) tested a 7 -in. diameter seal assembly similar but not identical to the 8 -in. seal assemblies used in U.S. RCPs. This full-scale test was conducted at a coal-fired plant in France in 1985. Although leakage occurred briefly through the first seal, and there were indications of brief leakage through the second seal, sustained instability of the seals did not occur. No static O-rings blew out, and there was little indication of extrusion of O-rings or channel seals. It cannot be assumed that the 8-in. seal assemblies normally used in Westinghouse plants in the U.S. will perform as well as these 7-in. seal assemblies, because there are potentially significant differences between the two.

Southern California Edison Company tested a 4-1/2-in.-diameter seal assembly in California in 1985. The tests used an operating boiler recirculation pump equipped with Bingham International seals similar to the 9-in. seals used in some U.S. nuclear applications. At some high-temperature conditions, flow fluctuations occurred consisting of brief excursions from the normal flow of 1.5 gallons per minute (gpm) to flows approaching $3 \mathrm{gpm}$. No damage to the main seal rings or the secondary seals was observed during posttest examination of the seal assembly.

The flow excursions are indication of the existence of the kind of bistable behavior predicted by the computer analysis described earlier in this summary. However, these test results consistently demonstrated lower leakage and much more stable behavior than predicted by the analysis.

\subsection{Conclusions}

In addition to the Westinghouse static O-rings determined by earlier testing to be susceptible to blow-out during station blackout conditions, one static O-ring in each stage of the Bingham International seal assemblies might be likewise susceptible. Certain assumptions that led to this conclusion need to be confirmed. 
In general, polymer secondary seals are not expected to degrade enough to lose their sealing ability, though degradation of the seals can occur. Degraded secondary seals operate with higher friction, and the extra friction greatly increases the risk of movable seal ring popping open under conditions where seal stability is marginal.

Computer simulations indicate that RCP seals will remain stable during station blackout provided that inlet pressure is sufficiently above saturation or back pressure is sufficiently high. Seal face convergence or divergence and seal face condition can also affect the likelihood of seal stability during station blackout. In a comparison of the computer simulations with the results of laboratory testing of convergent seal faces, the critical balance ratios measured during testing agreed within about $7 \%$ with the values calculated in the simulation. Full-scale tests conducted by others indicate that the computer simulations are conservative; for example, tests showed the seals to be stable under conditions predicted $b_{y}$ the simulations to produce unstable behavior.

\subsection{Application of the Research}

The results of this research were used to support the NRC effort regarding Generic Safety Issue 23, "Reactor Coolant Pump Seal Failures at Station Blackout Conditions." At the writing of this report, the resolution of this issue might include emergency provisions to provide cooling water to the seal assemblies under station blackout or other loss-of-seal-cooling conditions, or pump testing to verify seal stability under station blackout conditions. 


\section{SIGNIFICANCE OF RATTLING IN ELECTRICAL CABINETS DURING EARTHQUAKES}

\subsection{The Issue}

In some instances, electrical cabinets and the components they house were not subjected to seismic qualification testing for nuclear applications. Where qualification testing was performed, the cabinets and components were generally qualified at frequencies within the normal seismic frequency range of $33 \mathrm{~Hz}$ or less. (Earthquakes can be expected to produce a dynamic response in the reactor building in the frequency range of 3 to $15 \mathrm{~Hz}$.) If rattling occurs in an electrical cabinet during an earthquake, the rattle can produce a significant response in the cabinet at frequencies higher than $33 \mathrm{~Hz}$, as well as introduce additional response at lower frequencies. In some instances, the components were qualified in tests along with the cabinets in which they were installed, so that if rattling occurs in the test, the effects of rattling on the components will have been considered by the qualification testing. In other instances, however, particularly in the earlier plants, the components were tested separately or were subjected to analyses without testing. In those cases, depending upon the component's characteristics and functional requirements, neglecting frequencies above $33 \mathrm{~Hz}$ raises the question of whether the component will perform its design basis function in an earthquake.

The idea of simply fixing a rattle assumes that the rattling can be detected during the qualification test, the cause of the rattling can be isolated, and some acceptable amount of rattling is known not to affect functionality of supported electrical components. Without this information, reduction of rattling to acceptable levels in cabinets is uncertain. In addition, the practical effects of the fix must be considered; for example, rattling of a cabinet door may be reduced to acceptable levels by applying screws all around, but this makes the door unacceptably difficult to open.

The purpose of the research summarized here was threefold: (a) to determine the extent to which the potential for rattling may exist in elec- trical cabinets, (b) to determine the effect of cabinet rattling on the electrical components mounted in the cabinet, and (c) to provide information to support the effort to determine whether current qualification testing needs to be revised to address this problem. The research consisted of (a) a review of selected qualification test reports and an analysis to determine the existence and the effects of rattling in those tests, and (b) laboratory testing of typical electrical equipment to investigate their susceptibility to vibratory response typical of that induced by rattling in electrical cabinets. The research was conducted in 1988.

\subsection{Review of Qualification Tests}

One hundred test reports were selected from seismic qualification programs conducted at both the Norco and the Huntsville facilities of Wyle Laboratories. The reports were reviewed for the occurrence of anomalies and the occurrence of response amplification at frequencies higher than $33 \mathrm{~Hz}$.

The review identified anomalous behavior in several components. Most of the anomalies involved relays, switches, and circuit breakers. Contact chatter in relays was the most common anomaly. The review gave possible indication, but not conclusive proof, of a relationship between the occurrence of rattling and the anomalous performance of the components. Sources of rattling identified in the review were loose cabinet doors and loose device-mounting fasteners.

Of the 100 tests, six selected tests were analyzed in detail. The analyses revealed that a considerable amount of rattling occurred in five of the six cabinets. However, anomalous component behavior occurred in only two of the five. Thus, it was not possible from the available data to make a conclusive correlation between rattling and component malfunction. A serious limitation of this review was that the available data indicated only the occurrence of the anomaly, not the time 
during the test at which the anomaly occurred or the corresponding component response frequency.

\subsection{Testing of Electrical Components}

To further investigate the possibility that rattling in cabinets subjected to earthquake excitation can cause electrical components to malfunction, we conducted tests at Wyle Laboratories. Relays were selected for testing because the review described above indicated that of the electrical components typically installed in the cabinets, relays were most susceptible to the effects of rattling. Six relays were tested: three of the Westinghouse model AR660, and three of the General Electric model CRI20B. Both models are relays with normally closed contacts. Most of the tests were conducted with these relays de-energized, in the closed position (the configuration most susceptible to chatter).

The six relays were mounted on a fixture as shown in Figure 6-1, with eight accelerometers mounted at four locations as shown. The tests were performed on two test tables at Wyle Laboratories: a biaxial seismic test table, and a single axis vibration table.

Monitoring of the tests was designed to obtain data on (a) occurrence of contact chatter or change of state, (b) chatter duration and number of chatter events during each test, (c) acceleration level and frequency at which chatter occurred, and (d) the effects of contact chatter on other devices connected to the relay. To monitor item (d), each of the on-table relays was connected to an off-table relay, with the off-table relay energized by the on-table relay. The selection of off-table relays represented relays with different coil sizes, thus possibly offering different current and collapse-time sensitivities to on-table relay chatter.

The test sequence included (a) a resonance search consisting of a low level $(0.2 \mathrm{~g})$ sinusoidal sweep test to characterize the response of the fixture and the relays in the frequency band of 1 to $100 \mathrm{~Hz}$; (b) random excitation of the relays at specified peak acceleration levels (varying from 2 to $10 \mathrm{~g}$ ) throughout three frequency ranges: 3 to $15 \mathrm{~Hz}, 15$ to $100 \mathrm{~Hz}$, and 3 to $100 \mathrm{~Hz}$; and (c) sine

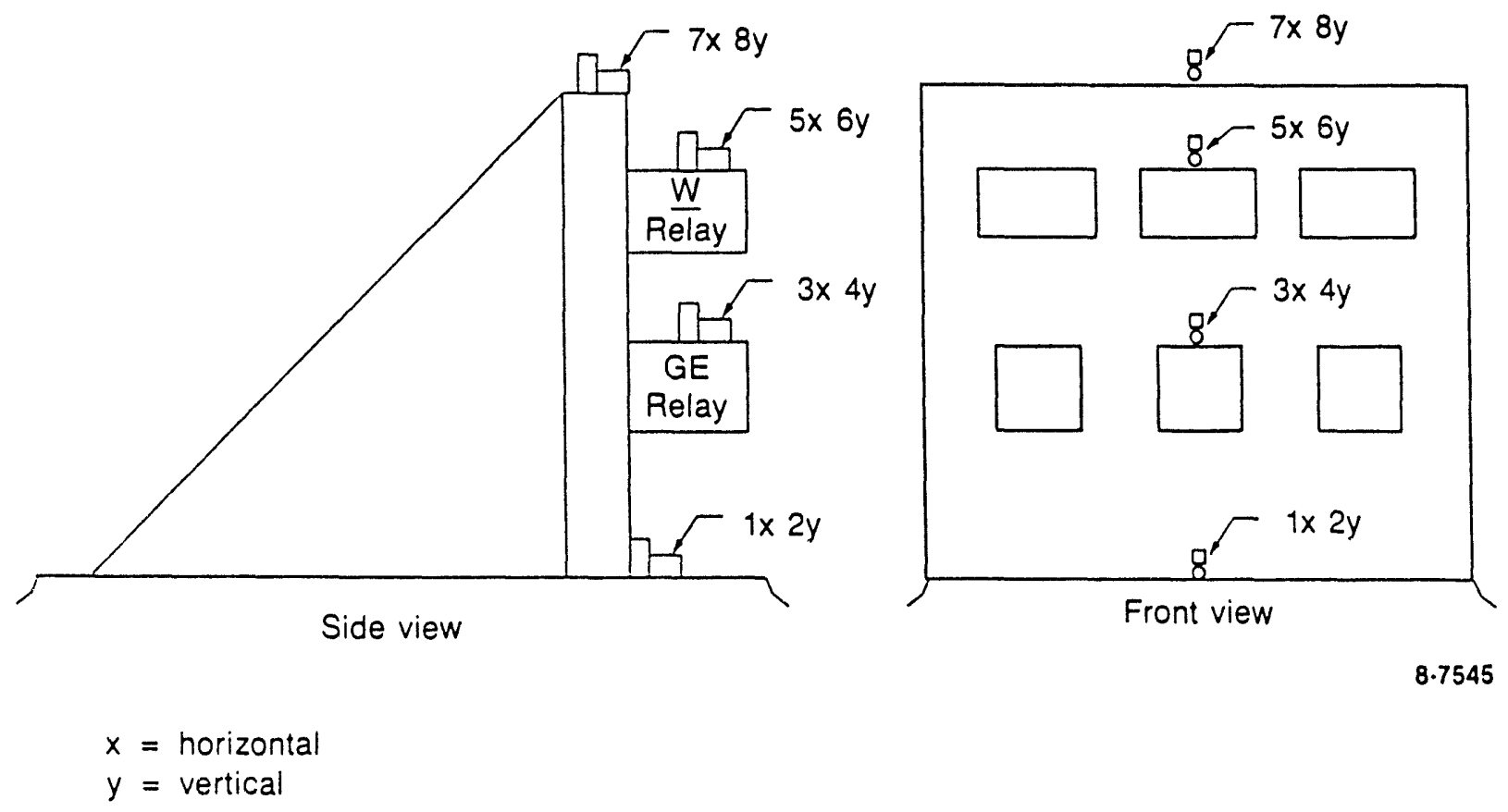

Figure 6-1. Sketch of the test fixture showing where the accelerometers were mounted. 
sweep excitation in the 4 to $100 \mathrm{~Hz}$ frequency range at successively increasing acceleration levels. The random tests in the $3-$ to 10()$-\mathrm{Hz}$ frequency band were performed to best replicate the waveforms expected during an earthquake with rattling occurring in a cabinet. The excitation was applied in the horizontal direction parallel to the relay contact line of action (the direction most likely to cause relay chatter) and in the vertical direction.

\subsection{Test Results}

A summary of the testing is presented in Table 6-1, with the test runs numbered from 1 to 41. Random tests in the horizontal direction in the low frequency range $(3$ to $15 \mathrm{~Hz}$ ) produced relay chatter with the peak acceleration level at about $10 \mathrm{~g}$, but not at lower peak accelerations. No chatter occurred in the high-frequency tests (15 to $100 \mathrm{~Hz}$ ) even with peak acceleration as high as $15 \mathrm{~g}$. In the composite frequency tests ( 3 to $100 \mathrm{~Hz}$ ), chatter occurred at about $10 \mathrm{~g}$ (peak acceleration), but not at lower peak accelerations. No chatter occurred in any of the random tests in the vertical direction. Test runs that produced chatter were run again later with the on-table relays energized; no chatter occurred.

The occurrence of chatter in both the lowfrequency and composite-frequency random tests at $10 \mathrm{~g}$ peak acceleration, along with the absence of chatter in the high-frequency random tests, indicates that chatter response to random motion is low-frequency sensitive. This sensitivity to low-frequency acceleration is more likely a product of contact inertia than of any resonant response.

A close examination of the data indicated that the duration of a measurement of high acceleration corresponded more closely with a chatter event than did the measurement of a peak acceleration. This phenomenon is illustrated in Figure 6-2, where chatter is closely correlated with a sustained period of relatively constant acceleration, indicated by the periods of relatively constant slope in the velocity trace in the figure. In effect, low-frequency displacements accompa- nied by sustained changes in velocity literally throw the contacts momentarily open. Note in Figure 6-2 that chatter in the Westinghouse relay is associated with a change in velocity in the negative direction, whereas chatter in the GE relay is associated with a change in velocity in the positive direction. This difference is due to the differences in the particular arrangement of the moving and stationary contacts in the different relays, providing further evidence that contact inertia, not resonant response, plays the important role in relay chatter.

Comparison of the responses measured at the inception of chatter (see Table 6-2) provides additional insights. Note that the instantaneous readings of acceleration on the relay case are lower at chatter events in test 16 (composite frequency) than in test 5 (low frequency). Apparently the high-frequency loads combine with the lowfrequency loads in such a way as to produce chatter events at lower accelerations in the composite-frequency test than in the lowfrequency test. A possible explanation for this phenomenon is that a momentary high-frequency acceleration, when superimposed upon a sustained low-frequency acceleration, adds a resonance effect to the inertial effect to trigger a chatter event at the lower instantaneous acceleration. However, note also that we are speaking here in terms of instantaneous acceleration. In terms of peak acceleration levels, the tests did not indicate a difference between the threshold levels for composite frequency tests as compared with low frequency tests. See Table 6-1. Chatter occurred at both frequency ranges at $10 \mathrm{~Hz}$ peak acceleration (tests 5 and 16), but in neither frequency range at $6.75 \mathrm{~Hz}$, the next lowest peak acceleration tested (tests 4 and 15).

In an effort to more clearly characterize the frequency dependence of the relay chatter, we performed uniaxial swept sine tests in the 4- 10 $100-\mathrm{Hz}$ range, as summarized in Table $6-1$. The peak acceleration levels indicated in the table for each of the swept sine test runs are the control limits that were supplied to the shake table controller and were intended to be maintained throughout each sweep. The sweep function used 
Table 6-1. Test run summary.

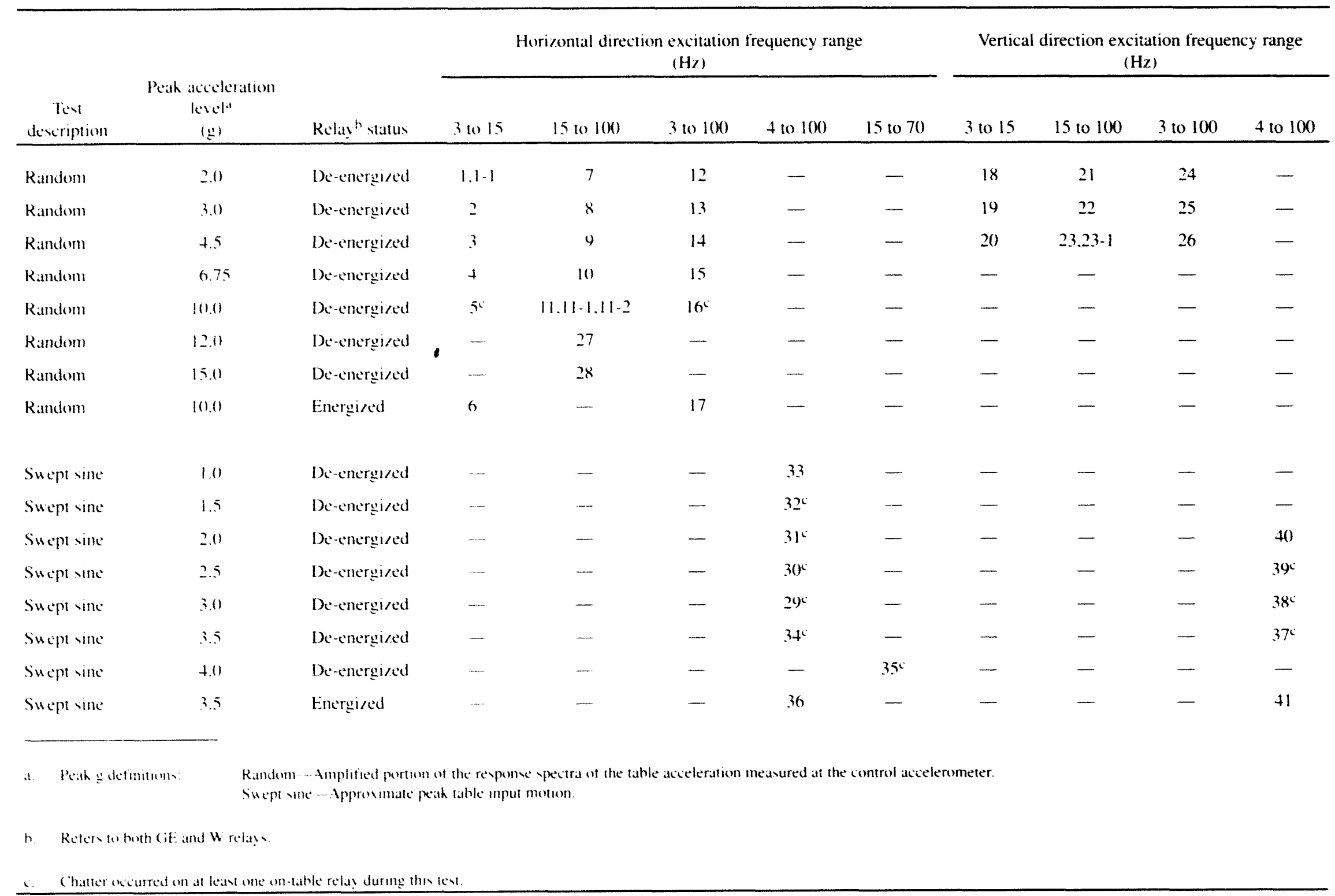




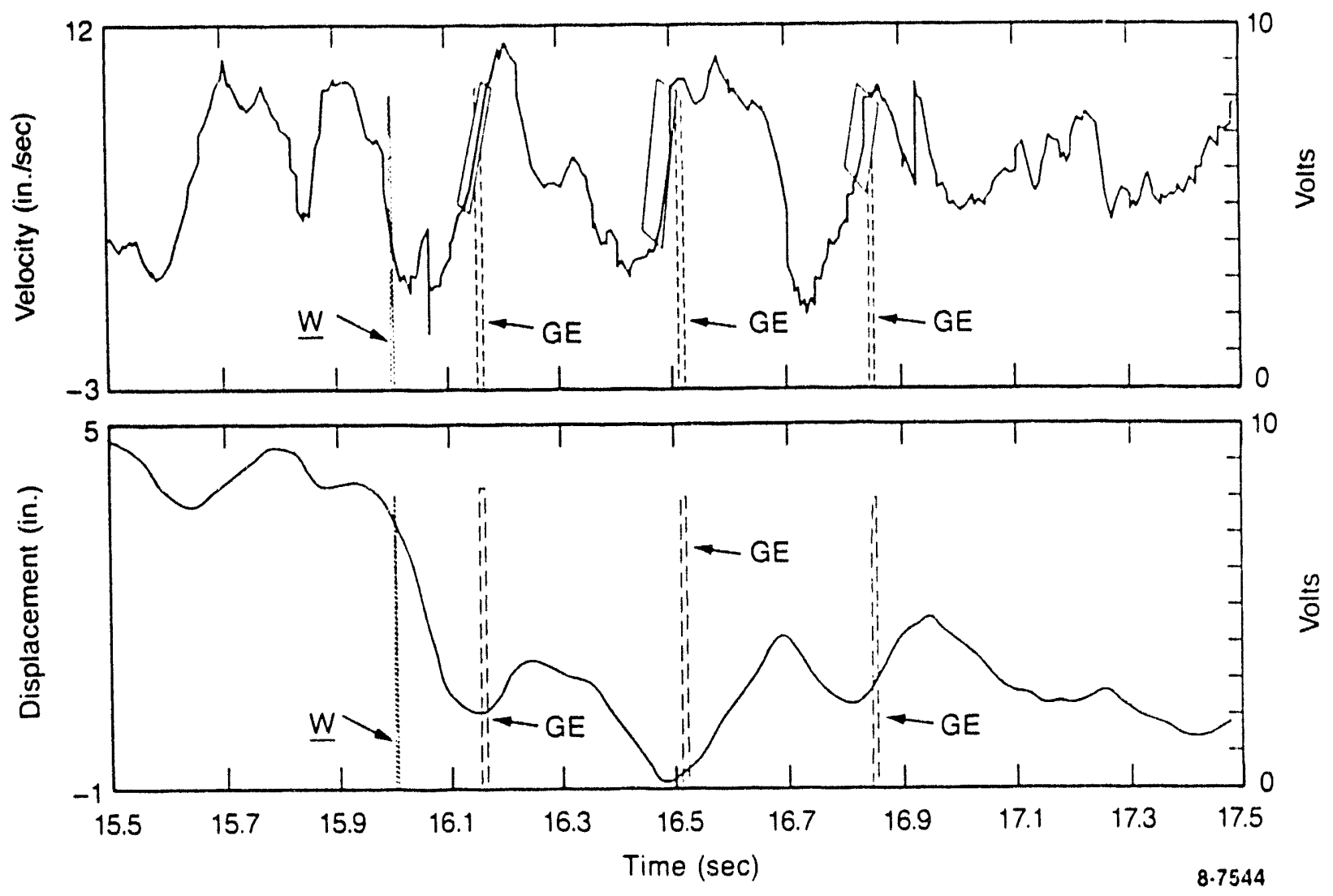

Figure 6-2. Velocity and displacement of the GE relay during recorded chatter events. Chatter events are indicated by the voltage pulses labeled $\mathrm{W}$ and $\mathrm{GE}$.

in each of the test runs was plotted against time to determine the excitation frequency at the recorded time of chatter on the relays. Chatter occurred in horizontal test runs with peak acceleration levels of $1.5 \mathrm{~g}$ or greater. The data indicalted sensitivity to chatter in the Westinghouse relays in the 45-10 8.5-Hz range and in the GE relays in the $60-1085-\mathrm{H} \%$ range. Both types of relays were ensitive to chatter in the low frequency range less than $15 \mathrm{H}$.

On-lable relay chatter event durations ranged from $2.31020 \mathrm{~ms}$, with 30 to $50 \%$ of the events having a duration of $51010 \mathrm{~ms}$. Almost all of the off-table relays that were energized by the onlable relays chattered at some lime during the testing in response to the chatter of the corresponding on-table relay. The causality between on-table chatler duration and off-lable chatter duration could not be clearly defined from the data. but it was clear that the off-table relays exhibited longer chatter durations than the corresponding on-table relays.

\subsection{Conclusions}

The rattling environment is indeed real, as evidenced by the results of some equipment qualification tests of cabinets. However, the existence of rattling does not necessarily mean that a cahinetsupported device is going 10 malfunction. Malfunction depends not only on the existence of rattling in the cabinet but also on the characteristics of the device and the characteristics of the vibrations induced in the cabinet and component.

There may be dynamic characteristics that better reflect operability than the commonly used (IEEE 344) peak acceleration parameler, inferred from the comparison of test response spectrat to required response spectra. For the relays tested in 
Table 6-2. Waveform characterization at time of chatter.

\begin{tabular}{|c|c|c|c|c|c|c|c|c|c|}
\hline \multirow[b]{3}{*}{$\begin{array}{l}\text { Test run } \\
\text { number }\end{array}$} & \multirow[b]{3}{*}{$\begin{array}{l}\text { Chattering } \\
\text { relay type }\end{array}$} & \multirow[b]{3}{*}{$\begin{array}{l}\text { Test time } \\
\text { at chatter } \\
\text { (sec) }\end{array}$} & \multicolumn{6}{|c|}{ Instantaneous measurement of dynamic response at the relay at chatter } & \multirow[b]{3}{*}{$\begin{array}{l}\text { Chattering relay sustained } \\
\text { average acceleration } \\
\text { (g) }\end{array}$} \\
\hline & & & \multicolumn{3}{|c|}{ General electric relay } & \multicolumn{3}{|c|}{ Westinghouse } & \\
\hline & & & $\begin{array}{c}\text { Acceleration } \\
(\mathrm{g})\end{array}$ & $\begin{array}{l}\text { Velocity } \\
\text { (in./sec) }\end{array}$ & $\begin{array}{c}\text { Displacement } \\
\text { (in.) } \\
\end{array}$ & $\begin{array}{c}\text { Acceleration } \\
(\mathrm{g})\end{array}$ & $\begin{array}{l}\text { Velocity } \\
\text { (in./sec) }\end{array}$ & $\begin{array}{c}\text { Displacement } \\
\text { (in.) }\end{array}$ & \\
\hline 5 & GE & 8.232 & 4.2 & 20 & 0.4 & 5.9 & 23 & 0.4 & 2.7 \\
\hline 5 & $\underline{w}$ & 10.068 & -5 & -30 & 4.6 & -6 & -25 & 5.1 & -2.4 \\
\hline 5 & $\underline{N}$ & 14.919 & -6.8 & -22 & 5.2 & -8.2 & -20 & 5.2 & -3.6 \\
\hline 5 & $\underline{w}$ & 17.065 & -5.5 & -18 & 3.8 & -6.0 & -18 & 3.6 & -3.3 \\
\hline 16 & GE & 13.483 & 1.6 & 11 & -0.6 & 2.1 & -9 & -1.4 & 1.4 \\
\hline 16 & $\mathrm{GE}$ & 16.151 & 2.0 & 8 & 0.4 & 2.5 & 8 & 1 & 1.5 \\
\hline 16 & GE & 16.508 & 3.0 & 10 & -0.6 & 3.6 & 16 & 0.6 & 1.6 \\
\hline 16 & $\mathrm{GE}$ & 16.842 & 3.2 & 9 & 0.7 & 3.5 & 8 & 1.4 & 1.7 \\
\hline 16 & $\underline{w}$ & 11.152 & -1.1 & -22 & -1 & -2 & -22 & -1 & -1.2 \\
\hline 16 & w & 15.996 & -0.8 & 3 & 3.4 & -1 & 0 & 3.0 & -2.1 \\
\hline
\end{tabular}


this study, levels of sustained acceleration correlated better with anomalous operation (chatter) than did peak acceleration response.

It appears that high-frequency loads combined with low-frequency loads reduce the acceleration level at which chatler occurs, compared to lowfrequency loads alone. Thus, the frequency content of the input spectra used in qualification testing may be more important than previously assumed.

Relay chatter and its effects on interfacing electrical equipment requires some consideration beyond the present seismic qualification test procedures. IEEE 344 presently requires the recording of only those chatter durations that are greater than $2 \mathrm{~ms}$. The effect on secondary relays of chatter in primary relays, as observed in this study. indicates that time intervals between chatter inci- dents and the response characteristics of the interfacing equipment should also be considered.

These results may also have implications for seismic probabilistic risk assessments (PRAs), which presently ignore the effects of relay chatter on interfacing electrical equipment. The concern here is the possibility that increased chatter duration in secondary relays could cause failure of a safety system. This, coupled with the fact that some safety-related circuits with auxiliary relays are not easily reset if chatter should cause them to trip out. highlights the need for more research in this area of concern.

\subsection{Application of the Research}

The information was made available to the IEEE Standards Committee for seismic qualification. 


\section{SHAG TEST SERIES: IN SITU SEISMIC TESTING OF A VALVE AND A PIPING SYSTEM}

The SHAG (Shakergebäude-building shaker) test series was an international project conducted by Kernforschungzentrum Karlsruhe (KfK). Researchers from the INEL joined researchers from the Argonne National Laboratory (ANL), the Electric Power Research Institute (EPRI), Kraftwerk Union (KWU), and the Staatliche Materialprüfungsanstalt (MPA) in participating with KfK in the test series. The tests were conducted in 1986 at HDR (Heissdampfreaktor), a decommissioned experimental facility located near Frankfurt, Germany.

\subsection{The Issue}

Seismic qualification of nuclear equipment is typically performed to industry standards, some of which are justified by only an analytical or extrapolated basis. This is especially true of qualification standards for valves and line-mounted equipment (transducers and other equipment mounted on the piping), for which seismic input is always analytically determined. SHAG testing provided an opportunity to measure actual, threedimensional loads and actual responses to a simuJated earthquake. thus providing empirical data to either confirm or challenge the analytical methods used in equipment qualification standards. The tests also provided an opportunity to evaluate the performance of an aged, motor-operated valve when operated during simulated earthquakes. The results served to contribute to the technical data base supporting the NRC effort regarding Unresolved Sarety Issue A-46, Seismic Qualification of Equipment in Operating Nuclear Power Plants (NUREG-1030). These tests were the first in situ experiments subjecting an entire containment building and its components, including a fullscale piping system, to simulated earthquake loadings.

\subsection{Test Description}

Earthquake loadings were simulated in the HDR building by means of a large, eccentric mass, coastdown shaker installed on the upper floor of the HDR. See Figure 7-1. For each test, the shaker was weighted with a specified amount of weight bolted to the two shaker arms. With the weighted arms opposite each other, the shaker was spun up to a specified speed corresponding to the starting frequency for that test (varying from 1.6 to $8 \mathrm{~Hz}$ ). The arms were then allowed to swing together, creating a revolving eccentric mass that shook the building as the shaker coasted down. The building and the equipment installed in the building responded in much the same way they would respond to an earthquake imparting dynamic energy to the building from the ground.

Our testing focused on the VKL (Versuchskreislauf-experimental piping loop), an existing stainless steel piping system located between the 18 and $24 \mathrm{~m}$ elevations in the HDR building. We modified the VKL by installing an aged 8 -in. dcpowered motor-operated gate valve and by installing snubbers, spring hangers, and struts to create a piping support system designed to be typical of U.S. nuclear installations. The configuration of the U.S. stiff support system was based on a computer analysis of the VKL and on acceptance criteria specified in the ASME Code. The 8 -in. gate valve was a 25 -year-old value from the decommissioned Shippingport Atomic Power Station. Figure 7-2 is a drawing of the modified VKL.

We installed 103 instruments on the VKL and on the HDU (Heissdampfumformer-steam generator), a large vessel to which the VKL is attached. The instruments measured acceleration, displacement, strain, force, temperature, pressure, differential pressure, valve position, valve motor amperage, and motor voltage.

The simulated earthquake tests were conducted with hot and cold pressurized water at pump flow in the piping. We monitored the operability of the valve by opening and closing the valve during and after the simulated earthquakes, with flow, pressure, and temperature loads imposed on the valve. 


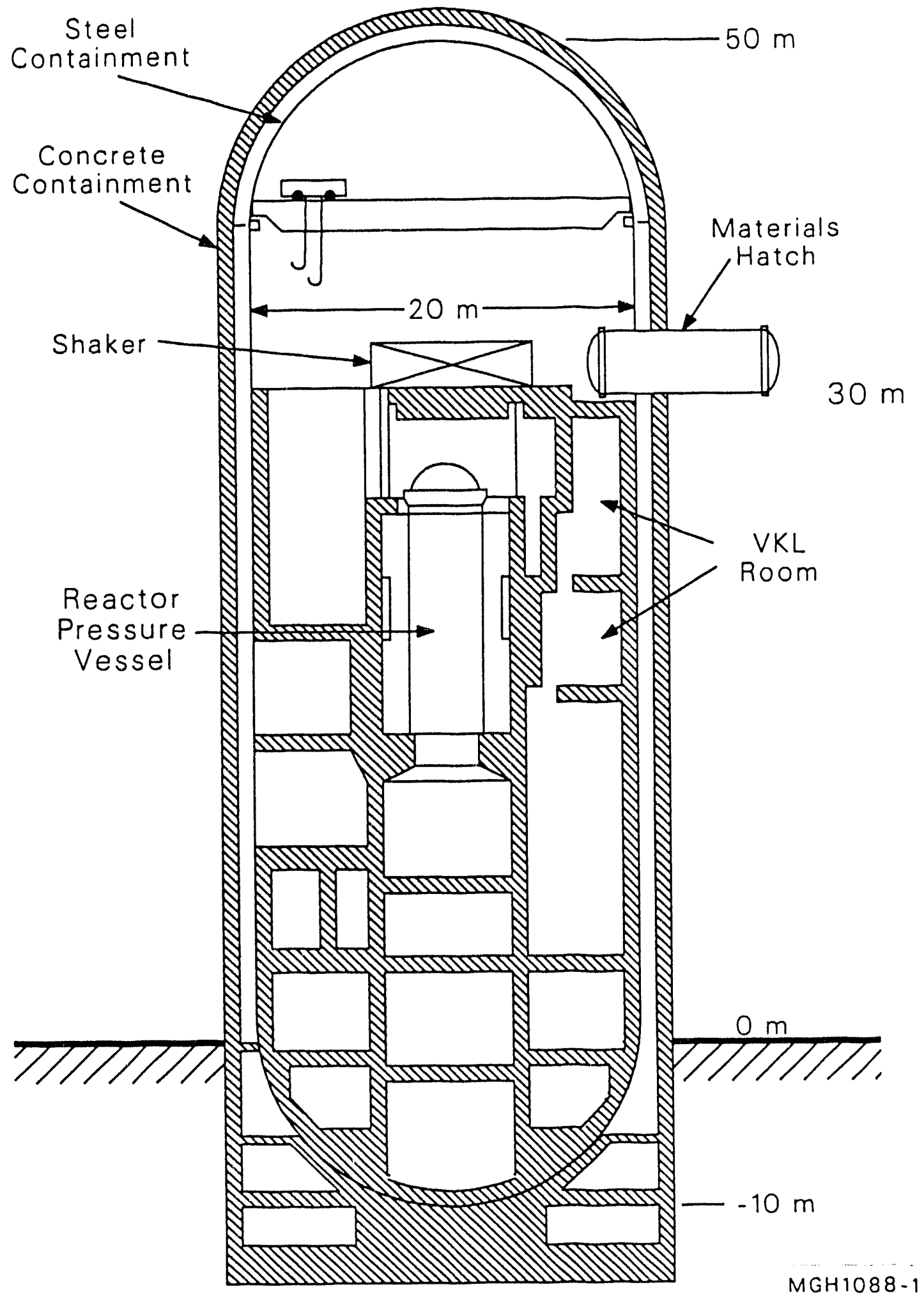

Figure 7-1. A simplified cross section of the HDR facility, showing the locations of the shaker, the VKL, and the reactor pressure vessel. 


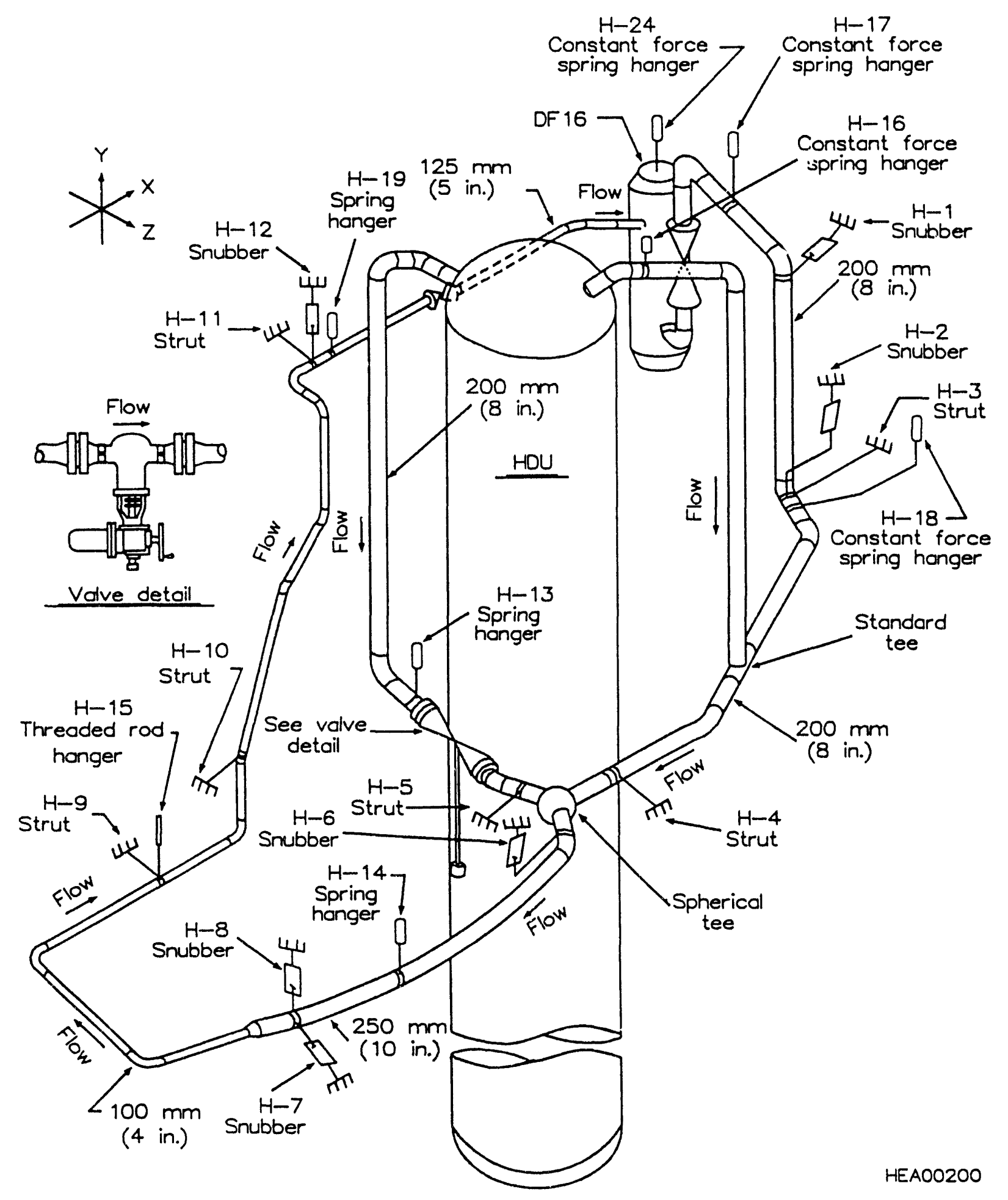

Figure 7-2. A schematic of the VKL showing the 8-in. gate valve and the U.S. stiff piping support system as configured for the SHAG tests.

The piping support configuration described above was designated the U.S. stiff system. Six other piping support systems sponsored by other participants were also installed at various times during the testing (see Table 7-1). The seven piping support systems used different combinations of 
Table 7-1. Type of supports used in the SHAG test series.

\begin{tabular}{lcccccc}
\hline \multicolumn{1}{c}{ Support system } & $\begin{array}{c}\text { System } \\
\text { number }\end{array}$ & Struts & Snubbers & $\begin{array}{c}\text { Viscous } \\
\text { mass } \\
\text { supports }\end{array}$ & $\begin{array}{c}\text { Impact } \\
\text { supports }\end{array}$ & $\begin{array}{c}\text { Flexure } \\
\text { supports }\end{array}$ \\
\hline U.S. stiff & 3 & 6 & $6^{\mathrm{b}}$ & 0 & 0 & 0 \\
KfK very flexible & 1 & 2 & 0 & 0 & 0 & 0 \\
KWU flexible & 2 & 5 & 0 & 0 & 0 & 0 \\
EPRI/Cloud impacting & 5 & 6 & 0 & 0 & 6 & 0 \\
EPRI/Bechtel energy-absorbing & 4 & 6 & 0 & 0 & 0 & 4 \\
GERB energy-absorbing & 6 & 5 & 0 & 2 & 0 & 0 \\
ANCO energy-absorbing & 7 & 6 & 0 & 6 & 0 & 0 \\
\hline & & & & &
\end{tabular}

various kinds of supports to represent piping systems ranging from stiff to very flexible. The VKL's dynamic response to simulated earthquakes was monitored with each of the support systems installed so that the results could be compared. In all, 25 tests were run, with eight tests at $8 \mathrm{~Hz}$, six tests at $6 \mathrm{~Hz}$, and the others at lower starting frequencies. Seven of the 25 tests were conducted with the U.S. stiff support system installed.

\subsection{Test Results}

The actual forces applied to the building in the frequencies of interest for piping and valve research (6- and $8-\mathrm{Hz}$ tests) met the requirements of the SHAG test project. Input spectra of $0.3 \mathrm{~g}$ ZPA (zero period acceleration) were measured at the HDU vessel and the piping system supports. The VKL responded not only to input from the building through the supports, but also intensities to even greater input from the HDU vessel through the piping connected to the top of the vessel. Input to the VKL exceeded the inputs typically calculated for U.S. East Coast safe shutdown earthquakes (SSEs) and West Coast operational basis earthquakes (OBEs). The acceleration responses of the piping averaged 1 to $3 \mathrm{~g}$ throughout the VKL. Some of the snubbers experienced loads approaching their ASME Code Level $\mathrm{C}$ allowables. Struts experienced loads of up to $11,000 \mathrm{lb}$ force.

\subsubsection{Comparison of Piping Support Sys-} tems. The philosophy reflected in the stiffness of the U.S. stiff systein is to avoid amplification and reduce resonant response by using snubbers and struts to stiffen the piping system so that the natural frequencies in the piping are higher than the frequencies at which the building responds to an earthquake. The U.S. stiff system performed as designed, raising the resonant frequency of the piping system. In general, the U.S. stiff system and the KfK very flexible system enveloped the response of the VKL. As expected, the stresses in the stiff system were lower than in the KfK very flexible system, but the differences were not as great as we expected. The moderately flexible KWU support system, with only half as many supports as the U.S. stiff design, responded with 
fewer high-peak responses and a smaller total system stress than any of the other systems.

\subsubsection{Performance of Piping and Snub-}

bers. The structural integrity of the valve and piping was not compromised by the seismic loads. None of the seven piping support systems' responses resulted in piping strain measurements that reached $50 \%$ of yield.

Snubbers are designed as either a hydraulic or a mechanical device to allow the low velocity motion typical of thermal expansion yet resist the high velocity motion typical of seismic events. Thus, snubbers can fail in two different ways: either by locking up when they should allow motion, or by allowing motion when they should lock up. The U.S. stiff system used five Pacific Scientific mechanical snubbers and one BergenPatterson hydraulic snubber. All of these snubbers functioned properly except for one brief instance ( 3 to $4 \mathrm{sec}$ ) with one mechanical snubber. The low force measurements in the snubber pin and the high acceleration measurements at the adjacent pipe indicated that the snubber temporarily failed to lock up. The anomaly was self correcting.

\subsubsection{Operability of the Motor-operated}

Valve. Operability of the motor-operated valve was not adversely affected by the seismic loadings. However, analysis of the data revealed anomalous performance not related to the seismic loadings. During several of the tests, the torque switch in the motor operator failed to trip at the end of the closing stroke. The result was motor stall.

An extensive investigation ensued to discover the cause of the anomalous performance. The investigation included additional in situ testing at HDR (more than 50 ) tests with various torque swilch settings and various flow and pressure loads). dynamometer testing of the Limitorque motor operator at Limitorque Laboratories. inspection of the torque spring. dynamometer testing of the motor (without the operator) at Peerless Winsmith (the motor manufacturer), and an analysis of the HDR circuit that suppliced power to the motor operator during the tests. The investigation produced three findings, one that relates to motor-operated valves in general, and two that relate to de-powered motor-operated valves:

1. The aged torque switch spring in the operator had taken a permanent set at about 1/2 in. shorter than its specified original length. Thus, it was necessary to change the torque switch from the nominal setting of 3 to a higher setting of 3.75 to achieve the specified torque at torque switch trip.

2. Resistance caused by heating in the de motor degraded the motor's performance. especially at the high currents that occur at higher loads. Heating incurred during a given test run affected the motor's performance in subsequent test runs if the motor windings did not have a chance to cool between runs.

3. Resistance in the external circuit (the circuit supplying power to the motor operator at HDR) likewise degraded the performance of the motor at high currents. Even though the circuit at HDR was typical of circuits for this application in U.S. nuclear power plants, and even though the cables were sized according to conventional methods. the circuit was not adequate when the motor drew higher currents at higher loads. The configuration of the circuit was such that four long cable runs contributed to the resistance, not two. The circuil configuration also made it difficult to measure voltage drops across all four cable runs. Thus, one of the main causes of the motor operator's anomalous performance, undersized cables in the external circuit. Was difficult to diagnose.

\subsubsection{High-Frequency Amplification in the} Valve Assembly. HDR test results indicated an unexpectedly large high-frequency response in the valve assembly. High-frequency accelerations were significantly amplified from the valve body to the valve operator. Figure $7-3$ show's power spectral density (a mathematlical representation of 

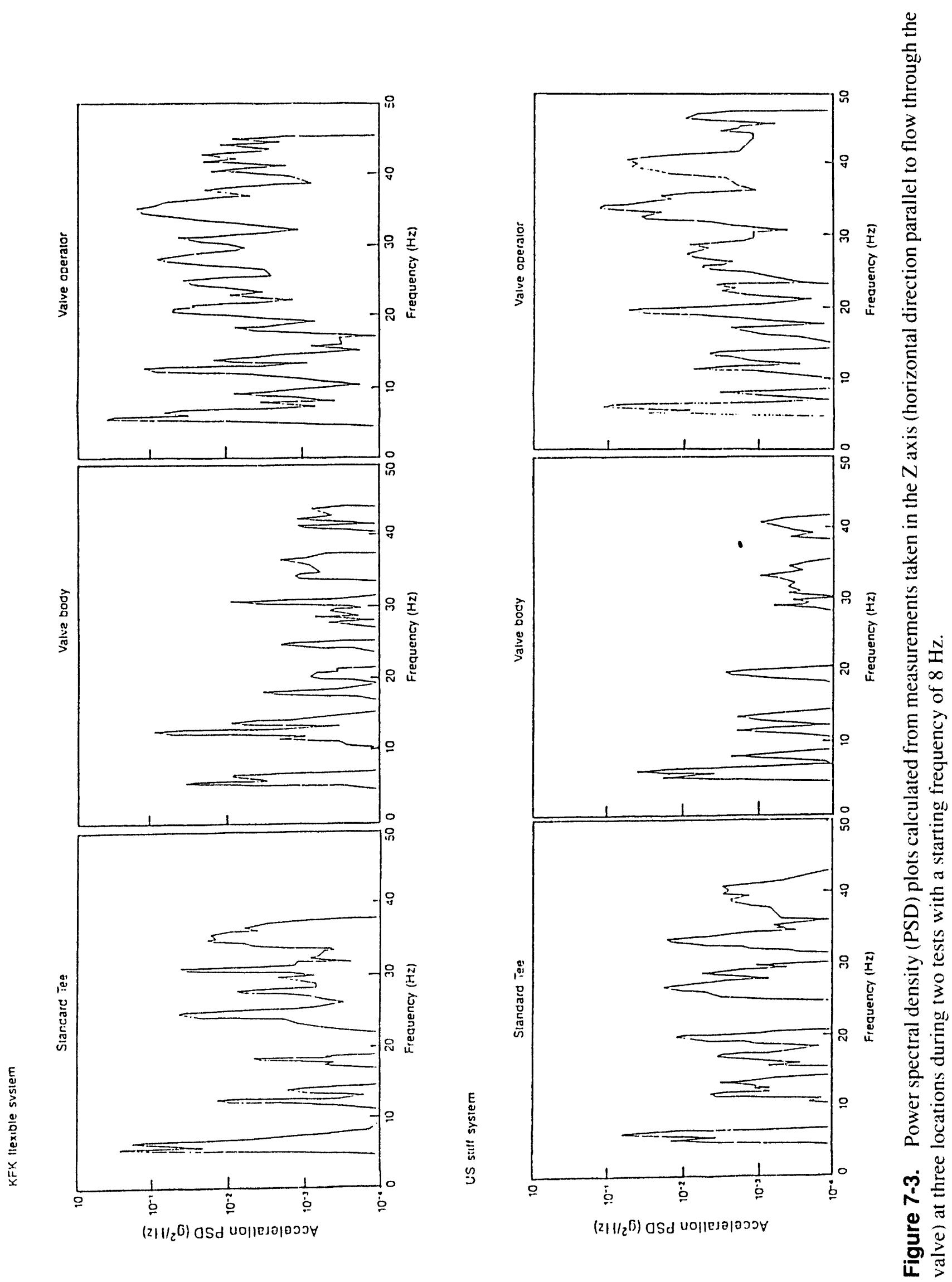
acceleration) calculated from measurements taken in the $\mathrm{Z}$ axis at three locations: the standard tee (see Figure 7-2), the valve body, and the valve operator. The results presented in the figure are from two tests, one with the KfK flexible support system installed and one with the U.S. stiff support system installed, both with a starting frequency of $8 \mathrm{~Hz}$. Amplification at the valve operator in the high-frequency range ( 33 to $50 \mathrm{~Hz}$ ) is evident.

This high-frequency response is not peculiar to the SHAG test series. A similar response was observed in an earlier test project, discussed in Section 3 of this summary report. Results from that test project were compared with the results from the SHAG tests to confirm the occurrence of this high-frequency response.

\subsection{Conclusions}

The stiff piping support systems typical of U.S. nuclear designs have disadvantages. The relative movement of the anchors in a stiff support system can actually add stress to a piping system during an earthquake or a water hammer event, and stresses caused by thermal expansion during normal operation may be large if snubbers malfunction by locking up when they should not. In general, the stresses measured with the KfK very flexible support system installed were indeed higher than those measured with the U.S. stiff system installed, but the differences were not great. Overall, stresses were lowest with the KWU moderately flexible system. These results support current thinking in the United States that the best design lies somewhere between stiff and flexible.

SHAG testing at HDR verifies that structurally, valves and piping are inherently tough. Earthquakes of credible magnitude are not likely to cause structural failure of valves or piping in piping systems designed according to methods commonly used in the U.S. nuclear industry.

Torque spring aging, motor heating, and undersized power cables can adversely affect the performance of dc-powered motor-operated valves in nuclear power plants. If the spring has taken a permanent set, and the switch is not set at a higher-than-nominal setting to compensate, the switch might trip too soon and leave the valve in a partially open position. Motor heating in a dcpowered operator can degrade the valve's performance if the valve is opened or closed more than once without time for the motor windings to cool. Undersized cables in the external circuit can present sufficient resistance to reduce the performance of the motor at high loads, when the motor demands high current. This problem (undersized cables) has appeared in several U.S. nuclear power plants. If power to the valve is marginal, whether because of motor heating or undersized cables, and the marginally powered valve is subjected to high loads on closing, the motor might stall, possibly with the valve in a partially open position. Motor stall can cause the thermal overload switches to open and render the motor operator temporarily unavailable for use. If the thermal overload switches have been bypassed or set too high, or if they malfunction, the motor will burn out. Conventional in-plant testing with no loads or with static pressure loads alone cannot detect potential deficiencies caused by motor heating or undersized cables.

The appearance of the high-frequency dynamic response in the valve operator is important because frequencies higher than $33 \mathrm{~Hz}$ are generally not accounted for in valve qualification procedures. It is not expected that response in this frequency range will affect the valve structurally. However, high-frequency response may affect valve operation by causing switches, relays, and other valve control devices to chatter.

\subsection{Application of the Research}

The results from seismic testing at HDR, as reported both by the INEL and by ANL, were included in the technical data base supporting the NRC effort regarding Unresolved Safety Issue A-46, Seismic Qualification of Equipment in Operating Nuclear Power Plants (NUREG$1(330)$.

The valve test results formed part of the basis for Generic Letter 89-10, "Safety-Related Motor- 
Operated Valve Testing and Surveillance." The cabling issue that surfaced during HDR testing provided insights that helped resolve a problem with a dc-powered valve at a U.S. utility and contributed to NRC Information Notice 89-11, "Failure of dc Motor-Operated Valve to Develop
Rated Torque Because of Improper Cable Sizing." The torque spring issue provided information that contributed to Information Notice 89-43, "Permanent Deformation of Torque Switch Helical Springs in Limitorque SMA-Type Motor Operators." 


\section{SHAM TEST SERIES: HIGH-LEVEL SIMULATED SEISMIC TESTS AT HDR}

Following the SHAG seismic tests described in Section 7 of this report, another international seismic research project, the SHAM (Servohydraulische Anregung Maschinetechnik) test series, was conducted in 1988 at HDR. Joining KfK in this effort were researchers from INEL, ANL, EPRI, KWU, the Fraunhofer Institut für Betriebsfestigkeit (LBF), and the Central Electricity Generating Board of the United Kingdom (CEGB).

\subsection{The Issue}

The SHAM test series provided additional information on the issues addressed by the SHAG test series. Specifically, the SHAM tests were designed to impose even higher earthquake-like loads on the aged, motor-operated valve (MOV) and on the VKL (experimental piping loop), with the following objectives: (a) determine the effects on valve operability and valve and piping structural integrity, (b) determine safety margins and failure modes of piping supports (snubbers, struts, etc.), (c) determine the effects of single and multiple support failures on the response of the piping system, (d) provide data so that the performance of the various piping support systems could be compared, and (e) provide additional data for the NRC effort regarding Unresolved Safety Issue A-46. Seismic Qualification of Equipment in Operating Nuclear Pow'er Plants (NUREG-1030).

\subsection{Test Description}

The SHAM test project used two large 40-ton servohydraulic shakers, each mounted with one end attached to the structure of the HDR building and the other end attached to the VKL. The shakers provided dynamic input to the VKL at locations $\mathrm{H}-5$ and $\mathrm{H}-25$, as shown in Figure 8-1. Earthquake-like displacement histories were input to the shakers to produce input spectra intensities ranging from $0.6 \mathrm{~g} \mathrm{ZPA}$ in the $100 \%$ SSE (nominal) tests to $4.8 \mathrm{~g} \mathrm{ZPA}$ in the $800 \%$ SSE (nominal) tests. The simulated earthquake tests were conducted with pressurized water in the piping at ambient temperature with no flow. In all, 51 experiments were conducted, with six different piping support systems varying from stiff to very flexible installed on the VKL during different segments of the test series. Table 8-1 lists the supports used in each of the six support systems. Nine of the tests were conducted with the U.S. stiff support system installed. Table $8-2$ presents the test matrix for those nine tests and three pretest runs. Figure 8-1 shows the locations of the supports installed on the VKL for the U.S. stiff system.

The U.S. stiff support system used earlier in the SHAG test series was modified for the SHAM testing to accommodate the hydraulic shakers. As in the SHAG tests, the U.S. support system for the SHAM tests was based on a pretest analysis of the VKL piping system using the NUPIPE-II computer code, commonly accepted industry practices, and ASME Code criteria.

The instrumentation system included over 300 instruments to measure acceleration, displacement, strain, force, fluid pressure, valve stem position, valve motor current and voltage, and other parameters. As in the earlier SHAG testing, the performance of the valve was monitored with the valve operating during the simulated earthquakes. For the SHAM tests, however, the valve's motor operator was powered by an ac motor instead of the dc motor used in the SHAG testing.

\subsection{Test Results}

8.3.1 Valve Operability. The ac-powered motor-operated gate valve performed smoothly during all the SHAM seismic tests. The valve body sustained accelerations as high as $7 \mathrm{~g}$ in the $800 \%$ SSE test, and the valve operator sustained accelerations as high as $12 \mathrm{~g}$, without adverse effect. As in the CPS seismic testing and the SHAG seismic testing discussed in Sections 3 and 7 of this report, an amplified response was measured in the valve operator at frequencies higher 


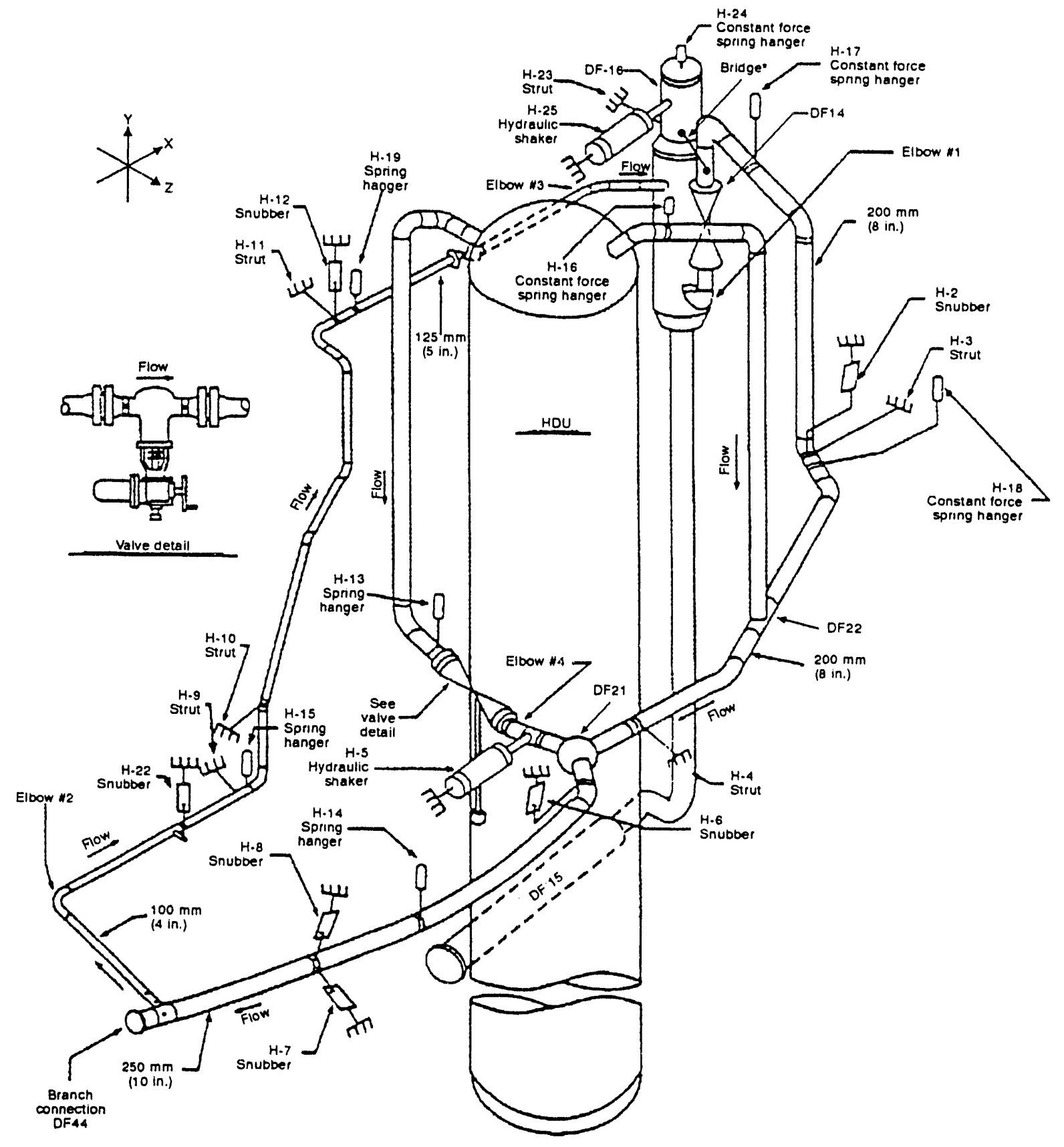

- Bridge between DF 16 and DF14 installed for NRC high level tests only

M638 rs.0692-01

Figure 8-1. A schematic of the VKL showing the 8-in. gate valve and the U.S. stiff piping support system as configured for the SHAM tests. 
Table 8-1. Participants' support configurations for the SHAM test series. ${ }^{a}$

\begin{tabular}{ccccccc}
\hline $\begin{array}{c}\text { Support } \\
\text { number }\end{array}$ & KfK & KWU & U.S. & $\begin{array}{c}\text { EPRI/ } \\
\text { Bechtel }\end{array}$ & $\begin{array}{c}\text { EPRI/ } \\
\text { Cloud }\end{array}$ & CEGB \\
\hline H-2 & - & - & S & - & SS & - \\
H-3 & - & - & RS & RS & RS & - \\
H 4 & RS & RS & RS & RS & RS & RS \\
H-5 & HS & HS & HS & HS & HS & HS \\
H-6 & - & - & S & - & SS & - \\
H-7 & - & - & S & EA & SS & RS \\
H-8 & - & - & S & EA & SS & RS \\
H-9 & - & RS & RS & RS & RS & RS \\
H-10 & - & RS & RS & RS & RS & - \\
H-11 & - & RS & RS & RS & RS & - \\
H-12 & - & - & S & - & SS & RS \\
H-22 & - & - & S & EA & SS & - \\
H-23 & RS & RS & RS & RS & RS & RS \\
H-25 & HS & HS & HS & HS & HS & HS
\end{tabular}

a. $\mathrm{S}=$ snubber, $\mathrm{RS}=$ rigid strut, $\mathrm{HS}=$ hydraulic shaker, $\mathrm{EA}=$ energy absorber, $\mathrm{SS}=$ seismic stop.

Table 8-2. U.S. stiff support system test matrix.

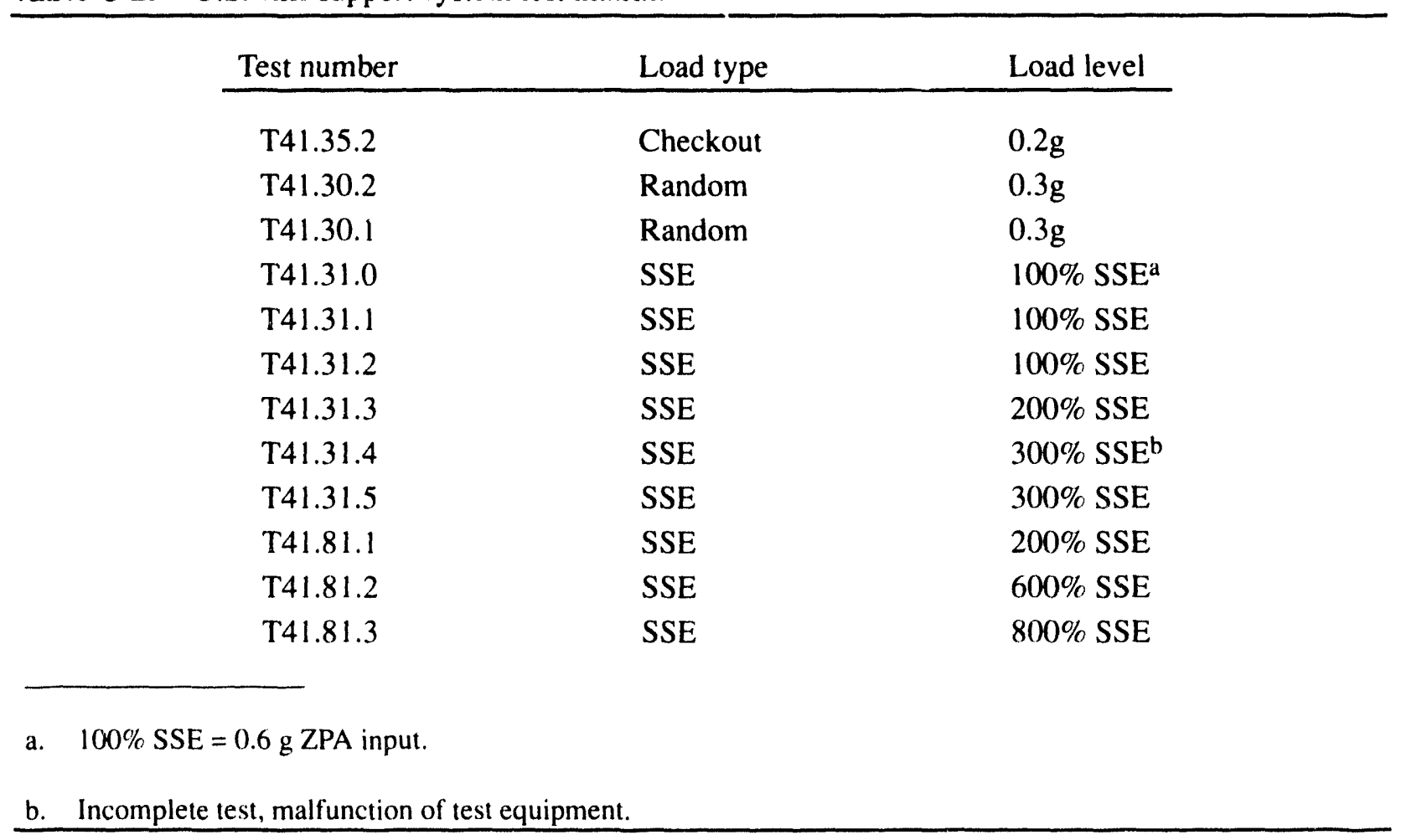


than those at which typical valve assemblies are qualified. Some contact chatter occurred in the switches in the motor operator, but operation of the motor was not affected. No visible structural damage occurred to the valve or the operator.

8.3.2 Snubber Failures. One of the objectives of the SHAM testing was to determine the loads at which snubbers and other dynamic piping supports would fail. The investigation also considered some of the more common devices for attaching piping supports to the building structure and to the piping. Among these were piping trunnion attachments and concrete anchors. None of the trunnion attachments failed. Some concrete anchors loosened somewhat, but no failures occurred. Even with loads as high as five times their rated loadings, no rigid struts failed.

Several snubbers failed. In most instances, the snubber failures occurred al loads well above their rated loadings. However, the snubber at location $\mathrm{H}-7$ failed in test T41.35.2 at a loading lower than its rated loading. A replacement snubber of the same manufacturer and model likewise failed in a subsequent test at a loading lower than its rated loading. Table $8-3$ lists the snubbers installed at the six snubber locations during the Iwelve test runs and provides information on snubber failures.

Table 8-3. Snubber installation matrix for U.S. stiff support system.

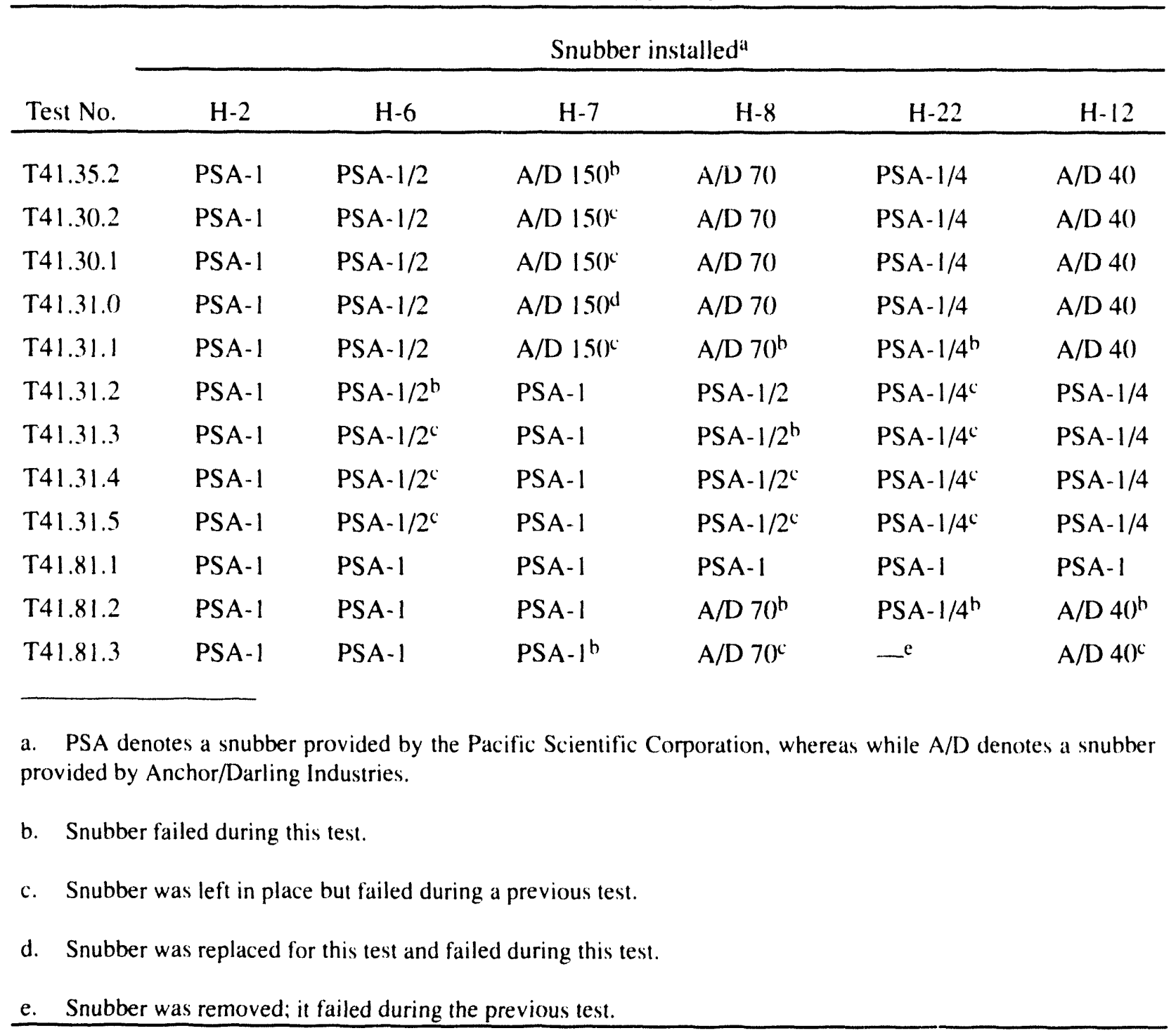


One snubber, the PSA-1/4 snubber installed at H-22 during lest T41.81.2, experienced a "rigid mode" failure: though it allowed excessive motion, it also resisted some force. The other snubber failures consisted of internal damage that allowed excessive motion without resistive behavior.
Where snubber failures did not oceur. snubbers successfully performed their design function, keeping displacements to a minimum. In some cases, snubbers resisted loads several times their rated loadings without failure. Table $8-4$ provides information on some of the loads successfully resisted by some of the snubbers.

Table 8-4. Maximum loads for struts and snubbers installed in the U.S. stiff support system.

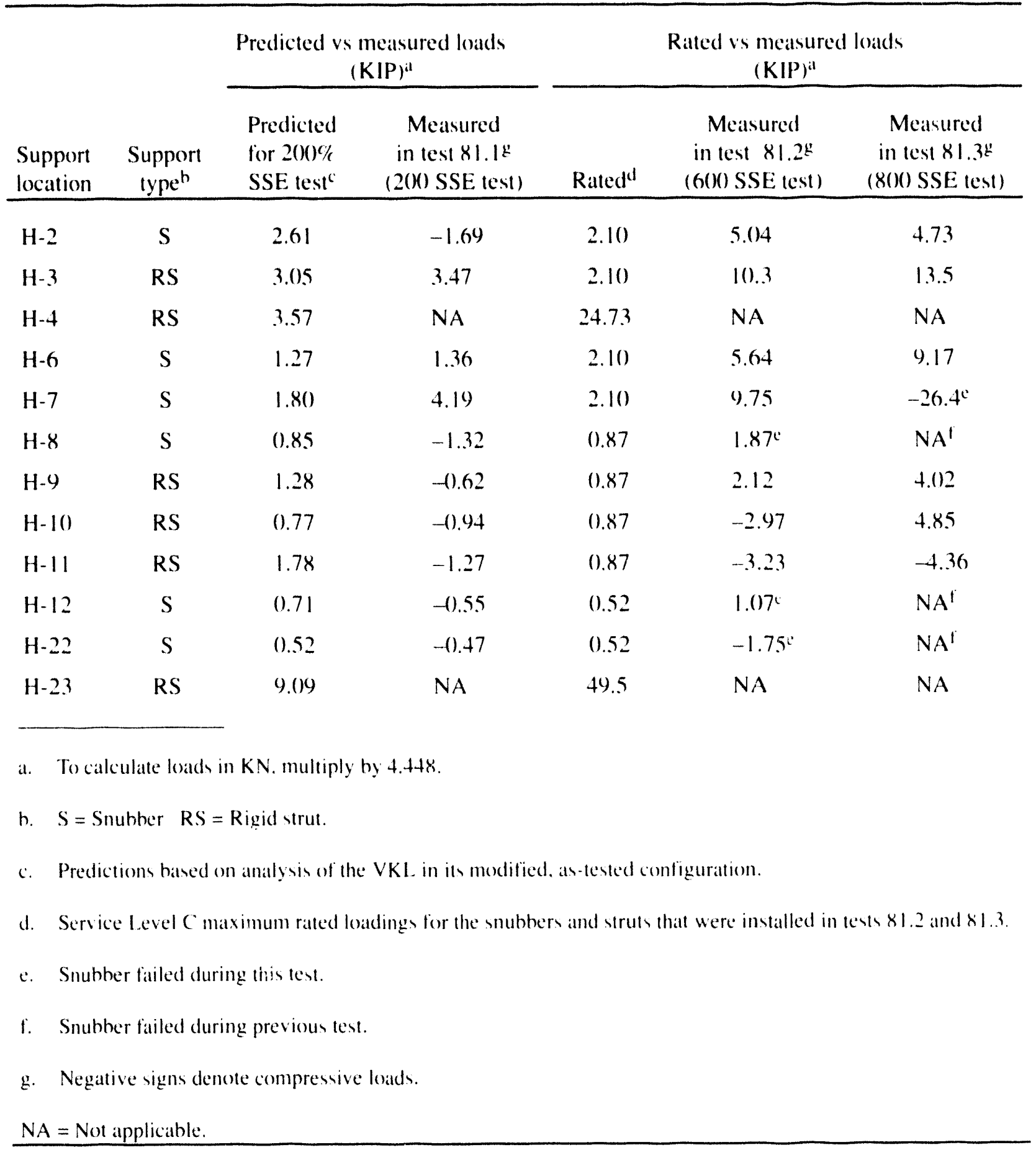




\subsubsection{VKL Response.}

Predicted versus Measured Loads.

Before testing began, we conducted a typical design analysis of the VKL to configure the support system and to predict the loads that would be imposed on the various support system components (snubbers, struts, etc.) so that the components could be sized. The VKL underwent modest modifications after that pretest analysis was conducted, so we conducted another analysis of the VKL in its as-tested configuration. We then compared the response of the VKL as predicted by the analysis with the response measured during testing.

The comparison showed fairly good agreement in most instances. The analysis predicted maximum stresses in the piping at the same locations where maximum strains were measured during the tests. Measured piping responses (displacements and accelerations) were generally in he same frequency bands as predicted by the analysis. Of the loads imposed on the struts and snubbers during the tests. half were underpredicted by the analysis, and half overpredicted, in most cases by not too large a margin. Table $8-4$ compares the support loads predicted for a $200 \%$ SSE test with the loads measured in test T41.81.1.

The most significant underprediction was for the snubber at location H-7. This underprediction may have been influenced by the sensitivity of the model to the support location and stiffness. The project scope did not include a posttest sensitivity study, so the exacl cause of the underprediction was not determined. (Note that sensitivity studies are not usually performed in the design of piping systems in nuclear power plants.) In any case, the conservatism in the support design usually provides functional margin at all credible loads. The Pacific Scientific snubber installed at the H-7 location during the later tests in the series successfully resisted the loads it experienced in the 60()$\%$ SSE test and failed only at severe overloads during the $800 \%$ SSE test.

Zipper Effect. One of the concerns addressed in seismic probabilistic risk assessments (PRAs) is the possibility that failure of a support during an earthquake would cause higher loads to be imposed on a nearby support, causing it, too, lo fail. Failure of a second support would, in lurn. cause at third support to fail, and so on. This phenomenon, known as the zipper effect, occurred during the $60(0) \%$ SSE test, during which three snubbers failed, one after the other. A fourth snubber failed during the $8(0) \%$ SSE test that followed. With several of its supports out of service, the VKL became more flexible and responded al lower frequencies, especially in the $Y$ (vertical) direction of the section that runs from the sphericall tee DF21 through branch connection DF44 to the DFlo component (see Figure 8-1). As expected, the test data indicated that displacements and strains increased with the failures of the snubbers. Strains were measured in excess of the $0.3 \%$ value used to define yield in stainless steel, with the highest strains measured at Elbows 1 and 2. Some plastic deformation occurred at these elbows, but no other structural damage occurred and no leakage occurred in any of the piping.

\subsection{Conclusions}

SHAM test results indicate that earthquake loadings will not have a significant adverse effect on valve operation, unless contact chatter in relays or switches in the motor operator consists of chatter events of sufficient duration to cause the motor controller to shut off power to the motor. This did not occur during the SHAM tests Further investigation of this issue was outside the scope of the SHAM test project.

In most instances, the measurements taken on the VKL during the tests agreed reasonably well with analytical predictions, but they did not exactly match. In particular, there was some disagreement between predicted support loads and measured loads. Generally speaking, piping system analyses using the ASME Code rules and procedures that we followed provide assurance that the piping system will perform its function with an adequate safety margin. This was the case with the analysis of the VKL piping system at HDR. Sensitivity studies could have improved the correlation between predicted and measured 
support loads, but such studies are typically not performed unless the ASME Code rules cannot be met.

The rigid struts used in the SHAM test project performed very well, resisting loads several times greater than their rated loadings without failure. Likewise, many of the snubbers performed without failure while resisting loads well above their rated loadings. All snubber results were supplied to the manufacturers for their information.

Most of the snubbers that failed did so at loads well above their rated loadings. One snubber resisted loads more than eight times its rated loading before it failed. Two snubbers of the same model failed at loads lower than their rated loadings. All snubber results were supplied to the manufacturers for their information.

Test results from the SHAM test series reaffirm the structural toughness of valves and piping. Tests conducted with multiple snubber failures show that piping can successfully withstand earthquake-type loadings when allowed more flexibility than is typical of piping support systems installed in U.S. plants. The results of other SHAM tests conducted at HDR by KfK and KWU using more flexible support systems (fewer piping supports) concur with this finding. This finding agrees with some of the current thinking in the U.S. that design practices could be revised to allow a less stiff support configuration and that such revision would not reduce the structural safety margins of piping to an unacceptable level. The tests also indicate that the zipper effect may be less of a concern than many people in the U.S. nuclear industry have supposed. No significant structural damage occurred to the piping even at very high simulated earthquake loadings with several supports disabled.

Most important, the results from the SHAM tests show that when commonly accepted design methods are applied, piping systems will likely maintain their pressure boundary during a credible earthquake; sufficient safety margins were shown to exist even with severe earthquake loadings and the loss of multiple supports.

\subsection{Application of the Research}

The results from seismic testing at HDR, as reported both by the INEL and by ANL, were included in the technical data base supporting the NRC effort regarding Unresolved Safety Issue A-46, Seismic Qualification of Equipment in Operating Nuclear Pow'er Plants (NUREG1030).

ANL used the test results in their effort to verify the Seismic Methodology Analysis Chain with Statistics (SMACS) computer code. 


\section{EARLY RESEARCH FOR THE GENERIC SAFETY ISSUE 87 TEST PROJECTS}

\subsection{The Issue}

The turbine steam supply line of the high pressure coolant injection ( $\mathrm{HPCl}$ ) pump communicates directly with the reactor vessel and runs outside the containment to the auxiliary building. where the HPCI turbine is located. The containment isolation valves in this line are normally open. The concern with these isolation valves is whether or not they would close against the large pressure and flow loads that would occur in the event of a guillotine break in this steam line outside the containment. In such an event, their failure to close could result in common-cause failures of other equipment in the auxiliary building that were not qualified for a harsh environment. This concern is the substance of Generic Safety Issue 87 (GSI 87), "Failure of the HPCI Steam Line Without Isolation."

Our early GSI 87 research, performed as part of the Environmental and Dynamic Equipment Qualification Research Program (EDQP) that is the subject of this summary report, included efforts to determine which systems are applicable to the GSI 87 concern, determine the type and qualification of the installed valves, and develop a research plan that outlined the work necessary to provide the technical basis for the NRC effort regarding GSI 87.

\subsection{Research Description}

Our work included a review of available industry and research information. That review determined that two additional reactor systems are applicable to the GSI 87 concern: the reactor core isolation cooling (RCIC) turbine steam supply line and the reactor water cleanup (RWCU) system supply line. (In some early plants the system is designated by another name, but the function is the same.)

At the time we performed this preliminary study, the qualification of containment isolation gate valves for flow interruption was not well understood. The only full-scale flow interruption testing that had been performed up to that time was the testing of 3-and 4-in. power-operated relief valves (PORVs) and PORV block valves in a test program performed by the Electric Power Research Institute (EPRI) at the Duke Power, Marshall facility in 1980, after the accident at Three Mile Island. (The results of that testing are available in EPRI NP-2514-LD. 1982). The tests were of the go/no-go variety, and several of the block valves initially failed to close at their design basis load. The EPRI tests, even after thorough review, had only marginal applicability to the smallest of the GSI 87 systems.

We surveyed industry data bases to determine the type and sizes of the valves used in the three GSI 87 systems. We contacted valve manufacturers to determine the extent of hardware qualification and to determine the methods used to calculate the valve forces necessary for closing against high energy flows. The results of the earlier valve testing were studied, sizing methods used by the motor operator manufacturers were determined, and a limited study of utility methods was conducted.

\subsection{Research Results}

We found that the flexible-wedge motoroperated gate valve was the predominant valve design used for containment isolation in all three systems. The predominant valve size was 4 in. for the RCIC system, 6 in. for the RWCU system, and $10 \mathrm{in}$. for the HPCI system. In addition, we found that none of the valve designs installed in the systems of interest had been qualified for their respective design basis flow interruption loads. (An exception might be the Velan valves installed in RCIC systems. They were tested in the EPRI block valve tests.)

The valve manufacturers and utilities all used basically the same equations to determine valve's operator torque and stem force requirements. (These calculations make it possible to size the operator for the valve and set the operator 
control switches.) However, there were inconsistencies in how some of the important variables in the equations were determined. For the operator torque equation (which calculates the operator torque needed to achieve a given stem force), some utilities used the stem nut friction coefficients specified by Limitorque, the operator manufacturer, while others used different stem nut friction coefficients specified by the valve manufacturer.

Similar inconsistencies were evident in the use of the stem force equation (which calculates stem force for a given set of valve dimensions, fluid pressures, etc.). The disc load portion of the stem force equation is basically the disc area multiplied by the differential pressure across the disc multiplied by a disc factor, typically 0.3 . We found that there were no standards on either the disc area term or the disc factor. Everything from the valve orifice area to the nominal pipe size was used to define the disc area. This difference alone made comparisons of one piece of work to another difficult. The biggest problem we found in the stem force equation was that the disc factor was analytically based and loosely associated with a friction factor. We could find no record of full-scale flow interruption testing having been performed to support the use of a disc factor of 0.3 to determine the stem force requirements of valves installed in GSI 87 applications.

\subsection{Conclusions}

We concluded that although some additional study would be helpful, full-scale flow interruption testing of typical gate valves would be necessary to provide the information needed to address the GSI 87 concerns. Our conclusions as to the state of the industry with regard to GSI 87 , along with a plan for the proposed test project, were submitted to the NRC in July 1987. The report, Generic Issue Number 87 Research Plan (EGGREQ -7676), is listed in the bibliography.

\subsection{Application of the Research}

The rest of the GSI 87 research was performed under NRC FINs A6857 and B5529. For the sake of continuity, we will briefly discuss the results of those research projects. Two 6-in. RWCU valves were subjected to testing at design basis conditions at the Wyle Test Laboratories in Huntsville, Alabama. The test results showed that the industry stem force equation was in fact not conservative. We also found that one of the two valve designs tested was susceptible to internal damage when closing against the design basis load. This internal plastic deformation and shearing of metal could not be predicted by any linear friction equation. The nuclear industry was reluctant to accept the results, because the two-valve sample was too small to form a basis for such important decisions.

A second full-scale test project followed, with three 6-in. valves subjected to flow interruption tests with both high energy water and high energy steam (to cover the RWCU and the RCIC concerns), and with three 10-in. valves subjected to flow interruption tests with high energy steam (to cover the HPCI concerns). These tests were performed at the Kraftwerk Union (KWU) facilities near Frankfurt Germany. The results of this test project confirmed the results of the first test project and established once and for all that the industry stem force equation did not adequately characterize valve behavior and did not conservatively bound valve requirements. Several reports on the results of these tests have been published. These are listed in the Bibliography for the reader's information.

The NRC issued a number of information notices as the research results were being analyzed, and later, because of the results of these GSI 87 test projects and because of other regulatw.y initiatives, the NRC issued Generic Letter 89-10, "Safety-Related Motor-Operated Valve Testing and Surveillance." The generic letter recommends that the utilities reanalyze the design basis conditions for each safety-related motoroperated valve, ensure that the operator control switches are set high enough to perform the design basis function, and, where possible, test the valve at design basis conditions to assure operability. The GSI 87 test results, along with other research results, also supported supplements to Generic Letter 89-10 that were issued to provide clarification for its implementation. 


\section{GENERAL CONCLUSIONS}

The results of the Environmental and Dynamic Equipment Qualification Research Program (EDQP), funded under FIN A6322, contributed to the technical basis for the NRC's effort involving several generic safety issues, one unresolved safety issue, and several other NRC initiatives. The work has already been implemented in some industry consensus standards and is being reviewed for implementation in others. The valve qualification standard ANSI B 16.41 is an example; it is being superseded by a new ANSI/ASME valve qualification standard that incorporates some of the early results of this work. The seismic testing performed in this program is expected to contribute significantly toward a new ASME standard on snubber qualification.

The work also identified a number of areas where further research was needed. That work is being performed in the Equipment Operability Research Program (FIN A6857) and the Nuclear Plant Aging Research Program (FIN A6389). The EPRI is also working on a valve research program to address research needs identified by the results of the EDQP and its follow-on work. 


\section{REFERENCES}

EPRI NP-2514-LD, 1982. Marshall Electric Motor Operated Valve (Block Valve) Interim Test Data Report.

NUREG-1264, 1987, U.S. Nuclear Regulatory Commission. Containment Integrity Research Program Plan.

NUREG-1030, 1987, U.S. Nuclear Regulatory Commission, Unresolved Safety Issue A-46. Seismic Qualification of Equipment in Operating Nuclear Power Plants.

NUREG-1209, 1986, U.S. Nuclear Regulatory Commission, Program Plan for Environmental Qualification of Mechanical and Dynamic (Including Seismic) Qualification of Mechanical and Electrical Equipment Program.

NUREG-0900, 1986, U.S. Nuclear Regulatory Commission, Nuclear Power Plant Severe Accident Research Plan.

NUREG-0737, 1980, U.S. Nuclear Regulatory Commission, Clarification of TMI Action Plan Requirements.

NUREG-0660, 1980, U.S. Nuclear Regulatory Commission, NRC Action Plan as a Result of the TMI-2 Accident.

U.S. Nuclear Regulatory Commission, 1989, Information Notice 89-11, "Failure of dc Motor-Operated Valve to Develop Rated Torque Because of Improper Cable Sizing."

U.S. Nuclear Regulatory Commission, 1989, Generic Letter 89-10, "Safety-Related Motor-Operated Valve Testing and Surveillance."

U.S. Nuclear Regulatory Commission, Generic Safety Issue 23, "Reactor Coolant Pump Seal Failures at Station Blackout Conditions," NUREG-0933, 1983 (with supplements to 1992), Prioritization of Generic Safety Issues.

U.S. Nuclear Regulatory Commission, Generic Safety Issue 87, "Failure of the HPCI Steam Line Without Isolation." NUREG-0933, 1983 (with supplements to 1992), Prioritization of Generic Safety Issues. 


\section{BIBLIOGRAPHY}

The research described in this summary report was reported in the documents listed here. The documents are listed in groups that correspond with the sections of this summary report, as indicated.

\section{CONTAINMENT PURGE AND VENT VALVES (Section 2)}

\section{MEETING PAPER}

J. A. Hunter, R. Steele, Jr., J. C. Watkins, "Reactor Containment Purge and Vent Valve Performance Experiments," ANS Topical Meeting, 1984.

\section{NUREG/CR REPORTS}

J. C. Watkins, R. Steele, Jr., R. C. Hill, K. G. DeWall, A Study of Typical Nuclear Containment Purge Valves in an Accident Environment, NUREG/CR-4648, EGG-2459, August 1986.

R. Steele, Jr., J. C. Watkins, Containment Purge and Vent Valve Test Program Final Report, NUREG/CR-4141, EGG-2374, September 1985.

R. Steele, Jr., J. C. Watkins, K. G. DeWall, and M. J. Russell, Motor Operated Valve Research Update, NUREG/CR-5720, EGG-2643, June 1992.

\section{CONTAINMENT PIPING AND PENETRATIONS (Sections 3 and 4)}

\section{REFEREED JOURNAL ARTICLES}

H. S. Crapo, "Containment Penetration System (CPS) Valve Tests Under Accident Loads," Nuclear Engineering and Design, 115, 1989, pp. 331-338.

R. Steele, Jr., R. C. Hill, J. A. Close, "Functionality and Leak Integrity of Containment Penetration Systems Subjected to Design Basis Dynamic Loads," Nuclear Engineering and Design, 108, 1988, pp. 7-13.

\section{MEETING PAPERS}

H. S. Crapo, "Containment Penetration System (CPS) Valve Tests Under Accident Loads," Proceedings of the 15th Water Reactor Safety Meeting, Gaithershurg, Maryland, October 26-30, 1987.

R. Steele, Jr., R. C. Hill, J. A. Close, "Functionality and Leak Integrity of Containment Systems Subjected to Design Basis Dynamic Loads," Proceedings of the 14th Water Reactor Safety Meeting, Gaithershurg. Maryland, October 27-31, 1986.

\section{NUREG/CR REPORTS}

H. S. Crapo, R. Steele, Jr., Containment Penetration System (CPS) Tests Under Accident Loads, NUREG/CR-5043, EGG-2524, June 1988.

J. A. Close, R. C. Hill, R. Steele, Jr., Seismic Testing of Typical Containment Penetration Systems, NUREG/CR-4734, EGG-2470, December 1986.

NRC TECHNICAL REPORTS (Informal Reports)

K. G. DeWall, D. K. Morton, R. Steele, Jr., Development, Identification and Quantification of Issues Relating to the Containment Isolation System Valve Integrity Test Program, EGG-RST-6978, August 1985. 


\section{SHAFT SEALS FOR PRIMARY COOLANT PUMPS (Section 5)}

\section{NUREG/CR REPORT}

D. B. Rhodes, R. C. Hill, R. G. Wensel, Reactor Coolant Pump Shaft Seal Stability During Station Blackout, NUREG/CR-4821, EGG-2492, AECL-9342, May 1987.

\section{RATTLING IN ELECTRICAL CABINETS (Section 6)}

\section{NUREG/CR REPORTS}

G. Thinnes and V. Glozman, Significance of In-Structure Generated Motion in Seismic Qualification Tests of Cabinet Mounted Electrical Devices, NUREG/CR-5031, EGG-2523, June 1988.

D. D. Kana and D. J. Pomerening, Similarity Principles for Equipment Qualification by Experience, NUREG/CR-5012, EGG-2521, July 1988.

\section{PIPING AND VALVE RESPONSE TO IN SITU SEISMIC TESTS AT HDR (Sections 7 and 8)}

\section{REFEREED JOURNAL ARTICLES}

R. Steele, Jr., and J. G. Arendts, "Performance of a Piping System and Equipment in the HDR Simulated Seismic Experiments," Nuclear Engineering and Design, 115, 1989, pp. 339-347.

R. Steele, Jr., P. E. MacDonald, J. G. Arendts, "Dynamic Load Effects on Gate Valve Operability and Snubber Performance," Nuclear Engineering and Design, 108, 1988, pp. 15-21.

\section{MEETING PAPERS}

R. Steele, Jr., "Valve and Piping System Test Results and Effects on Regulatory Standards," Proceedings of the 10th International Conference on Structural Mechanics in Reactor Technology, Anaheim. California, August 14-18, 1989.

R. Steele, Jr., "Piping Support and Gate Valve Behavior During High Level HDR Simulated Seismic Tests," Proceedings of the 16th Water Reactor Safety Meeting, Gaithershurg, Maryland, October 24-27, 1988.

R. Steele, Jr., J. G. Arendts, "Performance of a Piping System and Equipment in the HDR Simulated Seismic Experiments," Proceedings of the 15th Water Reactor Safety Meeting, Gaithershurg, Maryland, October 26-30, 1987.

\section{NUREG/CR REPORTS}

R. Steele, Jr., and M. E. Nitzel, Piping System Response During High-Level Simulated Seismic Tests at the Heissdampfreaktor Facility (SHAM Test Series), NUREG/CR-5646, EGG-2655, June 1992.

R. Steele, Jr., J. G. Arendts, A. G. Ware, SHAG Test Series Seismic Research on an Aged U.S. Gate Valve and on Piping System Responses of like Decommissioned Heissdampfreaktor (HDR), Volumes I and 2 , NUREG/CR-4977, EGG-2505, July 1989.

M. G. Srinivasan, C. A. Kot, B. J. Hsieh, Verification of Piping Response Calculations of SMACS Code with Data from Seismic Tests of an Inplant Piping System, NUREG/CR-5757, September 1991. 
M. G. Srinivasan, M. Mojtahed, C. A. Kot, Verification of Nonlinear Piping Response Calculations with Data from Seismic Testing of an Inplant Piping System, NUREG/CR-5841, March 1992.

NRC TECHNICAL REPORTS (Informal Reports)

A. G. Ware, Evaluation of Snubber Response Data During Selected HDR SHAG Tests-Quick Look Report, EGG-REQ-7710, May 1987.

C. A. Seaquist, Shippingport Valves Aging Assessment, Refurbishment and Requalification, EGGREQ-7276, June 1986.

Valve Research, HDR/VKL Phase II SHAG Testing Requirements, EGG-REQ-7148, Rev. 0, 1, and 2, May 1986.

\section{GENERIC ISSUE 87}

\section{NUREG/CR REPORTS}

K. G. DeWall and R. Steele, Jr., BWR Reactor Water Cleanup System Flexible Wedge Gate Isolation Valve Qualification and High Energy Flow Interruption Tesi, Volumes 1, 2, and 3, NUREG/CR-5406, EGG-2569, October 1989.

R. Steele, Jr., K. G. DeWall, J. C. Watkins, Generic Issue 87: Flexible Wedge Gate Valve Test Program, Phase II Results and Analysis, NUREG/CR-5558, EGG-2600, July 1990.

R. Steele, Jr., J. C. Watkins, K. G. DeWall, M. J. Russell, Motor-Operated Valve Research Update, NUREG/CR-5720, EGG-2643, October 1991.

NRC TECHNICAL REPORT (Informal Reports)

K. G. DeWall, Generic Issue Number 87 Research Plan, EGG-REQ-7676, July 1987.

\section{MISCELLANEUUS}

\section{NUREG/CR REPORTS}

H. W. Heiselmann, Identification of Equipment and Components Predicted as Significant Contributors to Severe Core Damage, NUREG/CR-3762, EGG-2311, May 1984.

NRC TECHNICAL REPORTS (Informal Reports)

K. G. DeWall, Generic Issue Number 87 Research Plan, EGG-REQ-7676, July 1987.

K. G. DeWall, Qualification of Valve Assemblies in High Energy BWR Systems Penetrating Containment, EGG-REQ-7387, September 1986.

K. G. DeWall, Summary of Valve Assemblies in High Energy BWR Systems Outside of ContainmentInterim Report, EGG-REQ-7297, June 1986. 


\begin{tabular}{|c|c|}
\hline $\begin{array}{l}\text { US. NUCLEAR REGULATORY COMMISSION } \\
\text { BIBLIOGRAPHIC DATA SHEET } \\
\text { See instruations on the reverse }\end{array}$ & 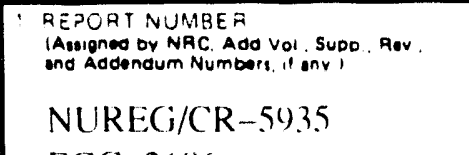 \\
\hline \multirow{3}{*}{$\begin{array}{l}\text { 2. TITLE AND SUBTITLE } \\
\text { Summary of Work Completed Under the Environmental and Dynamic Equipment } \\
\text { Qualification Research Program (EDQP) }\end{array}$} & $\mathrm{EGG}-2686$ \\
\hline & \begin{tabular}{|c|c|} 
MONTH & REAR \\
February & 1994 \\
\end{tabular} \\
\hline & $\begin{array}{l}\text { FIVOR GRANT NUMBEF } \\
\text { A6.322 }\end{array}$ \\
\hline $\begin{array}{l}\text { Robert Stecle. Jr. } \\
\text { Donovan L. Bramuell }\end{array}$ & $\begin{array}{l}\text { O TYPE OF REPORT } \\
\text { Technical }\end{array}$ \\
\hline $\begin{array}{l}\text { John C. Walkins } \\
\text { Kevin C. DeWall }\end{array}$ & $\begin{array}{l}7 \text { PERIOD COVERED inciusive Dales: } \\
198.310199 .3\end{array}$ \\
\hline 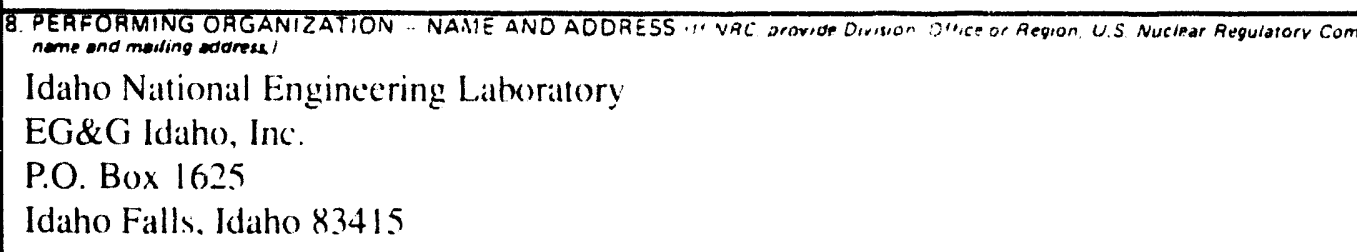 & ission. dnd maliting address. "l contracior provigu \\
\hline 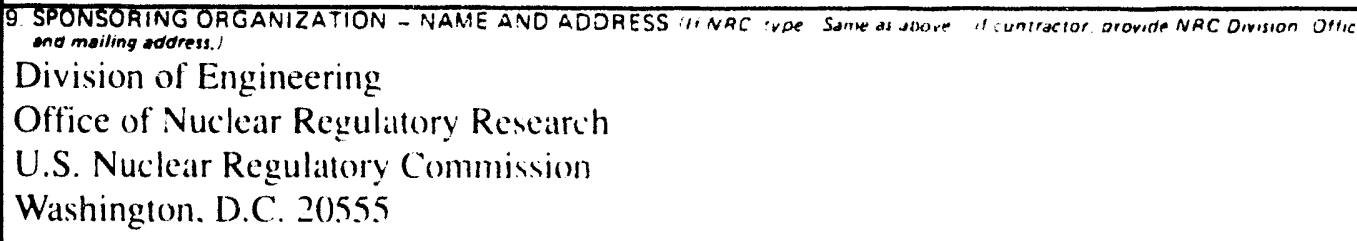 & or Region. U S. Nuclear Reguiatorv Commission. \\
\hline 10. SUPPLEMENTARY NCTES & \\
\hline $\begin{array}{l}\text { Th. ABSTRACT } 1200 \text { wores or iess. } \\
\text { This report documents the results of the main projects undertaken under the Environmer } \\
\text { Equipment Qualification Research Program (EDQP) sponsored by the U.S. Nuclear Reg } \\
\text { under FIN A6322. Lasting from fiscal year } 1983 \text { to } 1987 \text {. the program dealt with enviro } \\
\text { (including seismic) equipment qualification issues for mechanical and electromechanica } \\
\text { used in nuclear power plants. The research results have since been used by both the NR( } \\
\text { included seven major research projects that addressed the following issues: (a) containm } \\
\text { performing under design basis loss of coolant accident loads, (b) containment piping per } \\
\text { valves performing under seismic loadings and design basis and severe accident containn } \\
\text { (c) shaft seals for primary coolant pumps performing under station blackout conditions. } \\
\text { internals responding to in-structure generated motion (rattling), and (e) in situ piping an } \\
\text { seismic loadings. Another project investigating whether certain containment isolation va } \\
\text { basis conditions was also started under this program. This report includes eight main sec } \\
\text { provides a brief description of one of the projects, a summary of the findings, and an ov } \\
\text { the results. A bibliography lists the joumal articles. papers. and reports that document th }\end{array}$ & $\begin{array}{l}\text { tal and Dynamic } \\
\text { nulatory Commission (NRC) } \\
\text { nmental and dynamic } \\
\text { I components and systems } \\
\text { C and industry. The program } \\
\text { ent purge and vent valves } \\
\text { netrations and isolation } \\
\text { nent wall displacements, } \\
\text { (d) electrical cabinet } \\
\text { d valves responding to } \\
\text { alves will close under design } \\
\text { tions. each of which } \\
\text { erview of the application of } \\
\text { e research. }\end{array}$ \\
\hline $\begin{array}{l}\text { 12. KEY WORDS/DESCR!PTORS IList words or onroses that will assist reseoreners in localing ine redort. } \\
\text { Dynamic qualification of equipment } \\
\text { Environmental qualification of equipment } \\
\text { Seismic testing } \\
\text { Valves } \\
\text { Piping }\end{array}$ & 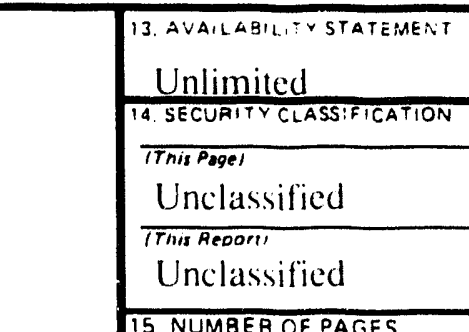 \\
\hline & $\begin{array}{l}\text { 15. NUMBER OF PAGES } \\
\text { 16 PRICE }\end{array}$ \\
\hline
\end{tabular}


